\title{
A GUIDE TO \\ FORMATION TESTING \\ USING ODP DRILL-STRING PACKERS
}

\author{
Ocean Drilling Program \\ Texas A\&M University \\ Technical Note No. 14
}

Keir Becker

Division of Marine Geology and Geophysics

Rosenstiel School of Marine and Atmospheric Science

University of Miami

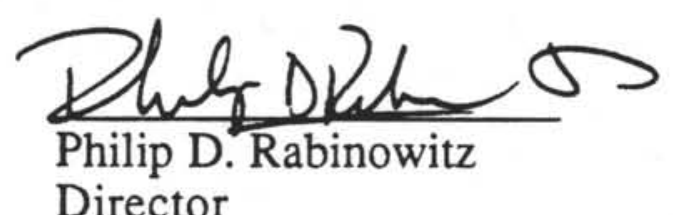

Director

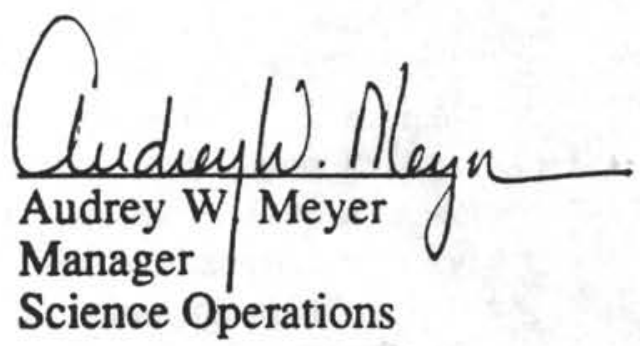

Th Aranni

Timothy J.G. Francis

Deputy Director 
Material in this publication may be copied without restraint for library, abstract service, educational or personal research purposes; however, republication of any portion requires the written consent of the Director, Ocean Drilling Program, Texas A\&M University Research Park, 1000 Discovery Drive, College Station, Texas 77845-9547, as well as appropriate acknowledgment of this source.

Technical Note No. 14

First Printing 1990

Distribution

Copies of this publication may be obtained from the Director, Ocean Drilling Program, Texas A\&M University Research Park, 1000 Discovery Drive, College Station, Texas 77845-9547. In some cases, orders for copies may require a payment for postage and handling.

\section{DISCLAIMER}

This publication was prepared by the Ocean Drilling Program, Texas A\&M University, as an account of work performed under the international Ocean Drilling Program, which is managed by Joint Oceanographic Institutions, Inc., under contract with the National Science Foundation. Funding for the program is provided by the following agencies:

Canada/Australia Consortium for the Ocean Drilling Program

Deutsche Forschungsgemeinschaft (Federal Republic of Germany)

Institut Français de Recherche pour l'Exploitation de la Mer (France)

Ocean Research Institute of the University of Tokyo (Japan)

National Science Foundation (United States)

Natural Environment Research Council (United Kingdom)

European Science Foundation Consortium for the Ocean Drilling Program

(Belgium, Denmark, Finland, Iceland, Italy, Greece, the Netherlands,

Norway, Spain, Sweden, Switzerland, and Turkey)

Any opinions, findings, and conclusions or recommendations expressed in this publication are those of the author(s) and do not necessarily reflect the views of the National Science Foundation, the participating agencies, Joint Oceanographic Institutions, Inc., Texas A\&M University, or Texas A\&M Research Foundation. 


\section{TABLE OF CONTENTS}

I INTRODUCTION TO ODP PACKERS …............................................. 1

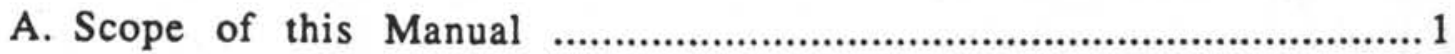

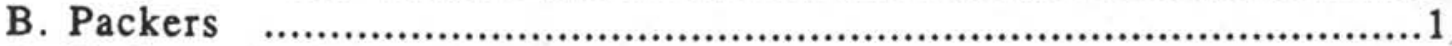

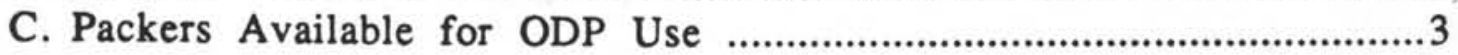

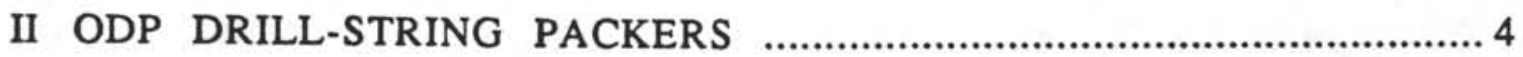

A. Use of Drill-String Packers in ODP...................................................... 4

1. Packer elements ........................................................................ 4

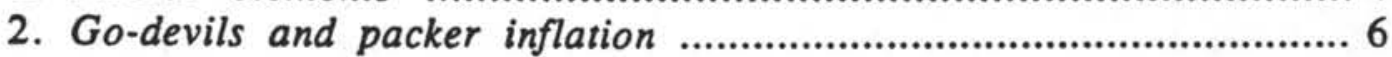

3. Temperature limitations ................................................................ 6

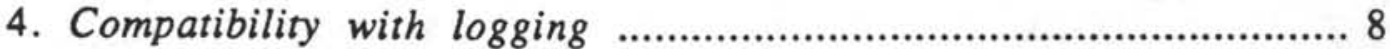

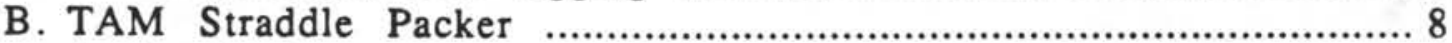

1. Go-devils .......................................................................... 9

2. Inflation/deflation and requirements for $B H A$...................................... 9

3. Assembly and testing ..............................................................11

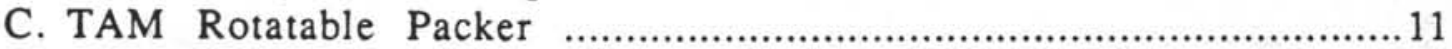

III DOWNHOLE AND RIG FLOOR INSTRUMENTATION .............................. 14

A. Downhole Pressure Recorders ......................................................14

B. Rig Floor Pumps and Gauges ..................................................... 15

1. Seawater pumps ................................................................ 15

2. Determining volumes of seawater pumped ....................................... 15

3. Pressures and pump rates measured at the rig floor ................................ 16

C. Pressures Measured During Formation Testing ……................................. 16

1. Packer inflation pressure ...........................................................16

2. Hydrostatic pressure, pore pressure, and test pressure ........................... 17

IV FORMATION TESTING -- THEORY AND ODP PRACTICE.......................... 18

A. Active Formation Testing …........................................................ 18

B. Pulse or "Slug" Tests ...................................................................... 19

C. Constant-Rate Injection Tests ........................................................ 22

D. Assumptions, Approximations, and Sources of Error and Uncertainty ............ 22

1. In-situ permeability vs. calculated bulk permeability ............................. 22

2. Integrity of the packer seal ............................................................ 22

3. Model-fitting procedures .............................................................. 23

4. Volume and properties of pressurized fluids ....................................... 23 
A. Steps in Processing Pressure Data Collected with a Packer .......................... 25

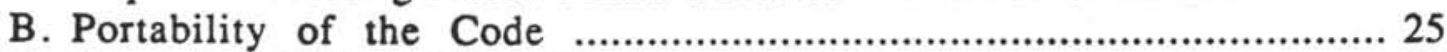

C. Notes on Using GRAPHER …..................................................... 26

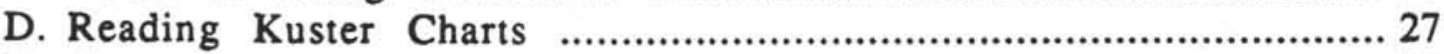

E. Converting Kuster Data Using KUSTER ............................................... 28

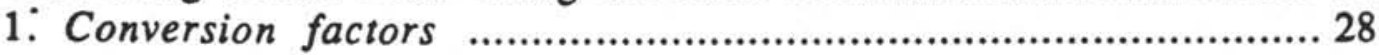

F. Editing Time-Pressure Data ......................................................... 29

G. Processing Individual Slug Tests Using SLUG ...................................... 29

H. Processing Injection Tests Using INJECT ............................................... 31

I. Corrections for the Effects of Previous Tests .......................................... 33

Example $V-1$. Output file from slug test ............................................... 35

Example V-2. Output file from injection test .......................................... 39

VI EXAMPLE - LEG 118 PACKER MEASUREMENTS IN HOLE 735B .............. 43

A. Final plan before commencing measurements ......................................... 43

B. Log of actual events during measurements ........................................... 45

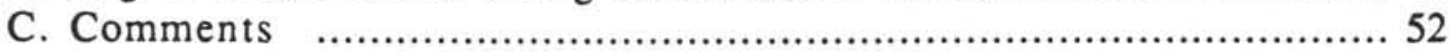

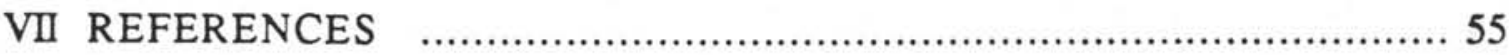

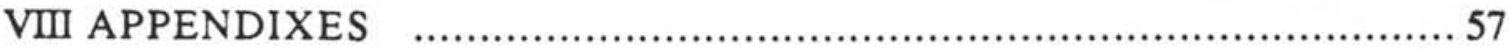

A. Straddle Packer Assembly and Testing Instructions ..................................57

B. Kuster K-3 Manual and Chart Reading Instructions ..................................... 77

C. Rig Floor Instrumentation Schematics ……..................................... 85

D. Installation Instructions and Listings of Packer Data Processing Programs........107 


\section{INTRODUCTION TO ODP PACKERS}

\section{A. Scope of this Manual}

The purposes of this manual are to describe (1) the available equipment and rig floor procedures for conducting formation tests with the drill-string packers operated by the Ocean Drilling Program (ODP), and (2) the computer programs written by the author for processing the pressure data collected during these measurements. The contents represent the experience of the author in developing a drill-string straddle packer for ODP and successfully conducting and interpreting packer experiments during ODP Legs 109, 111, and 118, with support from NSF. The information presented herein may supersede that given by Becker $(1986,1988)$, and is current as of October 1989, when the straddle packer was officially transferred to ODP for future routine use. As ODP accumulates further experience with drill-string packers, the equipment, procedures, and programs described herein will almost certainly be modified and improved, and the reader should contact ODP regarding any possible changes.

To date, packers are the only tools with which permeability -- the key hydrogeologic property of the formation -- has been measured in situ in DSDP or ODP holes. The intent of this manual is to provide the reader with all of the information necessary to successfully conduct such measurements. However, while all aspects of these measurements are described as completely as possible, the procedures are simply too complicated to be applied in a "cookbook" fashion. The example from Leg 118 presented in Chapter VI -- the most recent and perhaps most successful series of permeability measurements during a single DSDP/ODP packer deployment to date -- demonstrates that formation testing with a packer simply cannot be expected to proceed according to plan! Therefore, the guidelines and recommendations given herein should not be followed blindly; instead, they should be used by the packer scientist both to develop a customized plan for a particular experiment and to guide reactions to events that inevitably do not occur according to plan.

\section{B. Packers}

A packer can be defined simply as a device that produces a hydraulic seal in a borehole (Fig. I-1). If the integrity of this hydraulic seal is properly maintained, the hydrologic properties of the formation can be tested by applying differential fluid pressures to the isolated section. Formation properties that can be measured using a packer include pore pressure, transmissivity, from which permeability can be derived, and (less accurately) storage coefficient, which is directly related to formation porosity. In addition, it may be possible to sample fluids from the section of borehole isolated by a packer, if the formation is permeable enough, the sample may contain a component of formation fluids.

A drill-string packer is designed to be part of the bottom-hole assembly (BHA); a wireline packer is a separate tool lowered on a conducting cable into open hole, like a logging tool. A drill-string packer or a wireline packer can be.configured as a straddle packer, which incorporates two hydraulic seals and allows the zone between the seals to be . 
A

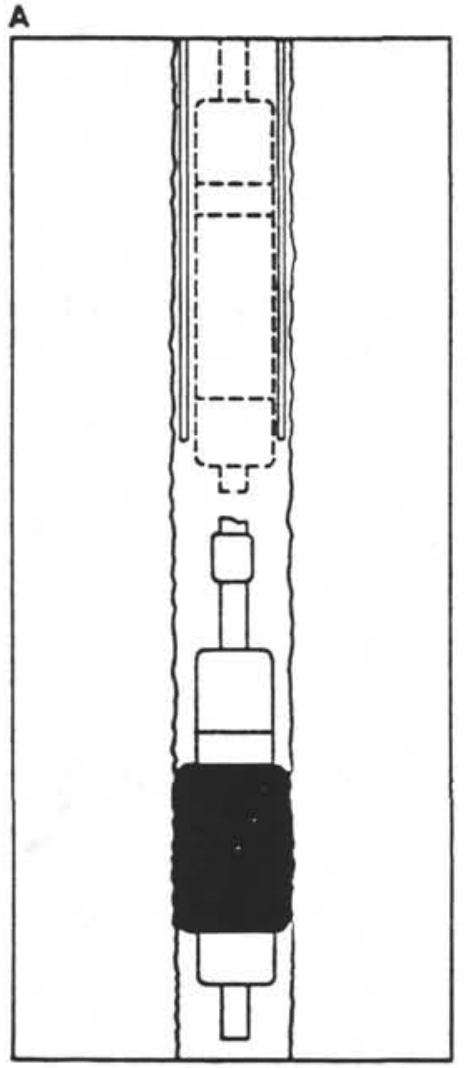

B

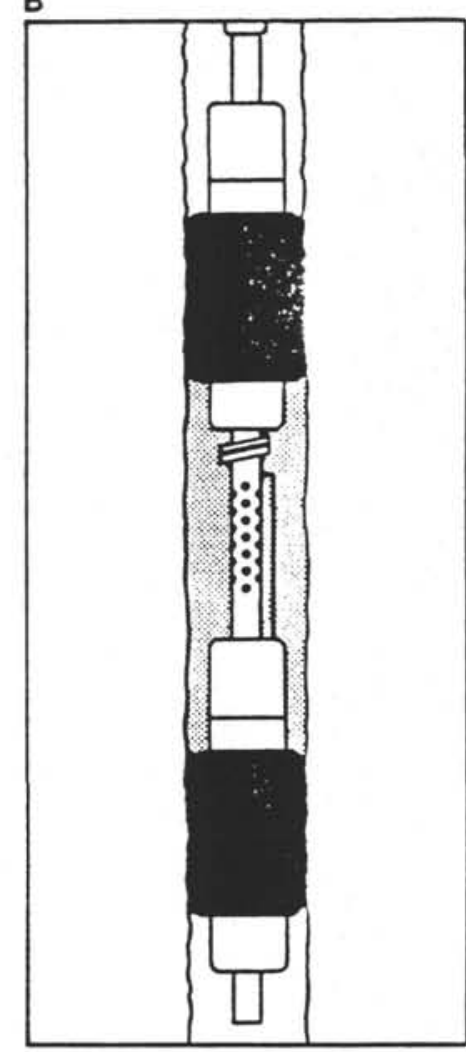

Figure I -1. Sketches of TAM inflatable drill-string packers.

A. A single-element packer, which isolates the formation between the element and the bottom of the hole.

B. A straddle packer, which separately isolates the zone between the elements and the zone between the lower element and the bottom of the hole. 
tested or sampled. In contrast, a single-element packer isolates the zone between the packer seal and the bottom of the hole.

\section{Packers Available for ODP Use}

Four packers are presently available for use during ODP legs, all manufactured by

TAM International of Houston, Texas:

(1) A non-rotatable drill-string packer developed with support from NSF grants OCE 85-13537 and OCE 88-00077 to the University of Miami. This packer is often called the TAM straddle packer, although it can be configured as either a single packer or a straddle packer. It was used successfully during Legs 109, 111, and 118, and in 1989 was formally transferred to ODP for routine use in reentry holes that penetrate stable : formations.

(2) A rotatable drill-string packer operated by ODP, intended for use in less stable formations, where a rotational capability may be required for safety reasons. It is a single packer only, and is sometimes called the "TDP" or TAM Drilling Packer. This packer was tested during Leg 110 , then was modified and successfully retested during Leg 123. The setting mechanism was modified further for use during Leg 131 at the Nankai Trough, although tests there were unsuccessful due to poor hole conditions and a strong current.

(3) A wireline packer operated by the Borehole Research Group at Lamont-Doherty Geological Observatory (LDGO), intended primarily for fluid sampling, may be capable of formation testing at limited pressures. This tool was first run in an ODP hole on Leg 133, with limited success. The wireline packer was developed through a subcontract from LDGO to Stanford University.

(4) The "Geoprops probe" developed with NSF and JOI/USSAC support to Comell University. This is essentially a short straddle packer to be deployed in a small-diameter hole drilled ahead of the normal-diameter bit with the motor-driven core barrel. It is intended to measure permeability, pore pressure, and temperature, and is scheduled for land tests during 1990. The tool is not currently scheduled for deployment at sea.

Use of the two drill-string packers will be discussed in this manual, emphasizing procedures for use of the straddle packer. As the rotatable packer has not yet been used successfully for scientific purposes, procedures for its use have not been finalized, and ODP should be contacted for information beyond that presented herein. The use of the wireline packer or Geoprops probe will not be described here, as they have not yet been tested fully or used successfully in ODP, and procedures for their deployment have not been established. In addition, the wireline.packer and Geoprops probe are "third-party" tools, meaning that they were developed outside ODP and are not documented or maintained by ODP. It is possible that some of the computer programs provided to interpret data collected with the drill-string packers may also be applied to data collected with the wireline packer and Geoprops probe, with appropriate modifications to account for the short lengths of the zones straddled with these tools (Hayashi et al., 1987). 


\section{ODP DRILL-STRING PACKERS}

\section{A. Use of Drill String-Packers in ODP}

As noted above, the ODP drill-string packers are each deployed as part of a BHA. As described more fully below, both ODP drill-string packers are compatible with logging, and with careful planning it may be possible to accomplish both logging and packer measurements during a single pipe trip.

Unless it is specially engineered, a drill-string packer should be kept in tension, like the drill pipe above the BHA, and should not be included as part of a coring, rotating BHA. Thus, formation testing with the non-rotatable drill-string straddle packer requires separate : pipe trips into reentry holes that penetrate stable formations that have already been cored.

The special engineering of the rotatable drill-string packer includes a strengthened internal mandrel to withstand both the torque and compressive loads of drilling, and a plumbing system that permits cuttings to be circulated away without inadvertently inflating the packer elements. While the ODP rotatable packer was designed to be compatible with coring, during initial testing rotation has destroyed the packer elements. Thus this packer has not yet been proven for use in an ideal mode of coring ahead, pausing for inflation and measurement, deflating, coring ahead, etc. Instead, it should probably be used in a reentry/logging mode, in holes where there is any chance that the formation may collapse around the packer, necessitating a rotating capability to free the BHA (e.g., in sediments).

\section{Packer elements}

The packers used in ODP are inflatable packers, which seal the borehole using hybrid rubber/steel elements that are inflated with seawater pumped down the drill string from the rig floor. Each of these elements consists of an internal rubber bladder, which is bonded to an expandable steel strength member, which in turn is bonded to an outer rubber cover. The outer rubber and the steel serve to 'grip' and seal against the borehole wall, and to protect the inner bladder, which must remain unpunctured for the packer to remain inflated.

The proprietary TAM design uses a tight weave of stainless steel wire rope as the internal strength member of the element (Fig. II-1). This allows good bonds to be maintained between the woven cable and both the inner and outer rubber during expansion and contraction of the element. However, this type of element may be weak at very high degrees of inflation, if the cable separates to the extent that the rubber in the gaps must bear too much of the inflation pressure.

The elements for the two TAM drill-string packers have the same external dimensions, threads, and seal surfaces, but different internal diameters. The internal mandrel of the rotatable packer is larger to withstand the torque during rotation. Thus the element for the

- rotatable packer has a larger internal diameter, and it can be used on the non-rotatable straddle packer. However, the elements for the non-rotatable.packer have too small an internal diameter to be used on the rotatable packer. 


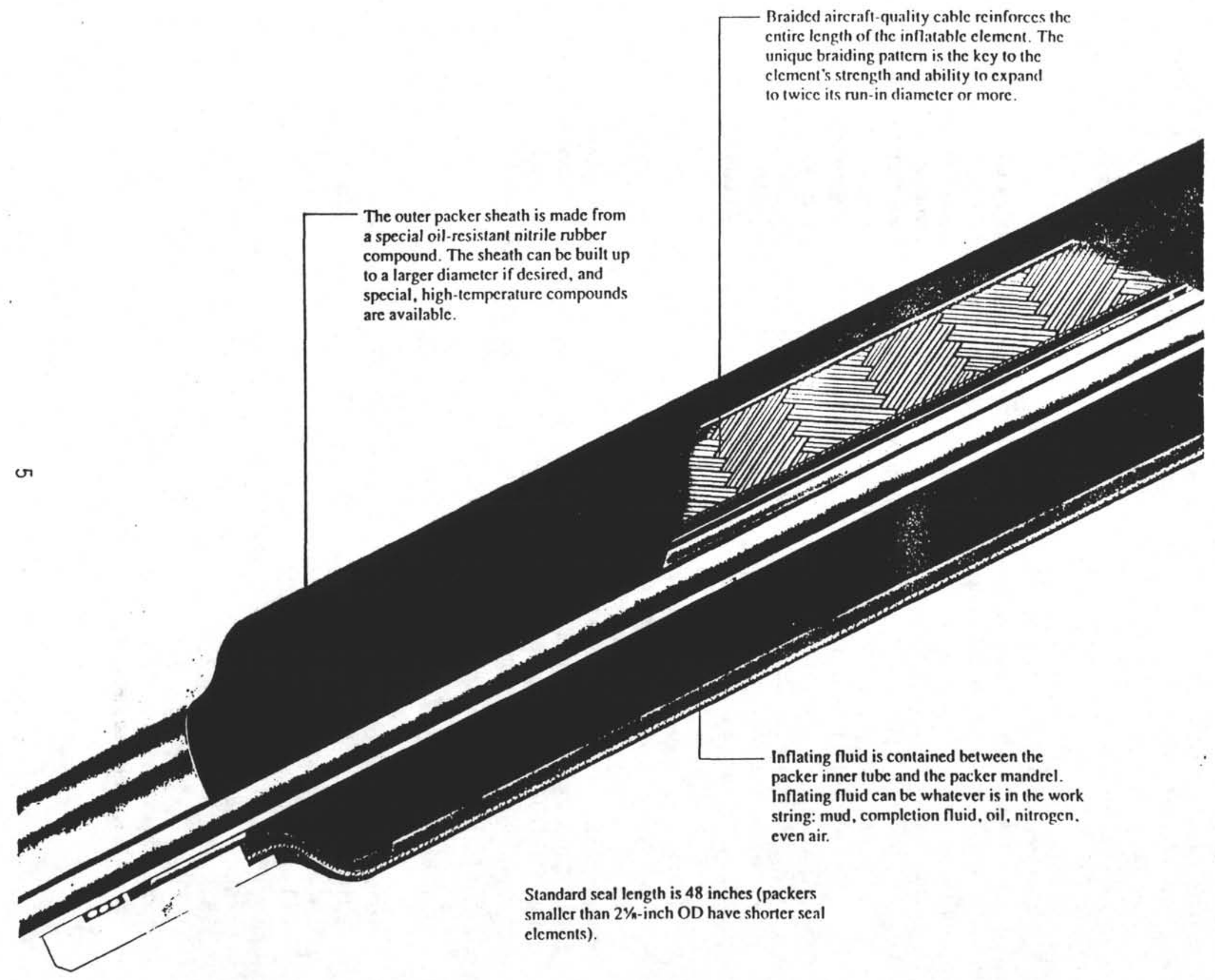

Figure II-1. Anatomy of the rubber elements used on the ODP drill-string packers manufactured by TAM International. 
The TAM packer elements can safely be inflated to as much as twice their uninflated diameters. However, a greater degree of expansion requires more time for full deflation, and produces a weaker hydraulic seal that can withstand a lesser range of test pressures (Figure II-2). Thus, effective formation testing requires that the packer(s) be positioned in zones where the borehole is in good condition and in gauge, where the degree of packer inflation can be kept reasonable. Such zones are usually apparent in logs that should be run before packer tests are begun, such as caliper, borehole televiewer, resistivity, density, and sonic logs.

\section{Go-devils and inflation of packer elements}

After the drill-string packer is positioned in the desired zone, inflation of the element(s) is accomplished by pumping seawater from the ship down the pipe. Before pumping, the inflation mechanism is enabled by free-falling a retrievable go-devil, which keys into the packer plumbing system. A properly seated go-devil may perform several functions:

(1) forming a hydraulic seal within the packer, to direct the fluids pumped from the rig either into the elements for inflation or into the formation for testing,

(2) carrying the pressure recorders that monitor the data needed to determine pore pressure and permeability, and

(3) possibly (in the future) carrying a sample chamber.

By using go-devils that are retrievable with the coring line, multiple sets of the ODP drillstring packers can be made, as long as the elements hold pressure and seal the borehole.

At present the go-devils for neither drill-string packer can sample formation fluids, but this capability is under development. In fact, for Leg 110, R. Barnes adapted the sampler go-devil formerly used with the DSDP packer for use with the rotatable packer, but this sampler has never been properly tested. In addition, J. Cann is presently developing an electronic sampler for the straddle packer that functions like a go-devil in controlling packer inflation. ODP engineers have also redesigned the go-devils for both packers so that a logging line can run down through the go-devil during deployment, which could facilitate fluid sampling, but this configuration has not yet been tested.

\section{Temperature limitations of the ODP drill-string packers}

The temperatures to which the drill-string packers can be used are limited by the temperature ratings of the rubber compounds that compose the packer elements and inner seals. Standard nitrile o-rings and elements are rated to about $100^{\circ} \mathrm{C}$. Commercially available o-rings made of special elastomers may be effective to temperatures as high as $250^{\circ}-300^{\circ} \mathrm{C}$. However, the combination of elasticity, strength, and resetability required of -the rubber in the inflation elementsis difficult to achieve at high temperatures.Packer . elements made with high-temperature rubber compounds will probably be effective to $200^{\circ}-250^{\circ} \mathrm{C}$, but only at limited test pressures and limited degrees of expansion $(<10 \%-20 \%)$, and such elements may last only for single settings. During Leg 111, two special elements rated to $120^{\circ} \mathrm{C}$ were successfully used at temperatures of $120^{\circ}-145^{\circ} \mathrm{C}$ in Hole 504B, but lasted for only one setting each. 


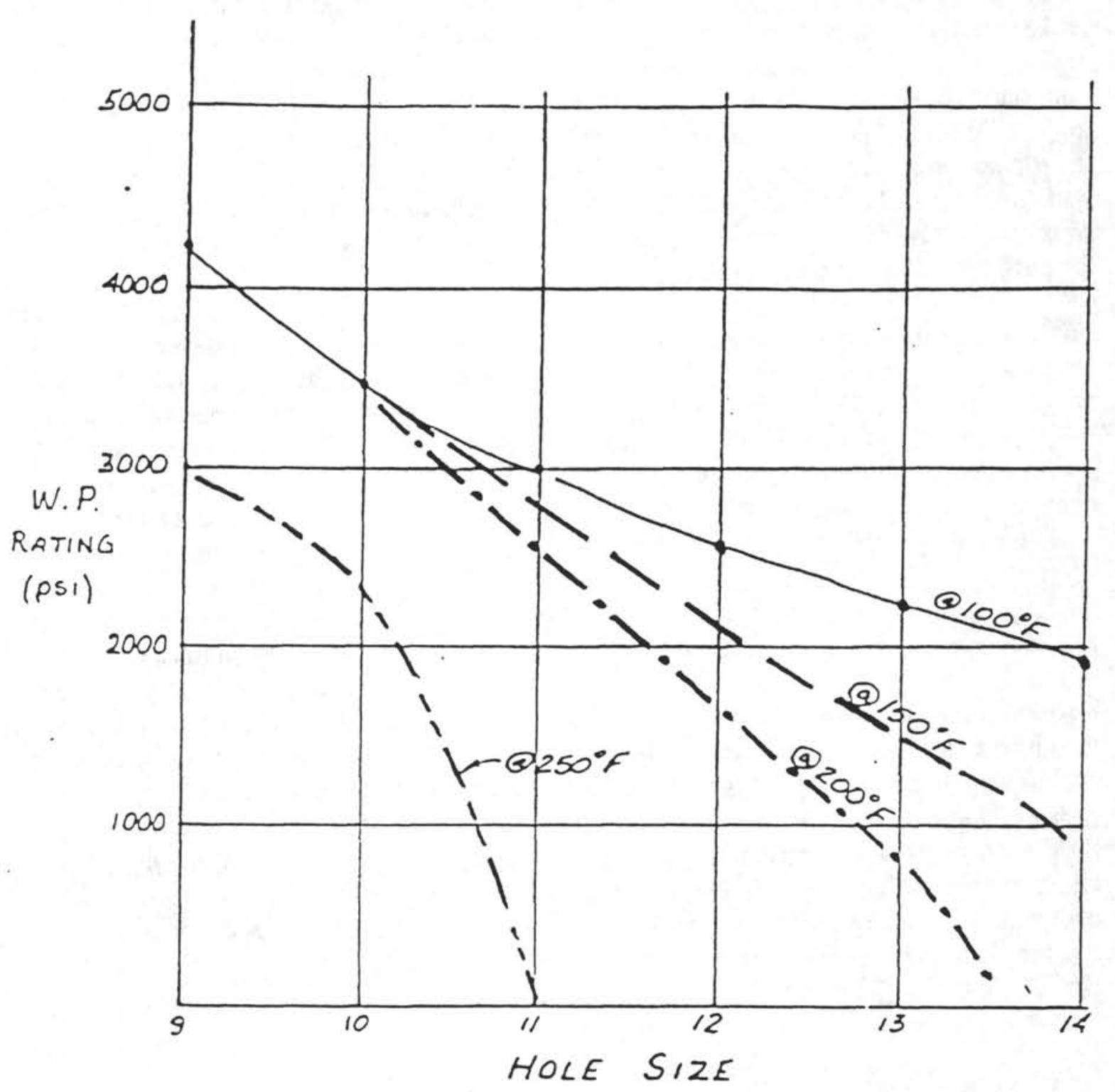

Figure II-2. Capabilities of the standard TAM elements to withstand differential test pressures versus hole size. 


\section{Compatibility of ODP drill-string packers with logging}

All of the standard logging tools will pass through either drill-string packer, unless a packer go-devil is in place. The minimum internal diameter of the non-rotatable packer is $3.94 \mathrm{in}$. in a single-packer configuration and 3.84 in. in a straddle-packer configuration; the minimum I.D. of the rotatable packer is also $3.84 \mathrm{in}$. Either packer can be built into a logging BHA, and packer measurements may not require a special pipe trip in addition to the trip necessary for logging. Packer measurements are usually run after the completion of wireline logging, because of the chances of a go-devil getting stuck in the pipe or of rubber from the packer elements stripping off in the hole. Also, the logs are usually important in locating formations in which to set the packer.

In some situations, it may be better for operational reasons to run a separate pipe trip for packer measurements. For example, the packer BHA may require more drill collars than an optimal logging BHA, to balance the upward force on pressurizing the zone isolated below the packer. It may be necessary that most or all of the BHA be in the hole below seafloor during logging, and a heavier, longer packer BHA would limit the shallowest depth to which logs could be run. Thus, if it is essential to log the upper $50 \mathrm{~m}$ of a reentry hole, separate pipe trips might be required for logging and packer measurements.

Logging or experiments through an inflated packer have not been permitted in the past, as this would involve unsafe procedures on the rig floor, as follows: When the packer is inflated and gripping the borehole wall, the BHA is immobilized, and the drill string must be heave-compensated to avoid tearing the packer loose. With the drill string compensated, the upper end of the pipe will move relative to the heaving rig floor, and it would be very difficult and unsafe to attempt to "stab" a long logging tool into the end of the pipe. One possible solution would require that the logging tool be run into the pipe before the packer is inflated, which would further require that the logging tool also function as the go-devil which enables inflation -- a complex but not impossible engineering task. In addition, the compensation of the wireline is not coordinated with the compensation of the drill string, and the chances of coiling or stretching the cable within the pipe might be unacceptable. A new go-devil design, which will allow the passage of a single-inductor logging cable for flow-meter or other measurements, is now under development.

\section{B. TAM Straddle Packer}

The design of the TAM straddle packer is quite simple, as it has no rotational capability and is intended primarily for measurements in reentry holes penetrating stable formations. By assembling it in the BHA with or without a few special parts, this packer can be used in four resetable modes:

(1) as a single-element packer,

(2) as a double-element (double-seal) single packer,

(3) as a straddle packer,

(4) as a straddle packer allowing the option to separately test the straddled interval or the interval below the packer.

All of these configurations are fully compatible with logging, so that packer measurements will not necessarily require an exclusive pipe trip. 
When a straddle configuration is used, the straddle interval can be as small as $1 \mathrm{~m}$, and can be changed by spacing normal 9-m joints or shorter "pup" joints of drill pipe between the elements. Hydraulic continuity between the elements is maintained by connecting them with $3 / 8$-in.-diameter stainless steel tubing external to the spacing drill pipe. Thus, if either element or the tubing fails to hold pressure, neither element can be inflated. This is a good safety feature, in that once the packers are inflated, a hydraulic failure anywhere in the system will result in deflation of both elements, not permitting an element to remain locked in an undeflatable position.

\section{Straddle-packer go-devils}

Depending respectively on whether a single or a straddle configuration is deployed, the first or both of two go-devils assembled from common parts will be used:

(1) a go-devil with 3.99-in.-diameter seals and stop rings, which seals above the single packer (or the upper straddle element) and keys into the sub-assembly that controls inflation and deflation of the single (or entire straddle) packer,

(2) a go-devil with 3.89-in.-diameter seals and stop rings, which passes through the control sub and seals the drill pipe at the lower straddle packer, allowing the straddled interval to be tested. As emphasized in the assembly instructions (Appendix A), these seals and rings look similar, and it is especially important to verify that seals and rings of the proper size are used in the proper go-devil!

Each go-devil must be retrieved with a standard overshot on the coring line. The use of the single packer configuration is fairly straightforward, requiring just one free-fall/retrieval round-trip of a single go-devil, whereas use of the straddle configuration requires a more complex and time-consuming sequence of go-devil operations: First, the upper go-devil must be dropped to allow inflation of both packers and possibly testing of the zone below the lower packer; second, to test the straddled interval, the upper go-devil must be retrieved, the lower go-devil dropped into place, and the upper go-devil dropped a second time; and third, at the end of the experiment, two trips of the coring line are required to retrieve both go-devils.

As described in Chapter IV, one or two self-contained pressure recorders are attached to the upper go-devil to record pressures in the isolated section, whether it be between a single packer and the bottom of the hole or between the two inflated elements of the straddle configuration. During operations with the straddle packer, a single pressure recorder can also be hung below the lower go-devil, to test for leakage from the straddled interval.

\section{Straddle-packer inflation/deflation and requirements for BHA}

Inflation of the TAM straddle packer utilizes the drill-string heave compensator, and requires a certain amount of weight in the BHA above the packer, as follows: To enable inflation, the upper go-devil must seal properly in the packer control sub. This assembly incorporates one principal moving part that can shift vertically by about $20 \mathrm{~cm}$, controlling whether or not the inflate/deflate port to the elements is open. This control tube is directly 
connected to the drill string, and its position is controlled from the rig floor using the sensitive drill-string heave compensator. When the drill string is freely suspended, both the flow paths into the elements and down the pipe up the annulus are open, so that pressure in the elements must remain the same as in the borehole. Thus the elements will remain uninflated until the upper go-devil is in place and the rig pumps are used to pressurize the elements. When the elements are fully inflated and actaally gripping the borehole wall, the heave compensator is adjusted to put some weight (roughly 15,000 lb) on the packer, shifting the control tube so that the inflate/deflate ports are closed and the packer elements are locked in the inflated position.

Then, after the completion of formation testing, the packers can be deflated by simply pulling up on the drill string at the rig floor, opening the inflate/deflate port whether or not the go-devil is in place. Note that the straddle packer deflates passively, and full retraction of the element will require up to half an hour before the packer can be moved in the hole, to avoid rubbing the outer cover off a partially deflated element. Thus, the packer can be deflated while the go-devil is left in place, and moved to another depth (after waiting for full deflation) and reinflated without having to retrieve the go-devil. In other words, the upper go-devil need only be retrieved to redress the pressure recorders when their recording times expire.

The weight applied to the packer to hold down the control tube to lock the packer inflated takes the form of drill collars in the BHA above the packer. The weight required can be determined as follows: If a single packer is used, applying pressure to the formation isolated by the packer also applies an upward piston force to part of the inflated packer itself. This force is of course proportional to the test pressures used, and must be balanced by weight above the packer to keep the packer in the hole! TAM gives a rule of thumb that about $12,000 \mathrm{lb}$ weight is needed per $1000 \mathrm{psi}$ anticipated test pressure. Typical test pressures should not exceed 1000-1500 psi (unless hydrofracture is to be attempted), so about $15,000 \mathrm{lb}$ weight should be included in the BHA for formation testing. At about $3000 \mathrm{lb}$ per drill collar, this corresponds to five or six collars above the packer. If hydrofracture is to be attempted, the straddle configuration is far better, because then the piston forces on the two packers will balance. Therefore, the straddle packer requires no more weight in the BHA than the single packer, even if much higher test pressures are anticipated. Obviously, attempting hydrofracture with a single packer will indeed require much more weight in the BHA, and is not recommended.

A typical BHA for the non-rotatable packer in either single or straddle configuration would therefore include (from the bottom up): the bit, crossover to the packer, packer, crossover to drill collars, drill collars, and 5-in. drill pipe. (See the example in Chapter VI.) A bumper sub is not recommended unless absolutely necessary, as it might affect the response of the control tube to adjustments in the heave compensator and it might be a weak point in the pressure integrity of the drill string. 


\section{Straddle-packer assembly and testing}

Appendix A contains assembly schematics and gives detailed instructions for:

(1) assembling the non-rotatable drill-string packer as a single packer or as a straddle packer,

(2) testing the assembled packer before deployment, and

(3) deploying and operating the packer and go-devil(s). General methods for formation testing from JOIDES Resolution, including use of the Kuster pressure recorders, are described in Chapters III and IV, and an example of formation testing using the straddle packer is discussed in detail in Chapter VI.

\section{TAM Rotatable Packer}

As noted above, the TAM straddle packer has no rotational capability, and is limited to use in reentry holes in stable formations. The TAM rotatable packer was designed to fulfill an important need for formation testing in single-bit holes or in holes into less stable formations where safety considerations require a reserve rotational capability. Such conditions commonly hold in sedimentary formations, especially at active margins, where it is now considered critical to measure formation hydrologic properties and to sample formation fluids.

As it must accommodate rotation and circulation without inflation of its element, the TAM rotatable packer is more complicated than the straddle packer. On the other hand, it is considerably simpler than the DSDP Lynes packer, which was designed for a similar purpose. The DSDP Lynes packer was never successfully used in a rotating mode, but was instead used in a reentry mode to measure permeabilities of the basalts penetrated in Holes 504B and 395A (Anderson and Zoback, 1982; Hickman et al., 1984; Anderson et al., 1985). Similarly, it may be more fruitful to use the TAM rotatable packer in a reentry mode rather than in a rotating mode.

The TAM rotatable packer is designed to be used only as a single packer, isolating the zone between the inflated packer and the bottom of the hole. It was initially envisioned to allow a four-step sequence of operations (Fig. II-3): (1) coring ahead, (2) inflating the packer and testing the formation, (3) deflating the packer, and (4) drilling ahead. However, it did not perform properly in this mode during tests on Leg 110 . Since then, it has been redesigned, retested in reentry mode on Leg 123, and redesigned further for Leg 131 drilling in the Nankai Trough. It now appears doubtful that the redesigned version will operate routinely in the core-ahead or drill-ahead modes, and it may be more realistic to plan to use it only for measurements in reentered holes that penetrate-less stable formations, with a very limited capability for coring or drilling ahead. With a minimum I.D. of $3.84 \ldots$ in., the TAM rotatable packer will be fully compatible with logging, as is more fully described in Section A above.

Inflation and deflation of the TAM rotatable packer are controlled by a go-devil and steel ball, without involving any manipulation of the drill-string heave comperisator (as is done with the TAM straddle packer). The original design involved separate inflation and 


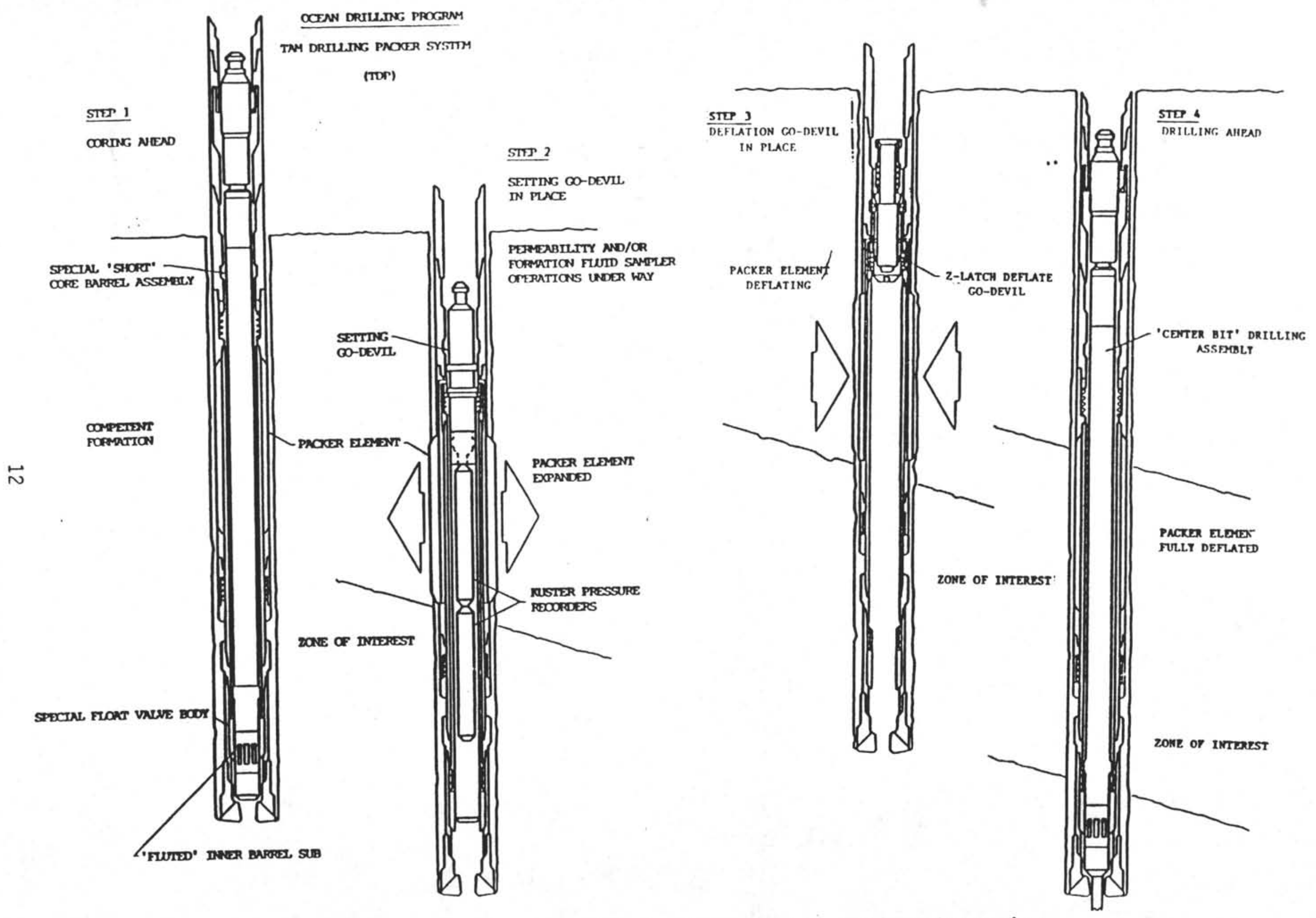

Figure II-3. Idealized sequence of operations with the ODP rotatable drill-string packer. 
deflation go-devils, but retrieving the inflation go-devil before dropping the deflation godevil posed an operational problem as described in Section $A$ above. Therefore, the design(s) for the go-devil(s) were modified for Leg 131, as follows: As with the straddle packer, the inflation go-devil will enable inflation and will carry the Kuster recorder(s) used to acquire pressure data during formation testing. After completion of formation testing, deflation will be accomplished by dropping a steel ball to land in the inflation go-devil, pressuring up to shift a sleeve within the go-devil and thereby expose the packer deflation port, and then releasing pressure within the drill string to allow deflation. All moving parts will be contained within the go-devil, which can be retrieved and redressed, so that the packer will operate for multiple sets during a single pipe trip.

A complete manual for assembly and operation of the TAM rotatable packer has been produced by the ODP engineers responsible for its development, and this manual will be updated as the go-devil design modifications are finalized. General procedures for formation testing using the rotatable packer will be similar to those using the straddle packer, and are described in the following two chapters.

As presently designed, the setting and deflation mechanisms for the rotatable packer differ from those of the straddle packer in two important ways. First, the new "no-pulse" go-devil used in the rotatable packer is designed to allow locking inflation pressure in the element without charging the isolated section of the borehole. This design was introduced with the hope that the packer could be used to isolate a section of a hole that penetrates an overpressured formation (such as is anticipated in parts of accretionary complexes) and actually allow a measurement of the overpressure. The setting mechanism in the straddle packer, in comparison, does charge the isolated formation with a pulse of pressure near that locked in the element(s).

Unfortunately, there is a large price to pay for not charging the formation during setting of the element. The no-pulse go-devil, used in the rotatable packer, has outside o-rings and poly-paks that must seal against the inside of the packer in order for pressure to be maintained in the element. If these seals are compromised, isolation of a section of the hole for testing is impossible. Strong surface currents during Leg 131 caused the pipe to strum so violently that the seals on the go-devil were stripped off during free-fall down the pipe. These seals are currently being redesigned by ODP engineers.

The seals around the upper go-devil used with the straddle packer, in comparison, need not maintain a perfect hydraulic seal in order to lock pressure in the inflation element. The seals around the lower straddle packer go-devil must be complete and working, when using this tool in true "straddle" configuration, in order to isolate the zone between the elements.

Repeated sets with the rotatable packer also require retrieval and redressing of the godevil and gauges, again in contrast to the straddle packer. This compromise was required because much of the setting control mechanism for the rotatable packer was built into the godevil, so that the mandrill could be made strong enough to withstand rotation. 


\section{DOWNHOLE AND RIG FLOOR INSTRUMENTATION}

Using a packer, several hydrologic parameters of the formation can be determined in various types of tests that involve controlled pumping of seawater from the rig floor into the isolated interval. In all of these tests, the critical parameter that is actually measured and from which the formation properties are derived is fluid pressure in the isolated section of the borehole. During testing it is also important to measure fluid pressure at the rig floor pumps, which may substitute for pressure measured downhole, and also to measure the volume and rate at which fluid is pumped into the isolated zone.

\section{A. Downhole Pressure Recorders}

Downhole pressures can be measured using several kinds of recorders. At present, ODP maintains five self-contained mechanical model K-3 recorders made by Kuster Co. These are calibrated for three different pressure ranges (0-9925, 0-12050, and 0-15200 psi), and can be set to record for 3,6 , or 12 hours. (A single clock belonging to the University of Miami may also be available to set one of the gauges to record for 9, 18, or 36 hours.) These recorders are very reliable, and have been used without mechanical failure in all of the packer measurements attempted to date during both DSDP and ODP operations. The brief but straightforward instructions supplied by Kuster Co. are included as Appendix B of this manual.

The Kuster pressure records are scratched quite accurately onto small coated brass charts. As only one size of chart is produced, some resolution is lost if a longer recording time is chosen; in recent practice, the recorders have been set for 3 or 6 hours. The charts must be read using a calipered, microscopic chart reader, which may take several hours per chart depending on the sampling density desired. If packer measurements are the last event of a leg, as has occurred in the past, it may not be possible to read all of these records during the leg, and they will need to be read ashore. Therefore, the reader recently used aboard JOIDES Resolution, which is the property of the University of Miami, may in certain situations be kept at Miami rather than on the drillship.

The Kuster K-3 recorders are housed in special carriers that are enclosed in sections of inner core barrel. The inner core barrel sections in turn attach to the go-devil(s) that are freefallen to the packer. This provides mechanical protection but allows borehole fluid pressures to reach the recorders. In normal practice with a single packer, two K-3 recorders are carried inside a section of inner core barrel about $12 \mathrm{ft}$ long attached to the go-devil, to provide redundant data in case one recorder malfunctions. In conducting packer .

experiments during Legs 109,111 , and 118, the author has generally set both gauges to record for 6 hours, but it might also be reasonable to set the backup gauge (i.e, that with poorer pressure resolution or greater range) to record for 12 hours. These times are longer than the 3 hours typically used during DSDP, because the rotatable packer allows the possibility of multiple sets at different depths during a single deployment of the go-devil with Kuster pressure gauges (as shown in the example in Chapter VI). 
If a straddle configuration is used, one K-3 should be attached to the lower go-devil to monitor pressure below the straddled interval, which will remain at hydrostatic if the packer seals properly. Therefore, resolution of time is not critical for this gauge, and the single clock available to allow one K-3 to record for 9, 18, or 36 hours might be appropriate to avoid the time-consuming procedure of retrieving and resetting the lower go-devil during a long sequence of formation testing and/or hydrofracture. If a short straddle configuration is used, spacing requirements may not allow more than one Kuster gauge to be attached to the upper go-devil, and a short section (about $6 \mathrm{ft}$ ) of inner core barrel must be used.

In the near future, self-contained electronic pressure recorders may be purchased. Like the Kuster mechanical recorders, these electronic recorders will be housed in special : carriers attached to the go-devil. Thus, the electronic recorders will be effectively interchangeable with the Kuster recorders, except that the electronic data will be accessible immediately after the go-devil is retrieved.

\section{B . Rig Floor Pumps and Gauges \\ 1. Seawater pumps}

Aboard JOIDES Resolution, two powerful pumps are available for inflating the packer and testing the formation: the "cement" pump and the "mud" pump. The mud pump is directly controlled at the rig floor by the driller and is more convenient, as the driller can also control the heave compensator in setting the packer. The cement pump is controlled from two levels below the rig floor and is thus much less convenient, as the pump operator and driller must remain in close communication to coordinate operations. The cement pump was used during Legs 109, 111, and the first segment of packer measurements during Leg 118 , before it was realized that the mud pump would be more convenient and equally suitable (see Chapter VI). However, the cement pump may still be more appropriate when accurately measured, smaller volumes of higher pressure fluid are required, as in a hydrofracture experiment.

\section{Determining volumes of seawater pumped}

As noted above, it is extremely important to record all volumes pumped during a packer experiment, i.e., during all operations conducted when the packer is inflated. This especially includes the small volumes of seawater pumped during slug tests (to determine compressibility, as discussed in the last section of Chapter IV), as well as the larger volumes pumped during injection tests and the rates at which these volumes were pumped. These volumes are so important that the packer scientist may wish to calibrate the various volume indicators, which are as follows:

When the mud pump is used, volumes are determined from the count of pump strokes, which is displayed in the driller's shack. At $98 \%$ efficiency, a single stroke of the mud pump is equivalent to 5 gallons or $18.93 \mathrm{~L}$. (Note: One gallon $=3.785 \mathrm{~L}$.)

When the cement pump is used, volumes of fluids pumped must be deternined by visually monitoring the fluid withdrawn from two 50-barrel reservoirs, which are marked 
in 5-barrel increments. When large volumes are pumped with the cement pump during an injection test, the operator must be careful to coordinate filling one reservoir while the other is being depleted, and then switching between reservoirs. When relatively small volumes are pumped with the cement pump, as in a slug test, the reservoir level may barely change, and the mechanical barrel counter attached to the pump should be used. (Note: One barrel = 42 gallons $=158.97$ L.)

\section{Pressures and pump rates measured at the rig floor}

Unless the isolated zone is shut-in downhole (which is not normal ODP practice), fluid pressures in the entire pressurized system can be monitored with electronic instrumentation at the rig floor as well as with the downhole.Kuster recorders.'Although the rig floor -electronic gauges will not resolve the absolute pressures downhole, they may resolve the relative pressure changes during formation tests as well as or better than the downhole gauges. They also offer the great advantage of real-time readings, so they should always be hooked up during formation testing, even if the downhole gauges are to be used for the primary pressure data.

Two different devices are available for monitoring pressures at the rig floor:

(1) A 5000 psi Gould PG3000 pressure transmitter owned by the University of Miami, and cable and control box built at LDGO to power the transmitter and condition its signal for output either to a strip-chart recorder or to the LDGO Masscomp computer. The transmitter should be attached to the stand-pipe aft of the rig floor, and connected by a cable strung around the rig floor into the downhole measurements lab. As the transmitter and cable are relatively fragile, these connections should probably be made after the pipe has been run into the hole and the pressure integrity of the drill string has been tested. Further details including schematics and specifications for the transmitter and control box are given in Appendix C.

(2) A similar Paine pressure transducer and magnetic flow meter owned by ODP may also be attached to the mud pump standpipe, and can drive a digital display and strip chart recorder in the driller's shack. Schematics for this hookup are given in Appendix C. These signals can also be fed to an IBM-PC in the ODP Operations Superintendent's office.

\section{Pressures Measured During Formation Testing \\ 1. Packer inflation pressure}

In testing the formation using a packer, it is important to carefully control the packer inflation pressure. This is defined as the pressure (relative to hydrostatic) at which fluid is pumped into the packer element(s) when it is inflated, and is measured at the rig floor pumps during inflation. The inflation pressure must be carefully chosen, based on anticipated hole conditions and formation properties, and on the planned test pressures.

"Given good hole conditions in basement formations, the elements should be inflated to about 500-1000 psi, or to roughly half the planned test pressures if higher test pressures are planned. If the inflation pressure is improperly chosen (either too high or toolow), a 
"leaky" packer seal may result, which will certainly affect any measurements but will not necessarily be recognizable in the pressure data. In addition, care must be taken not to inflate the element(s) to a pressure high enough to actually fracture the formation and thereby invalidate any testing. This upper limit on inflation pressure will depend on the lithostatic pressure and strength of the formation, and may be relatively low and difficult to estimate in less stable sedimentary formations as encountered in accretionary complexes.

\section{Hydrostatic pressure, pore pressure, and test pressure}

It is critical to measure and distinguish three different pressure values in the isolated section of the borehole: hydrostatic pressure, in-situ pore pressure, and test pressures. This necessity dictates the overall sequence in the testing procedure at each isolated zone:

(1) Hydrostatic pressure must be measured first, before the packer is inflated, both to check the recorder calibrations and to provide a reference baseline to compare the measurements of in-situ pore pressure and test pressures. The hydrostatic pressure baseline is usually obtained by waiting 10-20 minutes after the go-devil lands in the packer, before pressuring up to inflate the packer.

(2) When the packer is inflated, fluid pressure in the isolated section of the borehole will slowly approach in-situ pore pressure of the formation, which may differ from hydrostatic pressure. If it is critical to determine pore pressure, as much as 2-3 hours of passive recording may be required before active testing, to provide sufficient pressure data to accurately extrapolate to in-situ pressure.

(3) In active testing, permeability can be estimated from the transient behavior of pressure in the borehole (measured downhole and/or at the rig floor), in response to controlled pumping from the rig floor through the go-devil and into the formation. Two principal kinds of tests have been used in previous DSDP/ODP permeability measurements, pulse or "slug" tests and constant-rate injection tests, which are described in Chapter IV. 


\section{FORMATION TESTING -. THEORY AND ODP PRACTICE}

\section{A. Active Formation Testing}

The permeability of a formation that is isolated by a packer can be determined by a number of methods. The simplest and most direct of these are pulse tests and constant-rate injection tests, both of which involve applying controlled fluid pressure to the isolated zone using the rig floor pumps. 1

In a pulse test, the downhole and rig floor pressure recorders monitor the decay of a short, effectively instantaneous pressure pulse applied by the rig floor pumps. In a relatively impermeable formation, the decay of such a pulse will be long compared to the duration of the pulse, and the pressure data can be treated with the theory for an instantaneous pulse (Cooper et al., 1967; Papadopulos et al., 1973; Bredehoeft and Papadopulos, 1980). As detailed below, the decay of an instantaneous pulse is described by a complicated integral involving two dimensionless parameters, which depend respectively on "transmissivity" (a function of permeability) and "storage coefficient" (a function of porosity). Fitting pulse test pressure data to this function generally resolves transmissivity much better than storage coefficient, yielding estimates of permeability but not necessarily of porosity.

In a relatively permeable formation, a pressure pulse will decay too rapidly to allow resolution of transmissivity, and constant-rate injection tests are appropriate. These involve pumping into the formation from the rig floor at a known constant rate, and monitoring the approach of the downhole pressure to a nearly steady-state value. The transmissivity and permeability can be estimated using the theory for a constant line-source with a Darcy's Law boundary condition (e.g., Matthews and Russell, 1967). In practice, it may take up to an hour of constant-rate injection for quasi-steady-state to be reached, and permeability is usually estimated from the results of several injection tests at different rates.

Formation tests, particularly pulse tests, may be more accurate if the isolated formation is "shut-in" downhole, i.e., if the fluids in the tested interval are kept isolated from the fluids in the borehole above the test interval. Downhole shut-in can be achieved using a oneway valve in the go-devil that will allow pumping into the isolated formation but will not allow pressure to transmit up the drill string once pumping is stopped. If the isolated zone is shut-in, the downhole pressure data may provide more accurate estimates of formation properties, but the pressures measured at the rig floor will reveal nothing about the downhole testing. If the test interval is not shut-in, dowrihole conditions can be monitored by measuring pressure and flow rate at the rig floor, but the downhole pressure data must be corrected for the properties of the entire pressurized column of fluid in the borehole, and larger errors are likely in calculating permeabilities. Downhole shut-in has not been attempted in ODP packer work to date, partly because of go-devil complications, but mostly because it has been deemed much more important to monitor downhole conditions and events in real time with the rig floor gauges and recorders.

1Figures VI-1, VI-2, and VI-3 reproduce the Kuster pressure records from Leg 118 that illustrate both kinds of tests; this example is discussed in more detail in Chapter VI. 
In oceanic sediments and crust, the ranges of permeability over which pulse tests and constant-rate injection tests yield reasonable permeability estimates overlap, and it is often not possible to determine before testing which type of test will be more appropriate. As injection tests disturb the pressure field in the isolated formation to a greater degree than pulse tests, it is advisable to attempt pulse tests before injection tests. If several pulse and/or injection tests are to be attempted in a single formation, the pressurized system should not be allowed to "flowback" between tests; instead the pressure should be allowed to decay naturally as much as possible between tests. If the hole is thereby kept shut-in at the rig floor, the pressure effects of the individual tests will be superimposed in a straightforward manner, and it will be possible to correct for the effects of previous tests.

The programs of testing will vary from hole to hole, depending on the formation permeability. Further guidance can be gleaned from several good examples: the work done during DSDP in Hole 395A by Hickman et al. (1984) and in Hole 504B by Anderson and Zoback (1982) and Anderson et al. (1985), and the measurements made during ODP Legs 109, 111 , and 118 in Holes 395A, 504B, and 735B by Becker (1989, 1990, and in press). In particular, the last example is discussed in considerable detail in Chapter VI, and provides a draft working plan that may be applied with suitable modification to many ODP situations.

\section{B . Pulse or "Slug" Test Procedures}

Slug tests in DSDP and ODP have been conducted following the methods for the "modified" slug test of Bredehoeft and Papadopulos (1980), which is an adaptation of the slug test method of Cooper et al. (1967) and Papadopulos et al. (1973) for formations with relatively low permeabilities. The modified slug test involves applying a short pressure pulse to the fluid in the zone isolated by the packer, and monitoring the decay of this pulse as fluid flows from the borehole into the isolated formation.

The decay of such a pressure pulse is analogous to the decay of the frictional heating pulse on penetration of an oceanographic heat-flow probe into sediments (Bullard, 1954; Carslaw and Jaeger, 1959), and is described by virtually the same equation (Cooper et al., 1967; Bredehoeft and Papadopulos, 1980):

$$
P(t) / P_{0}=F(\alpha, B) .
$$

Here, $P$ is pressure in excess of an initial reference value, $P_{0}$ is the initial pressure increase, $\alpha$ is a dimensionless parameter that depends on the storage coefficient (S) and porosity ( $\emptyset$ ) of the isolated formation, $B$ is a dimensionless parameter that depends on the transmissivity $(\mathrm{T})$ and permeability $(\mathrm{k})$ of the formation, and $\mathrm{F}$ is a complicated infinite integral. More specifically,

$$
\begin{aligned}
& \alpha=\pi \mathrm{a}^{2} S / V_{w} C_{w} \rho_{w g} \\
& B=\pi T t V_{w} C_{w} \rho_{w g} g \\
& S=b \sigma C_{i} \rho_{i} g \\
& T=b k \rho_{i} g / \mu,
\end{aligned}
$$


where $t$ is time, $g$ is gravitational acceleration, $a$ is the radius of the hole in the isolated zone, $\mathrm{b}$ is the height of the isolated zone, $\mathrm{C}_{\mathrm{i}}, \rho_{\mathrm{i}}$, and $\mu$ are respectively the compressibility, density, and dynamic viscosity of the fluid in the isolated zone, and $C_{w}$ and $\rho_{w}$ are the compressibility and density of the fluid in the total pressurized volume $\mathrm{V}_{\mathbf{w}}$. The function $F(\alpha, \beta)$, shown in Figure IV-1, is given by

$$
F(\alpha, \beta)=\left(8 \alpha / \pi^{2}\right) \int \operatorname{du} \exp \left(-\beta u^{2} / \alpha\right) / u f(u, \alpha) \text {, }
$$

where $f(u, \alpha)=\left[u J_{0}(u)-2 \alpha J_{1}(u)\right]^{2}+\left[u Y_{0}(u)-2 \alpha Y_{1}(u)\right]^{2}, u$ is the variable of integration, and $J_{0}, J_{1}, Y_{0}$, and $Y_{1}$ are Bessel functions of the first and second kind.

Processing the pressures measured during slug tests involves the standard curve-fitting method described by Cooper et al. (1967) and Papadopulos et al. (1973), as follows: A plot of the decay of measured pressures vs. log time is superposed on a family of typecurves of $F(\alpha, \beta)$ vs. $\log B$ calculated for various values of $\alpha$ spanning several orders of magnitude. The data plot is then shifted along the abscissa of the type curve plot to visually determine the value of $\alpha$ for which the data best fit the type curve. Then the transmissivity and average permeability of the tested interval are calculated from the correspondence between the values of time and $B$ for the best-fit curve, using the definitions for $B$ and transmissivity listed above.

As noted by Cooper et al. (1967), Papadopulos et al. (1973), Bredehoeft and Papadopulos (1980), and Hickman et al. (1984), the calculated type-curves are fairly similar over a wide range in values of $\alpha$, and significant errors in the choice of $\alpha$ are likely in the curve-matching procedure. Fortunately, the large errors possible in determining $\alpha$ result in relatively small corresponding errors in the determination of transmissivity and permeability. Thus this procedure yields relatively poor estimates of the storage coefficient and porosity, but reasonable determinations of transmissivity and average permeability.

To justify the application of this theory for an instantaneous pressure pulse to real slug test data, the rise time of the slug test should be short compared to the decay time. For slug tests conducted during Legs 109,111 , and 118 , the ship's cement pump or mud pump was used to inject a small volume or "slug" of seawater into the drill string (which was already full of seawater at hydrostatic pressure), and the decay of the resultant pressure pulse was monitored with the downhole and rig floor recorders. Typically, 200-1000 L (1-6 bbl) was pumped into the drill string in 0.5-1 min, to produce a pulse with an initial pressure rise on the order of $0.5-2.5 \mathrm{MPa}$ in the isolated zone. The volume pumped for a pulse depends partly on the transmissivity of the isolated zone and partly on the compressibility of the pressurized system. The periods of decay of such pressure pulses must be sufficiently long (>10 $\mathrm{min}$ ) to justify application of the theory for an instantaneous pressure pulse. 


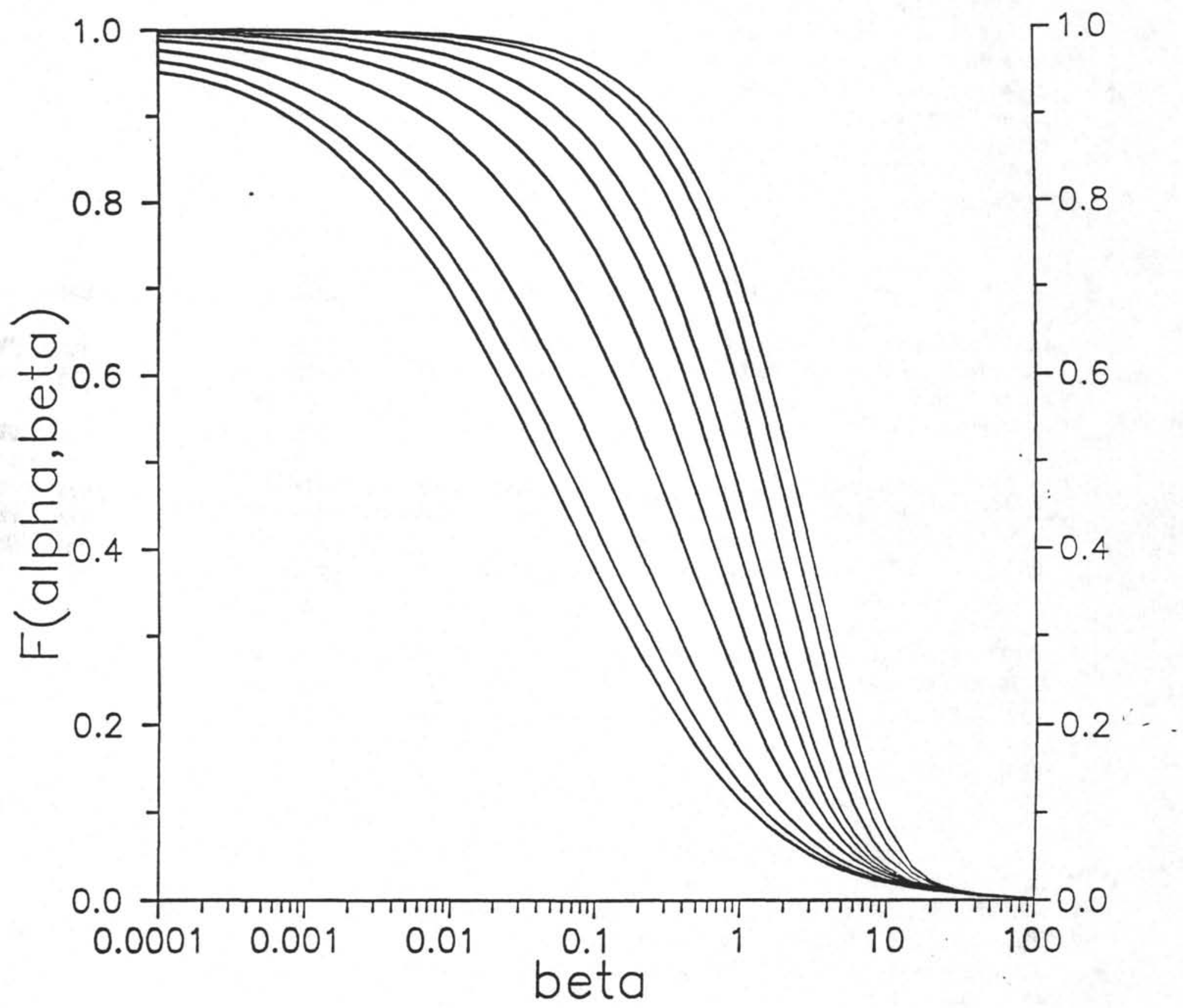

Figure IV-1. $F(\alpha, \beta)$ type curves versus $B$, for the following ten values of $\alpha$ : (left to right) 3.0, $2.0,1.0,0.3,0.1,0.03,0.01,0.001,0.0001,0.00001$. 


\section{Constant-Rate Injection Tests}

In a relatively permeable formation, a slug test will decay quite rapidly, and a better determination of permeability can be obtained by conducting a constant-rate injection test. In such an experiment, borehole pressure within the isolated zone is monitored as fluids are pumped into the formation at a constant rate. The rise of pressure as injection proceeds for a fairly long time is analogous to the rise of temperature of a heated needle probe used to measure thermal conductivity of sediments (Jaeger, 1958; Von Herzen and Maxwell, 1959), and is described by nearly the same equation (Homer, 1951; Matthews and Russell, 1967):

$$
\mathrm{P}(\mathrm{a}, \mathrm{t})=(\mathrm{q} \mu / 4 \pi \mathrm{kb}) \ln \left(\tau ø \mu \mathrm{C}_{\mathrm{i}} \mathrm{a} 2 / 4 \mathrm{kt}\right),
$$

where $q$ is the flux of injected fluids, $\tau$ is Euler's constant, and the remaining parameters are defined above. Thus the transmissivity and average permeability of the isolated zone can be determined directly from the slope of a plot of pressure vs. log time, given the measured constant injection rate.

For the injection tests attempted during Legs 109 and 118, seawater was pumped into the zones isolated by the packer, for $0.4-0.7 \mathrm{hr}$ at fixed rates of about $8-30 \mathrm{~L} / \mathrm{s}$. During each of these tests, the rate of injection was kept constant within 5\%-10\%. The actual rates were determined by timing the rate of withdrawal of seawater from the cement pump reservoirs or by counting the strokes of the mud pump, as is described in Chapter III.

\section{Assumptions, Approximations, and Sources of Error and Uncertainty}

1. In-situ permeability vs. calculated bulk permeability

Both slug and injection tests involve an important assumption -- that the permeability of the rock in the zone isolated by the packer is uniform and isotropic. This assumption is often not strictly valid for the formations cored by ODP, where permeability may be dominated by isolated fractures. Nevertheless, it probably "becomes more valid as the scale of the permeability tests [i.e., the length of the zone isolated by the packer] increases with respect to the spacing of the fractures" (Hickman et al., 1984; Parsons, 1966). The computed permeabilities are Darcian or equivalent porous-media permeabilities, denoted as bulk permeabilities, obtained by applying the theory for uniformly permeable media. If the in-situ permeability is indeed dominated by isolated fractures, the actual hydraulic conductivities of such fractures may be orders of magnitude greater than the computed transmissivities.

\section{Integrity of the packer seal}

The validity of results obtained with a packer obviously depends on the hydraulic integrity of the seal made with the inflatable elements. However, given that the annulus of an ODP hole is open to an infinite reservoir of seawater at hydrostatic pressure, it is generally very difficult in an ODP hole to sense any possible leakage of fluids upward past the inflation element(s). A method used during Leg 118 to verify the integrity of the packer seal utilizing the reentry video system is described in Chapter VI, but it may not be feasible 
at holes in deeper water. Slight leakage past the packer is always possible during formation testing, even if there are no direct indications of its occurrence. Such slight leakage would result in calculated transmissivities and permeabilities greater than the real values, so the values computed from ODP formation tests must be considered upper bounds on the transmissivities and bulk permeabilities of the isolated zones.

\section{Model-fitting procedures}

For both slug tests and injection tests, the bulk permeability is derived from parameters determined from the best fit of measured pressures to those predicted by models valid for isotropically permeable formations. For injection tests, the bulk permeability is calculated from the slope of a plot of pressure vs. log time; this slope is calculated using standard leastsquares techniques, which then allow objective error estimates. However, as noted above, the analysis for slug tests involves fitting measured pressures to type curves subjectively, with no rigorous assessment of possible errors. In interpreting past slug test results in the upper oceanic crust, Anderson and Zoback (1982), Hickman et al. (1984), and Anderson et al. (1985) estimated the uncertainties in calculated transmissivities and bulk permeability values by deliberately mis-fitting the type curves by \pm an order of magnitude in $\alpha$. For bulk permeabilities typical of young oceanic crust, the uncertainties so estimated for the results of slug tests are about $30 \%$.

\section{Volume and properties of the pressurized fluids}

The equations listed above demonstrate that the transient pressures measured during both slug and injection tests depend on the volume and physical properties of the pressurized fluids, particularly viscosity and compressibility, which vary with both temperature and pressure. Unless a shut-in valve is used in the packer go-devil, the volume of the pressurized fluid includes not only the volume of open hole isolated by the packer but also the volume within the drill string and rig floor plumbing. Calculation of the isolated volume requires measurement of the radius of the borehole with a caliper log. The volume within the drill string and rig floor plumbing will of course vary with depth and also depends on the specific BHA deployed; these volumes should be calculated at the time of the tests with guidance from shipboard operations personnel.

For the temperature-dependent viscosity of seawater, most ODP investigators have followed Anderson et al. (1985) in using Gartling's (1977) equation, $\mu\left(10^{-3} \mathrm{~Pa}-\mathrm{s}\right)=$ $16.68 \mathrm{~T}-0.8987$, with $\mathrm{T}$ in ${ }^{\circ} \mathrm{C}$. For in-situ temperatures ranging from $10^{\circ} \mathrm{C}$ to $140^{\circ} \mathrm{C}$ in the zones tested during Legs 109, 111, and 118, the viscosities calculated using this equation range over an order of magnitude, from about 0.2 to $2 \times 10^{-3} \mathrm{~Pa}-\mathrm{s}$.

As noted by Neuzil (1982), the compressibility of the fluid in a shut-in hole is sometimes greater than that of the pure fluid (seawater in this case), because of (1) compliance of the drill string and test equipment and (2) air possibly trapped in the system. While every effort should be made during ODP formation tests to purge all air from the drill string, pump, and connecting plumbing, it is possible that some air will remain in the

system. Such trapped air will affect the system compressibility, and the transmissivity and 
bulk permeability calculated in a slug test, which are directly proportional to the compressibility. As recommended by Neuzil, during slug tests the pumped volumes should be carefully recorded, to determine the effective compressibility of the pressurized fluid system by the definition of compressibility: $C=d V / V d P$. Results of such calculations during Legs 111 and 118, like Neuzil's, showed actual compressibilities greater (on average by about half an order of magnitude) than the tabulated values for seawater. 


\section{PROGRAMS FOR PROCESSING ODP PACKER PRESSURE DATA}

It should be clear from the discussion in the last chapter that processing packer pressure data to determine permeability is fairly complicated. It requires the scientist to perform some careful and somewhat subjective fitting of measured pressures to type curves, which probably should not be completely automated on a computer. In 1989, the author supplied ODP with three programs to interactively process the pressure data collected during formation testing using a packer. These three programs are:

(1) KUSTER, to convert Kuster $x-y$ charts to time and pressure,

(2) SLUG, to process a single slug test for permeability, and

(3) INJECT, to process a single injection test for permeability. Appendix D contains listings of these Fortran programs, and installation instructions for use on shipboard IBM-compatible personal computers. Use of these programs is described in this chapter.

\section{A. Steps in Processing Pressure Data Collected with a Packer}

Using the programs listed above, the packer scientist can process pressure data collected with a packer for permeability, beginning with the small $x-y$ chart from a Kuster recorder, in the following sequence:

(1) Read the Kuster chart using a microscopic reader, to produce a single file of Kuster $\mathrm{x}-\mathrm{y}$ readings for the entire go-devil lowering.

(2) Run the program KUSTER to convert this file of $x-y$ readings to a file of timepressure data, and produce a plot of the entire data file.

(3) Using a word processor or text editor, edit this file into separate files of timepressure data for each slug and/or injection test.

(4) Using the programs SLUG or INJECT, process each test to determine bulk permeability and transmissivity in the interval isolated by the packer, producing relevant plots.

The various tests at a given inflation depth should be processed in the order in which they were conducted, as the pressure data from a given test must of course be corrected for the superposed extrapolation of the pressure signal(s) from previous test(s). Determining these corrections is the most complicated aspect of processing a series of slug and/or injection tests; it is also the least programmable aspect of the procedure and therefore requires special care by the packer scientist, as described below. The remainder of this chapter contains detailed instructions for implementing the full sequence of packer data processing outlined above.

\section{B . Portability of the Code}

The three data-processing programs were written in Fortran specifically for compilers available for IBM-compatible personal computers, and will run much faster on a PC equipped with a math co-processor. The code could probably be compiled on other computers, with two major modifications: First, the programs utilize a PC graphics package written by Golden Software called GRAPHER, and a suitable replacement would 
be required on another machine. Second, the programs call this package via a "call system" library routine available with PC Fortran compilers from Lahey, and a suitable replacement routine would be required with another compiler.

The programs were written specifically for processing the analog pressure data collected with the Kuster recorders. When digitized manually on the chart reader, the Kuster charts typically produce reasonably small data files, and the programs use appropriate array sizes, as specified below. To process the more rapidly sampled, larger data files produced with electronic pressure gauges, the appropriate array sizes and loop indices should of course be increased.

\section{Notes on Using GRAPHER}

Before detailing the use of the three programs for processing packer data, it is important to review a few guidelines for using GRAPHER, which is called several times during the sequence. GRAPHER is a flexible, menu-driven scientific graphics program, and the packer scientist should review its manual to fully understand its options. The dataprocessing programs branch to GRAPHER in its full implementation, and then return to processing when the user exits GRAPHER. While in GRAPHER, the user can make complete use of all capabilities of GRAPHER, such as scaling plots for better screen presentation of the data, or producing hard copies of the plots.

GRAPHER can produce any of three kinds of graph or plot files: (1) a graph file, identified with a .GRF suffix, which reads specified data files and can be imported into and displayed within GRAPHER, (2) a generalized plot file, identified with a .PLT suffix, which can be saved for viewing (using the accompanying program VIEW) after GRAPHER is exited, and (3) an optimized plot file, identified with an .OPT suffix, that can only be sent to a particular output device for a hard copy.

The guidelines presented here are intended to prevent misuse of GRAPHER with respect to the data-processing programs. First and foremost, the data-processing programs write several data files that are read by certain graph (.GRF) files for screen displays of the data, and the user should be careful not to change these data files or the relevant graph files. The files that should not be changed are named with GR_prefixes; if these files are somehow changed by the user, they should be restored from an archive source. The GR_xxx.GRF files are in effect template graphs which always call the same GR_xxx.DAT files; the GR_xxx.DAT files are rewritten every time the data-processing programs are run so that new data are displayed by GRAPHER in the template graphs. These template files could be changed inadvertently by the user if he or she elects to "save" a graph or data file while running GRAPHER. For this reason, the following guidelines should be followed:

(1) GRAPHER should be configured in the "expert" mode, in which prompts to the user to save graph and data files are minimized.

(2) The user should not use the GRAPHER spreadsheet to edit data files. Data edited within the GRAPHER spreadsheet will be changed only in the GR_xxx.DAT file, 
but not in the data arrays actually being processed! If bad data are encountered, they should be edited from the user's data files using a text editor or word processor.

(3) While operating within GRAPHER, the user may freely adjust axes, add text, etc., to improve the screen resolution of data. However, he or she should never choose the "save graph on disk" option on the GRAPHER Main Menu unless he or she wishes to permanently change the template graph. Instead, if the user desires a hard copy or a plot file for future reference or viewing, he or she should choose the "print or plot graph" option to make a .PLT and/or..OPT file(s), being careful to give the relevant files new names.

\section{Reading Kuster Charts}

Reading the Kuster records can be very tedious, as each $x-y$ data point must be read manually and entered into the computer. It may require several hours if a detailed digitization is desired -- encompassing, for example, a few hundred data points per chart. For processing with the KUSTER program, the file of $x-y$ data from the Kuster chart should be entered with one $x$-y pair per line, with the $x$-value first, a space, and the $y$-value.

Instructions for using the Kuster chart reader are reproduced in Appendix B. It is especially important to orient the reader properly with respect to the chart, so that the baseline of the chart is exactly aligned with the axis of the reader and the baseline $y$-value consistently reads 0.0000 . If this is not done, the user may find that the baselines at the start and end of the chart do not give the same y-reading; if so, the entire reading procedure (several hours' work!) may have to be repeated. If the baseline reading at the end of the chart does indeed match the zero reading for the baseline at the beginning of the chart, then the data file is suitable for processing.

When reading a Kuster chart, the user should be careful to adequately sample the key pressures which are described in Chapter III: the reference hydrostatic pressure, the pore pressure if it was specifically measured, and pressures during the active formation tests. As discussed in Chapter IV, pressures during slug and injection tests approach asymptotic values on a time scale like the natural log of time, not linear time. As presently written, the curve-fitting algorithms in the SLUG and INJECT programs weight each data point equally. Therefore, pressures at the beginning of each slug or injection test should be sampled at closer intervals than pressures at the end of the test, with a sampling interval roughly proportional to the natural log of time since the pressure pulse or beginning of injection, respectively. Otherwise, the curve-fitting algorithms will over-weight the data from near the ends of the tests.

For a slug test, it is especially important to read the record in great detail at the very beginning of the pressure pulse, particularly if it is not a well-behaved, effectively instantaneous and smoothly decaying pulse. The algorithms in the SLUG program will allow the user to select an effective origin time for the pressure pulse, but only from among the data points read from the chart. 


\section{E. Converting Kuster $\mathbf{x}-\mathbf{y}$ Data Using KUSTER}

The KUSTER program will convert a file of up to $1000 \mathrm{x}$ - $\mathrm{y}$ readings from a Kuster pressure recorder to a second file of time-pressure data. It prompts the user for the file names to use for input and output, and for the conversion factors to obtain time and pressure from $x$ and $y$. As it ends, it calls GRAPHER for a display of time-pressure data written to a third file only for GRAPHER, and the user may utilize GRAPHER for a hard copy of the time-pressure data file. Before converting a file of $x-y$ readings, the readings should be checked for erroneous data entries, either with a text editor or graphically with a program such as GRAPHER.

To convert the $x-y$ data, be sure the current directory contains a copy of the file of $x-y$ data as well as the executable version of KUSTER, and type "kuster". The program will prompt the user for the following information:

(1) the file name of $x-y$ data to convert,

(2) the file name for the converted time-pressure data,

(3) the serial number of the clock,

(4) the clock range in hours $(3,6,12,9,18,36)$,

(5) a calibrated factor to convert $\mathrm{x}$ values to time,

(6) the serial number of the pressure sensor,

(7) factors to convert y values to pressure.

The program will then ask for confirmation of the values entered, and then convert the $x-y$ data to time and pressure. As it ends, KUSTER calls GRAPHER for a display of the timepressure data, and the user may elect to plot a hard copy or save a plot file for future reference.

\section{Conversion factors}

The parameters to be input in running KUSTER are fairly obvious, except for the conversion factors, which can be obtained as follows:

(a) For the conversion of $x$ values to time, either a nominal factor or a calibrated factor can be used. The nominal factor is obtained by assuming that the full $\mathbf{4}$ in. of Kuster chart corresponds exactly to the range of the clock. Instead of using the nominal factor, it is possible to calibrate the clock by attaching a pump to the small orifice in the cover of the pressure sensor and applying pulses of pressure at specified time intervals, say every

- hour. The chart will then contain recognizable spikes, and a conversion factor can be calculated from the spacing between spikes (as measured with the chart reader). In past experience, calibrated conversion factors have agreed with the nominal factors within $1 \%$. However, the interpretation of a slug or injection test depends on the accuracy of times measured relative to the beginning of the test, and the characteristics of the springdriven clocks can change with use. Therefore, it is recommended that each clock be calibrated at least once during each leg with packer measurements, if only to check that the nominal conversion factors are a reasonable representation of actual clock performance.

(b) For the conversion of $y$ values to pressure, the user is prompted for one or two factors, which can be calculated from the calibration data supplied by Kuster. The tables 
supplied by Kuster of pressures for every 0.001 in. of y-reading are not particularly useful; instead, conversion factors can be calculated by regression from the actual calibration data of y-readings for every 1000 psi pressure (given in Appendix B). These calibration data are not exactly linear over the entire range, so some care is required in calculating particular conversion factors appropriate to the range of pressures actually measured. In the past, the author has obtained conversion factors by regression using only those two or three calibration data pairs that bracket the range of pressures measured downhole at the actual packer depth.

The program will accept two kinds of conversions: either in the form of pressure $=\mathrm{P}_{0}$ $+b^{*} y$-value, or (if the user.assigns $P_{0}=0$ ) in the form of pressure $=b^{*} y$-value. The author has preferred to use the latter, because it is a conversion forced through the origin, so that pressures both at the rig floor (which should read 0 ) and downhole will be accurately converted. The two factors for the former kind of conversion can be obtained by standard linear regression through the appropriate calibration data pairs. If there are $n$ appropriate calibration data pairs denoted as $y_{n}, p_{n}$, the single factor for the latter kind of conversion can be obtained simply as the sum of the $n$ products $\left(y_{n}{ }^{*} p_{n}\right)$ divided by the sum of the $n$ products $\left(y_{n}{ }^{*} y_{n}\right)$.

\section{F . Editing Time-Pressure Data}

Before processing the converted time-pressure data, they must be edited into individual files for the separate slug and/or injection tests. This editing should be done with a text editor or word processor to produce ASCII or DOS text files, as opposed to files in word processor formats, and the user should of course use a rational file-naming scheme. The processing programs SLUG and INJECT both allow the user to graphically adjust the effective start and end times of the pressure pulse or injection, respectively, so that there is no need to pick these start and end points exactly when editing the data files. In fact, the individual edited files should probably overlap a bit, so that the tail of one test appears at the beginning of the data file for the next test.

\section{G. Processing Individual Slug Tests Using SLUG}

The SLUG program allows interactive processing of a file containing up to 200 timepressure readings for a single slug test, to estimate permeability by the type-curve-fitting method of Bredehoeft and Papadopulos (1980). It allows the data to be corrected to a reference value that accounts for hydrostatic pressure as well as the effects of previous slug and/or injection tests, and then fits the corrected data against the $F(\alpha, \beta)$ function described by Cooper et al. (1967) and Bredehoeft and Papadopulos (1980). Multiple trial fits of the data to several type curves can be attempted-before calculating transmissivity and permeability. GRAPHER is called at least twice, once for a display of the corrected data, and each time the corrected data are fit against a type-curve, and can be used to produce a plot file or hard copy of any of these displays.

To process a slug test, the user must be sure the current directory contains the file of edited time-pressure data as well as the executable version of SLUG, and type "slug". The 
program will first prompt for the following, in order: leg \#, hole \#, slug test \#, input file name, output file name. After this entire group has been entered, the user will be asked for confirmation of the entered values, and the status of the input and output files will be checked before the data are read and processed.

The first step in processing the data is one of the more critical and complicated steps: adjusting pressures to a reference value which includes hydrostatic pressure and corrects for the extrapolated effects of any previous tests. The user will be prompted to choose one of two options: (1) adjust only for hydrostatic pressure, simply by entering its value, or (2) adjust for the effects of previous tests, by means of a correction file which must have been prepared before running SLUG. The instructions for preparing such correction files are described in section I below. With the exception of the very first test conducted at a given packer depth, a correction file should be used for the most accurate processing. Nevertheless, a preliminary, quick look at the results of a slug test could be obtained by using only the hydrostatic correction.

After the data are corrected to a reference pressure, GRAPHER is called for a graphical display. At the same time, a tentative origin and end of the pressure pulse are selected (simply by searching for the peak pressure and the lowest pressure occurring after that peak), and are circled on the display. The user may adjust these points, and will be prompted to do so after he or she exits GRAPHER and returns to SLUG, simply by specifying the number of data points to shift one or both circles (+ for increasing time, - for decreasing time).

The choice of an effective origin is not a trivial matter, as processing involves scaling all pressures by the pressure at the effective origin. Sometimes, the pressure pulse is not clean, stable, and smoothly decaying, but instead may peak at an unstable value and drop to a lesser but more stable value in the few seconds after the peak pressure is reached. Becker $(1989,1990)$ interpreted such irregularities as the effect of the pressure wave applied from the rig floor pump down the long drill string filled with a slightly compressible fluid. In such cases the very peak pressure may not be the best choice of an effective origin, and instead the first reasonably stable pressure should be chosen. A poor choice of the effective origin will result in a poor fit to the type curves, which will be obvious later in the program. The choice of the effective origin can be changed later in the program, allowing the data to be reprocessed and refit to the type curves.

Once the user is satisfied (for the moment) with the choice of origin and end points, the data are processed and are written to the output file (see Example V-1), and the program moves on to fitting the processed data to the $F(\alpha, \beta)$ type curves. The user will be prompted to choose among 10 possible values of $\alpha$ for which the type curve is tabulated in the file FAB.FIL. The program will then find by least squares the shift of the data along the $B$ axis that produces the best match to type curve for the specified value of $\alpha$, and call GRAPHER for a screen display of the fit of the shifted data to the type curve. After returning to the processing program, the user will have several options, including (1) accepting the best fit 
and calculating permeability, (2) manually adjusting the shift to the present type curve (perhaps to de-emphasize the effect of certain data points on the least-squares fit), (3) specifying a new value of $\alpha$ and type curve, or (4) reprocessing the slug test with a new origin. Thus the user may try many type curves and best fits of the data to these type curves, until accepting the fit to the type curve that suits the data best and then calculating permeability from this best fit.

Once the user elects to calculate permeability, he/she will be prompted to supply several of the physical parameters that are described in Chapters III and IV, in the following order:

(1) the thickness of isolated zone, in m;

(2) the average radius of the isolated section of hole, in $\mathrm{m}$;

(3) the total volume of pressurized fluid, in $\mathrm{m}^{3}$;

(4) a choice of three options for the compressibility of the pressurized fluid:

(a) the value for pure seawater $\left(4 \times 10^{-10} \mathrm{~Pa}^{-1}\right)$,

(b) a value calculated from the volume of fluid pumped during the slug test, in $\mathrm{m}^{3}$,

(c) a specified value, in $10^{-9} \mathrm{~Pa}^{-1}$ (perhaps from a previous slug test),

(5) a choice of two options for the viscosity of the pressurized fluid:

(a) a value calculated from the average temperature in the pressurized zone, in ${ }^{\circ} \mathrm{C}$,

(b) a specified value, in $\mathrm{Pa}-\mathrm{s}$.

These values will be repeated for confirmation by the user, before the transmissivity and bulk permeability are finally calculated. The user will then have the option of writing these results to the output file, and/or returning to an earlier step to reprocess or adjust the processing of the slug test. Thus, the user can calculate permeability and transmissivity from many trials at processing the data. All or some of these results can be written to the output file at the user's discretion, and it is the user's responsibility to justify the selection of the most accurate values for the in-situ transmissivity and permeability.

\section{H. Processing Injection Tests Using INJECT}

The INJECT program allows interactive processing of a file containing up to 200 timepressure readings for a single injection test, to estimate permeability from the linear segment of a semi-log plot of pressure vs. time. Like the SLUG program, INJECT allows the data to be corrected to a reference value that accounts for hydrostatic pressure as well as the effects of previous slug,and/or injection tests. GRAPHER is called twice, once for a display of the corrected data, and again for a plot of the pressure rise vs. the log of time since the start of injection, and can be used to produce a plot file or hard copy of either of these displays.

To process an injection test, be sure the current directory contains the file of edited timepressure data as well as the executable version of INJECT, and type "inject". The program will first prompt for the following, in order: leg \#, hole \#, injection test \#, input file name, output file name. After this entire group has been entered, the user will be asked for confirmation of the entered values, and the status of the input and output files will be checked before the data are read and processed. 
The first step in processing the data is one of the more critical and complicated steps: adjusting pressures to a reference value which includes hydrostatic pressure and corrects for the extrapolated effects of any previous tests. The user will be prompted to choose one of two options: (1) adjust only for hydrostatic pressure, simply by entering its value, or (2) adjust for the effects of previous tests, by means of a correction file which must have been prepared before running INJECT. The instructions for preparing such correction files are described in section I below. As the very first test conducted at a given depth with the ODP drill-string packers will be a slug test, a correction file should be used for the most accurate processing. Nevertheless, a preliminary, quick look at the results of an injection test could be obtained by using only the hydrostatic correction.

After the data are corrected to a reference pressure, GRAPHER is called for a graphical display. At the same time, a tentative origin and end of the period of injection are selected (simply by searching for the lowest pressure in the first part of the data file and the peak pressure occurring after that minimum), and are circled on the display. The user may adjust these points, and will be prompted to do so after he or she exits GRAPHER and returns to INJECT, simply by specifying the number of data points to shift one or both circles (+ for increasing time, - for decreasing time). The choice of these points for an injection test is often more straightforward than for a slug test.

Once the user is satisfied with the choice of origin and end points, the data are processed and are written to the output file (see Example V-2). The program then calls GRAPHER for a display of the processed data vs. the log of time since injection started.

As described in Chapter IV, the pressure increase during injection should approach a linear relationship with the log of time, and the user will be asked to adjust two tentative endpoints for the linear segment of the curve. The program simplistically picks these as the start and end of injection, which are circled on the GRAPHER display. However, the start of injection is usually not the start of the linear segment, so the user should expect to adjust the start point. After exiting GRAPHER and returning to INJECT, the user will be prompted to adjust these tentative endpoints simply by specifying the number of data points to shift one or both circles ( + for increasing time, - for decreasing time).

Once the user is satisfied with the choice of endpoints of the linear segment of the semilog plot and elects to calculate permeability, he or she will be prompted to supply several of the physical parameters that are described in Chapters III and IV, in the following order:

(1) the thickness of the isolated zone, in m;

(2) the rate of injection into the isolated zone, in L/s;

(3) a choice of two options for the viscosity of the pressurized fluid:

(a) a value calculated from the average temperature in the pressurized zone, in ${ }^{\circ} \mathrm{C}$,

(b) a specified value, in Pa-s.

These values will be repeated for confirmation by the user, before the transmissivity and bulk permeability are finally calculated. The user will then have the option of writing 
these results to the output file, and/or returning to an earlier step to reprocess or adjust the processing of the injection test. Thus, the user can calculate permeability and transmissivity from many trials at processing the data. All or some of these results can be written to the output file at the user's discretion, and it is the user's responsibility to justify the selection of the most accurate values for the in-situ transmissivity and permeability.

\section{Corrections for the Effects of Previous Tests}

As emphasized in sections $\mathrm{G}$ and $\mathrm{H}$ above, adjusting the pressures measured during a slug or injection test to a reference value which includes hydrostatic pressure and corrects for the extrapolated effects of any previous tests is one of the more critical and complicated processing steps. In both the SLUG and INJECT programs, the user will be prompted to choose one of two options: (1) adjusting only for hydrostatic pressure, simply by entering its value, or (2) adjusting for the effects of previous tests, by means of a correction file which must have been prepared before running SLUG or INJECT.

The latter option should be used for the most accurate processing, although a preliminary, quick look at the results of a slug or injection test can be obtained by using only the hydrostatic correction. Only the first test (nearly always a slug test) at a given packer inflation depth can be accurately processed using a correction for hydrostatic pressure. All subsequent tests need to be corrected for the same hydrostatic pressure plus the superposed extrapolations of the pressure disturbances caused by previous tests at the given packer inflation depth.

The parameters required to correct for the effects of previous tests must be contained in a correction file that should be edited before processing each subsequent test. The correction file is constructed of one line for each pressure effect, with several parameters on each line depending on the type of correction it represents, as follows:

(1) A constant correction is denoted by a 1 at the beginning of the line, followed by the value of that constant correction. This is used primarily for the hydrostatic pressure, but can also represent any constant offset in pressures that may occur during the test sequence.

(2) The correction for the extrapolation of the shut-in period after injection is stopped is denoted with a 2 at the beginning of the line, followed by three parameters that allow a correction of the form of a constant multiplying the log of the ratio (time since start of injection/time since end of injection). This correction will of course go to zero at infinite time after the injection test.

(3) The correction for the extrapolation of the decay of a pressure pulse is denoted with a 3 at the beginning of the line, followed by four parameters that allow a correction: of the form of $\mathrm{P}_{0} * \mathrm{~F}(\alpha, \beta)$. This correction will also go to zero at infinite time after the slug test.

The first line of each correction file should of course represent the hydrostatic correction at the packer inflation depth. Subsequent lines can be obtained from the output files produced by SLUG and/or INJECT, as follows: The last line written each time 
permeability is calculated is exactly what should be entered into the correction file, and in fact could easily be copied to the correction file using a word processor or text editor. However, as emphasized above, both SLUG and INJECT allow many calculations of permeability from a single test, and the user must justify which calculation best represents in-situ permeability and transmissivity. Only when this decision is made can the proper line be transferred to the correction file for use in processing subsequent tests.

Thus, processing a series of formation tests at one packer setting requires very complete processing of earlier tests before subsequent tests are processed. In fact, the results of applying the full corrections to the subsequent test will provide some feedback as to the validity of the previous corrections and permeability calculations, as follows: If the proper correction is applied, the corrected pressures should be as low as exactly zero, within reason. If the corrected pressure immediately before a pressure pulse or the beginning of injection is significantly different from zero, then either the correction or the previous permeability calculation is in error and should be carefully checked. Similarly, if the pressure at the end of the pressure pulse or shut-in after injection drops significantly below zero, then the previous permeability calculation and correction should be checked. 
Example V-1. Output file produced by SLUG in processing slug test \#1 on Figure VI-1. Figure V-1 shows the fits of the processed data to several type curves, corresponding to the three permeability calculations at the end of this file.

\section{Leg 118 Hole 735B Slug Test \# 1}

Corrected for hydrostatic pressure $=7.7965 \mathrm{MPa}$

$\mathrm{T}_{0}=0.7118 \mathrm{hr} \quad \mathrm{P}_{0}=0.6759 \mathrm{MPa}$

\begin{tabular}{|c|c|c|c|c|c|}
\hline $\begin{array}{l}\text { Time } \\
\text { (hr) }\end{array}$ & $\begin{array}{c}\text { Pressure } \\
\text { (MPa) }\end{array}$ & $\begin{array}{l}\mathrm{T}-\mathrm{T}_{0} \\
\text { (hr) }\end{array}$ & $\begin{array}{l}\mathrm{Log} \\
\mathrm{T}-\mathrm{T}_{0}(\mathrm{~s})\end{array}$ & $\begin{array}{l}\text { P-Pref } \\
(\mathrm{MPa})\end{array}$ & $\begin{array}{c}\text { P-Pref } \\
/ \mathrm{P}_{0}\end{array}$ \\
\hline $\begin{array}{l}0.5624 \\
0.7050 \\
0.7058 \\
0.7062 \\
0.7104 \\
0.7113\end{array}$ & $\begin{array}{l}7.7965 \\
7.8222 \\
8.4724 \\
8.2871 \\
8.1787 \\
8.7691\end{array}$ & & & $\begin{array}{l}0.0000 \\
0.0257 \\
0.6759 \\
0.4906 \\
0.3822 \\
0.9726\end{array}$ & \\
\hline 0.7118 & 8.4724 & 0.0000 & & 0.6759 & 1.0000 \\
\hline 0.7134 & 8.4097 & 0.0016 & 0.7604 & 0.6132 & 0.9072 \\
\hline 0.7149 & 8.3698 & 0.0031 & 1.0477 & 0.5733 & 0.8482 \\
\hline 0.7164 & 8.3412 & 0.0046 & 1.2191 & 0.5447 & 0.8059 \\
\hline 0.7179 & 8.2956 & 0.0061 & 1.3416 & 0.4991 & 0.7384 \\
\hline 0.7194 & 8.2814 & 0.0076 & 1.4371 & 0.4849 & 0.7174 \\
\hline 0.7209 & 8.2557 & 0.0091 & 1.5153 & 0.4592 & 0.6794 \\
\hline 0.7224 & 8.2300 & 0.0106 & 1.5816 & 0.4335 & 0.6414 \\
\hline 0.7239 & 8.2158 & 0.0121 & 1.6391 & 0.4193 & 0.6204 \\
\hline 0.7254 & 8.1958 & 0.0136 & 1.6898 & 0.3993 & 0.5908 \\
\hline 0.7269 & 8.1730 & 0.0151 & 1.7353 & 0.3765 & 0.5570 \\
\hline 0.7284 & 8.1473 & 0.0166 & 1.7764 & 0.3508 & 0.5190 \\
\hline 0.7299 & 8.1359 & 0.0181 & 1.8140 & 0.3394 & 0.5021 \\
\hline 0.7314 & 8.1216 & 0.0196 & 1.8486 & 0.3251 & 0.4810 \\
\hline 0.7329 & 8.1159 & 0.0211 & 1.8806 & 0.3194 & 0.4726 \\
\hline 0.7344 & 8.1102 & 0.0226 & 1.9104 & 0.3137 & 0.4641 \\
\hline 0.7359 & 8.0874 & 0.0241 & 1.9383 & 0.2909 & 0.4304 \\
\hline 0.7374 & 8.0589 & 0.0256 & 1.9645 & 0.2624 & 0.3882 \\
\hline 0.7389 & 8.0247 & 0.0271 & 1.9893 & 0.2282 & 0.3376 \\
\hline 0.7404 & 7.9990 & 0.0286 & 2.0127 & 0.2025 & 0.2996 \\
\hline 0.7419 & 7.9847 & 0.0301 & 2.0349 & 0.1882 & 0.2784 \\
\hline 0.7434 & 7.9762 & 0.0316 & 2.0560 & 0.1797 & 0.2659 \\
\hline 0.7449 & 7.9733 & 0.0331 & 2.0761 & 0.1768 & 0.2616 \\
\hline 0.7464 & 7.9705 & 0.0346 & 2.0954 & 0.1740 & 0.2574 \\
\hline 0.7479 & 7.9676 & 0.0361 & 2.1138 & 0.1711 & 0.2531 \\
\hline 0.7494 & 7.9648 & 0.0376 & 2.1315 & 0.1683 & 0.2490 \\
\hline 0.7509 & 7.9619 & 0.0391 & 2.1485 & 0.1654 & 0.2447 \\
\hline 0.7524 & 7.9591 & 0.0406 & 2.1648 & 0.1626 & 0.2406 \\
\hline & 7.9534 & 0.0421 & 2.1806 & 0.1569 & 0.2321 \\
\hline 0.7554 & 7.9476 & 0.0436 & 2.1958 & 0.1511 & 0.2236 \\
\hline & 7.9419 & 0.0451 & 2.2105 & 0.1454 & 0.2151 \\
\hline 0.758 & 7.9362 & 0.0466 & 2.2247 & 0.1397 & 0.2067 \\
\hline & 7.9305 & 0.0481 & 2.2384 & 0.1340 & 0.1983 \\
\hline 0.76 & 7.9220 & 0.0496 & 2.2518 & 0.1255 & 0.1857 \\
\hline 076 & 7.9191 & 0.0511 & 2.2647 & 0.1226 & 0.1814 \\
\hline
\end{tabular}




$\begin{array}{cccccc}\begin{array}{c}\text { Time } \\ (\mathrm{hr})\end{array} & \begin{array}{c}\text { Pressure } \\ (\mathrm{MPa})\end{array} & \begin{array}{c}\mathrm{T}^{-\mathrm{T}_{0}} \\ (\mathrm{hr})\end{array} & \begin{array}{l}\text { Log } \\ \mathrm{T}(\mathrm{T})\end{array} & \begin{array}{c}\text { P-Pref } \\ (\mathrm{MPa})\end{array} & \begin{array}{c}\text { P-Pref } \\ / \mathrm{P}_{0}\end{array} \\ 0.7644 & 7.9163 & 0.0526 & 2.2773 & 0.1198 & 0.1772 \\ 0.7674 & 7.9106 & 0.0556 & 2.3014 & 0.1141 & 0.1688 \\ 0.7704 & 7.9020 & 0.0586 & 2.3242 & 0.1055 & 0.1561 \\ 0.7734 & 7.8906 & 0.0616 & 2.3459 & 0.0941 & 0.1392 \\ 0.7764 & 7.8792 & 0.0646 & 2.3665 & 0.0827 & 0.1224 \\ 0.7794 & 7.8678 & 0.0676 & 2.3862 & 0.0713 & 0.1055 \\ 0.7839 & 7.8592 & 0.0721 & 2.4142 & 0.0627 & 0.0928 \\ 0.7884 & 7.8564 & 0.0766 & 2.4405 & 0.0599 & 0.0886 \\ 0.7929 & 7.8535 & 0.0811 & 2.4653 & 0.0570 & 0.0843 \\ 0.7974 & 7.8507 & 0.0856 & 2.4888 & 0.0542 & 0.0802 \\ 0.8019 & 7.8450 & 0.0901 & 2.5110 & 0.0485 & 0.0718 \\ 0.8094 & 7.8393 & 0.0976 & 2.5458 & 0.0428 & 0.0633 \\ 0.8168 & 7.8364 & 0.1050 & 2.5775 & 0.0399 & 0.0590 \\ 0.8243 & 7.8336 & 0.1125 & 2.6075 & 0.0371 & 0.0549 \\ 0.8393 & 7.8307 & 0.1275 & 2.6618 & 0.0342 & 0.0506 \\ 0.8543 & 7.8279 & 0.1425 & 2.7101 & 0.0314 & 0.0465 \\ 0.8693 & 7.8250 & 0.1575 & 2.7536 & 0.0285 & 0.0422 \\ 0.8843 & 7.8222 & 0.1725 & 2.7931 & 0.0257 & 0.0380 \\ 0.8993 & 7.8222 & 0.1875 & 2.8293 & 0.0257 & 0.0380 \\ 0.9742 & 7.8222 & 0.2624 & 2.9753 & 0.0257 & 0.0380 \\ 1.0117 & 7.8165 & 0.2999 & 3.0333 & 0.0200 & 0.0296 \\ 1.0492 & 7.8107 & 0.3374 & 3.0844 & 0.0142 & 0.0210 \\ 1.1241 & 7.8079 & 0.4123 & 3.1715 & 0.0114 & 0.0169\end{array}$

Permeability and Transmissivity calculation \# 1

$\mathrm{T}_{0}=0.7118 \mathrm{hr} \quad \mathrm{P}_{0}=0.6759 \mathrm{MPa}$

Alpha $=0.00100$

Type curve shift $=10^{1.66}$

Thickness of isolated zone $=451.0 \mathrm{~m}$

Average radius of isolated hole $=0.1300 \mathrm{~m}$

Total pressurized volume $=29.660 \mathrm{~m}^{3}$

Compressibility of pressurized fluid $=0.1438 \mathrm{E}-07 \mathrm{~Pa}^{-1}$

Average temperature of pressurized zone $=10.00^{\circ} \mathrm{C}$

Viscosity of pressurized fluid $=0.2106 \mathrm{E}-02 \mathrm{~Pa}-\mathrm{s}$

Calculated transmissivity $=0.3044 \mathrm{E}-04 \mathrm{~m} 2 / \mathrm{s}$

Calculated permeability $=0.1387 \mathrm{E}-13 \mathrm{~m}^{2}$

To update a correction file based on these results, copy the following line to the file:

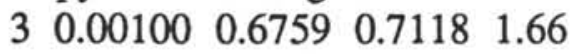


Permeability and Transmissivity calculation \# 2

$\mathrm{T}_{0}=0.7118 \mathrm{hr} \quad \mathrm{P}_{0}=0.6759 \mathrm{MPa}$

Alpha $=0.00010$

Type curve shift $=101.55$

Thickness of isolated zone $=451.0 \mathrm{~m}$

Average radius of isolated hole $=0.1300 \mathrm{~m}$

Total pressurized volume $=29.660 \mathrm{~m}^{3}$

Compressibility of pressurized fluid $=0.1438 \mathrm{E}-07 \mathrm{~Pa}-1$

Average temperature of pressurized zone $=10.00^{\circ} \mathrm{C}$

Viscosity of pressurized fluid $=0.2106 \mathrm{E}-02 \mathrm{~Pa}-\mathrm{s}$

Calculated transmissivity $=0.3922 \mathrm{E}-04 \mathrm{~m} 2 / \mathrm{s}$

Calculated permeability $=0.1787 \mathrm{E}-13 \mathrm{~m}^{2}$

To update a correction file based on these results, copy the following line to the file:

$\begin{array}{lllll}3 & 0.00010 & 0.6759 & 0.7118 & 1.55\end{array}$

Permeability and Transmissivity calculation \# 3

$\mathrm{T}_{0}=0.7118 \mathrm{hr} \quad \mathrm{P}_{0}=0.6759 \mathrm{MPa}$

Alpha $=0.00001$

Type curve shift $=101.46$

Thickness of isolated zone $=451.0 \mathrm{~m}$

Average radius of isolated hole $=0.1300 \mathrm{~m}$

Total pressurized volume $=29.660 \mathrm{~m}^{3}$

Compressibility of pressurized fluid $=0.1438 \mathrm{E}-07 \mathrm{~Pa}^{-1}$

Average temperature of pressurized zone $=10.00^{\circ} \mathrm{C}$

Viscosity of pressurized fluid $=0.2106 \mathrm{E}-02 \mathrm{~Pa}-\mathrm{s}$

Calculated transmissivity $=0.4825 \mathrm{E}-04 \mathrm{~m} 2 / \mathrm{s}$

Calculated permeability $=0.2198 \mathrm{E}-13 \mathrm{~m}^{2}$

To update a correction file based on these results, copy the following line to the file:

$\begin{array}{lllll}3 & 0.00001 & 0.6759 & 0.7118 & 1.46\end{array}$ 

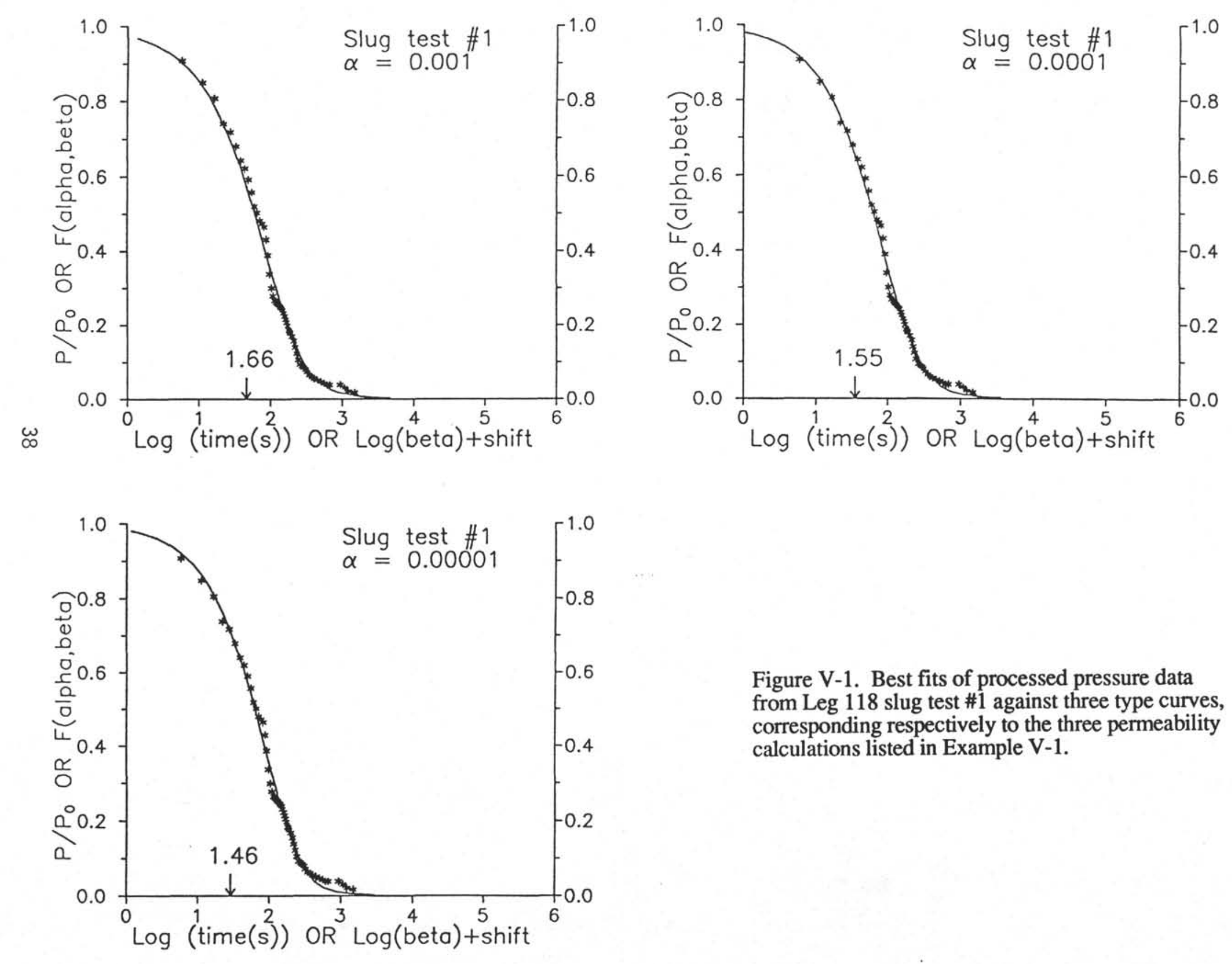

Figure V-1. Best fits of processed pressure data from Leg 118 slug test \#1 against three type curves, corresponding respectively to the three permeability calculations listed in Example V-1. 
Example V-2. Output file produced by INJECT in processing injection test \#3 on Figure VI-1. Figure V-2 shows the semi-log plot of the processed data, and the linear segment that was used to calculate permeability and transmissivity at the end of this file.

\section{Leg 118 Hole 735B Injection Test \# 3}

Corrected with reference pressure file: PREFINJ2.DAT

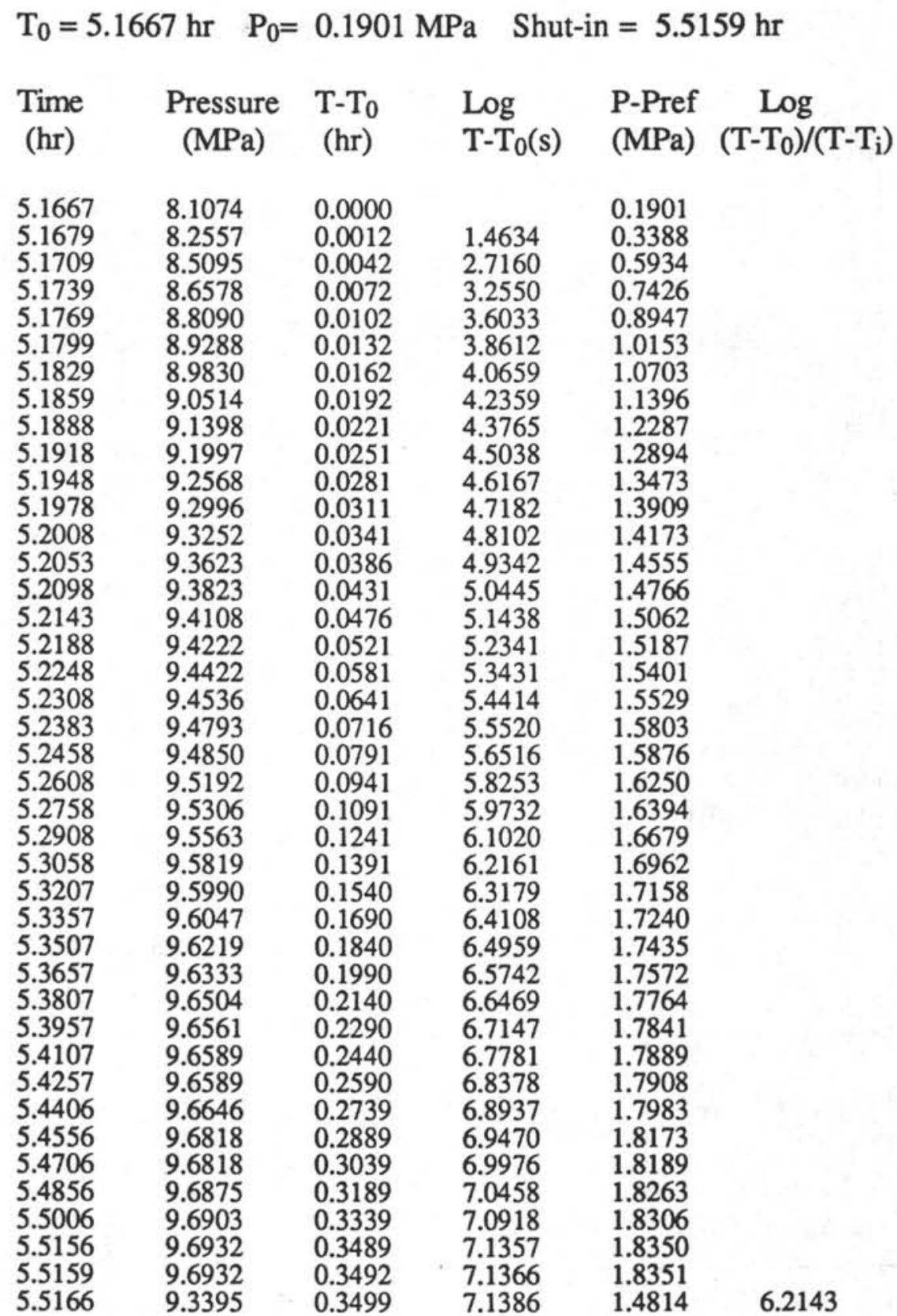




\begin{tabular}{|c|c|c|c|c|c|}
\hline $\begin{array}{l}\text { Time } \\
(\mathrm{hr})\end{array}$ & $\begin{array}{c}\text { Pressure } \\
(\mathrm{MPa})\end{array}$ & $\begin{array}{l}\mathrm{T}-\mathrm{T}_{0} \\
\text { (hr) }\end{array}$ & $\mathrm{Log}_{\mathrm{T}} \mathrm{T}_{0}(\mathrm{~s})$ & $\begin{array}{l}\text { P-Pref } \\
(\mathrm{MPa})\end{array}$ & 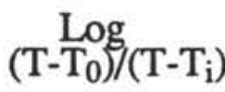 \\
\hline 5.5186 & 9.1798 & 0.3519 & 7.1443 & 1.3219 & 4.8702 \\
\hline 5.5216 & 9.1085 & 0.3549 & 7.1528 & 1.2509 & 4.1314 \\
\hline 5.5246 & 9.0543 & 0.3579 & 7.1612 & 1.1970 & 3.7169 \\
\hline 5.5276 & 9.0001 & 0.3609 & 7.1695 & 1.1431 & .4290 \\
\hline 5.5306 & 8.9687 & 0.3639 & 7.1778 & 1.1120 & 3.2090 \\
\hline 5.5336 & 8.9259 & 0.3669 & 7.1860 & 1.0695 & 3.0315 \\
\hline 5.5366 & 8.8917 & 0.3699 & 7.1942 & 1.0356 & 2.8831 \\
\hline 5.5396 & 8.8575 & 0.3729 & 7.2022 & 1.0016 & 2.7558 \\
\hline 5.5426 & 8.8290 & 0.3759 & 7.2103 & 0.9734 & 2.6447 \\
\hline 5.5456 & 8.7862 & 0.3789 & 7.2182 & 0.9309 & 2.5461 \\
\hline 5.5486 & 8.7548 & 0.3819 & 7.2261 & 0.8998 & 2.4578 \\
\hline 5.5516 & 8.7206 & 0.3849 & 7.2339 & 0.8659 & 2.3778 \\
\hline 5.5546 & 8.6921 & 0.3879 & 7.2417 & 0.8376 & 2.3049 \\
\hline 5.5576 & 8.6607 & 0.3909 & 7.2494 & 0.8065 & 2.2380 \\
\hline 5.5606 & 8.6350 & 0.3939 & 7.2570 & 0.7811 & 2.1761 \\
\hline 5.5650 & 8.6008 & 0.3983 & 7.2681 & 0.7473 & 2.0933 \\
\hline 5.5695 & 8.5694 & 0.4028 & 7.2794 & 0.7163 & 2.0169 \\
\hline 5.5740 & 8.5466 & 0.4073 & 7.2905 & 0.6939 & 1.9474 \\
\hline 5.5785 & 8.5352 & 0.4118 & 7.3015 & 0.6828 & 1.8838 \\
\hline 5.5845 & 8.5095 & 0.4178 & 7.3159 & 0.6577 & 1.8067 \\
\hline 5.5905 & 8.4810 & 0.4238 & 7.3302 & 0.6297 & 1.7371 \\
\hline 5.5965 & 8.4553 & 0.4298 & 7.3443 & 0.6045 & 1.6738 \\
\hline 5.6025 & 8.4411 & 0.4358 & 7.3581 & 0.5908 & 1.6159 \\
\hline 5.6085 & 8.4268 & 0.4418 & 7.3718 & 0.5769 & 1.5626 \\
\hline 5.6145 & 8.3983 & 0.4478 & 7.3853 & 0.5489 & 1.5133 \\
\hline 5.6205 & 8.3783 & 0.4538 & 7.3986 & 0.5294 & 1.4675 \\
\hline 5.6280 & 8.3584 & 0.4613 & 7.4150 & 0.5101 & 1.4147 \\
\hline 5.6355 & 8.3412 & 0.4688 & 7.4311 & 0.4935 & 1.3660 \\
\hline 5.6430 & 8.3156 & 0.4763 & 7.4470 & 0.4684 & 1.3211 \\
\hline 5.6505 & 8.3042 & 0.4838 & 7.4626 & 0.4576 & 1.2794 \\
\hline 5.6580 & 8.2899 & 0.4913 & 7.4780 & 0.4439 & 1.2405 \\
\hline 5.6655 & 8.2728 & 0.4988 & 7.4931 & 0.4273 & 1.2042 \\
\hline 5.6730 & 8.2585 & 0.5063 & 7.5081 & 0.4135 & 1.1702 \\
\hline 5.680 & 8.2500 & 0.5138 & 7.5228 & 0.4056 & 1.1383 \\
\hline 5.6880 & 8.2443 & 0.5213 & 7.5373 & 0.4004 & 1.1083 \\
\hline 5.695 & 8.2243 & 0.5287 & 7.5514 & 0.3809 & 1.0802 \\
\hline 5.710 & 8.2015 & 0.5437 & 7.5793 & 0.3591 & 1.0280 \\
\hline 5.7254 & 8.1787 & 0.5587 & 7.6065 & 0.3373 & 0.9809 \\
\hline & 8.1644 & 0.5737 & 7.6330 & 0.3240 & 0.9382 \\
\hline 5.755 & 8.1473 & 0.5887 & 7.6589 & 0.3078 & 0.8994 \\
\hline & 8.1330 & 0.6037 & 7.6840 & 0.2944 & 0.8638 \\
\hline 5.785 & 8.1159 & 0.6187 & 7.7086 & 0.2782 & 0.8311 \\
\hline & 8.1102 & 0.6337 & 7.7325 & 0.2734 & 0.8008 \\
\hline 5.807 & 8.1017 & 0.6412 & 7.7443 & 0.2653 & 0.7866 \\
\hline 5.8141 & 8.0817 & 0.6474 & 7.7539 & 0.2456 & 0.7752 \\
\hline
\end{tabular}

\section{Permeability calculation \# 1}

$\mathrm{T}_{0}=5.1667 \mathrm{hr} \quad \mathrm{P}_{0}=0.1901 \mathrm{MPa}$

Thickness of isolated zone $=453.0 \mathrm{~m}$ Average injection rate $=0.1169 \mathrm{E}-01 \mathrm{~L} / \mathrm{s}$

Average temperature of pressurized zone $=10.00^{\circ} \mathrm{C}$ Viscosity of pressurized fluid $=0.2106 \mathrm{E}-02 \mathrm{~Pa}-\mathrm{s}$ 
Calculated permeability $=0.2436 \mathrm{E}-13 \mathrm{~m}^{2}$

Calculated transmissivity $=0.5371 \mathrm{E}-04 \mathrm{~m} 2 / \mathrm{s}$

To update a correction file based on these results, copy the following line to the file:

$20.17753 \quad 5.16675 .5159$ 


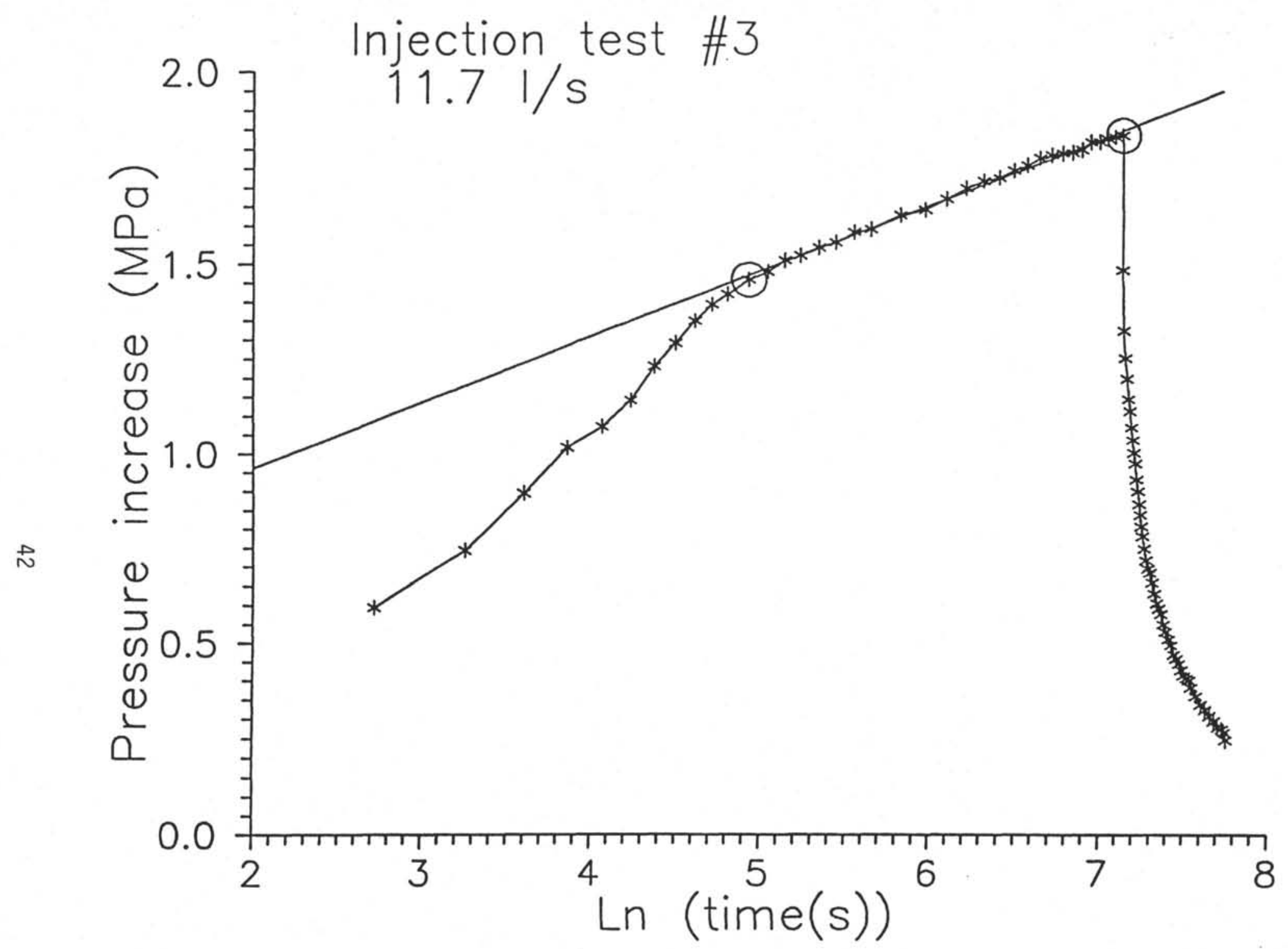

Figure V-2. Processed pressure data from Leg 118 injection test \#3, showing the approach of the pressure increase to a linear relationship with the log of time since injection was started. The permeability calculation in Example V-2 used the slope of the line determined by linear regression through those points between the two circled points. 


\section{EXAMPLE - LEG 118 PACKER MEASUREMENTS IN HOLE 735B}

This chapter reviews shipboard operations during a very successful example of ODP packer measurements -- those conducted during Leg 118 in Hole 735B. These measurements are analyzed in detail by Becker (in press), from which section B of this chapter is excerpted. Hole 735B penetrates $500 \mathrm{~m}$ of gabbros $731 \mathrm{~m}$ below sea level in the transverse ridge of the Atlantis II transform fault of the Southwest Indian Ridge (Robinson, Von Herzen, et al., 1989). The straddle packer was used in a single-packer configuration and was inflated six times at four depths to determine the bulk permeabilities of the respective intervals between these depths and the bottom of the hole. This represents the most extensive set of measurements yet obtained during a single DSDP or ODP packer deployment, and thus provides an excellent operational example for future deployments.

In addition, the sequence of events that occurred during these measurements proves that even the most successful packer operations generally do not proceed according to plan. In fact, at the beginning of these measurements, it was not even clear that the packer was functioning properly! The operations during Leg 118 provide several examples of major ways in which the detailed plan was modified and greatly improved, thanks largely to the expertise of the SEDCO drilling superintendent and core techs. A detailed plan is always necessary for ODP packer measurements, but the packer scientist must be prepared to modify it as events unfold.

\section{A. Final Leg 118 Packer Plan Before Commencing Measurements}

The following two pages reproduces verbatim the final plan for the Leg 118 packer measurements that was distributed to ODP and SEDCO operations personnel a few days before the measurements commenced. Although it was modified considerably as events occurred during Leg 118 (as is discussed in section B), the detailed plan for these measurements still provides a good model for the operational plans that should be prepared for future measurements. 


\section{PACKER MEASUREMENTS, HOLE 735B Final Plan -- 12/8/87}

Single packer to be run. The packer is not meant to withstand compression or rotation, so reentry needs to be made as carefully as possible.

Packer setting depths are $\pm 3 \mathrm{~m}$, to allow best positioning of top of string at rig floor. First packer setting depth as determined from the logs:

(1) $780 \mathrm{~m}$ below rig floor.

Subsequent depths will be chosen from the following possibilities, depending on the results at the first depth:

- $760 \mathrm{~m}$

$--954 \mathrm{~m}$

-- $1030 \mathrm{~m}$

$--1120 \mathrm{~m}$.

While the packer is being inflated and during the entire time that it is inflated:

-- Except for an emergency, do not bleed off pressure or flowback the system unless asked to do so.

-- Record volumes of fluid pumped during all operations.

Packer sequence

(1) Run pipe to first test depth.

(2) Test integrity of rig plumbing to 3000 psi before dropping go-devil.

(3) Drop go-devil with two Kuster pressure recorders covered with 12-ft inner core barrel. Kusters to be set for 6 hours recording. Attach circulating head, bleed air from system, and pump go-devil down with cement pump at about $2 \mathrm{bbl} /$ minute.

(4) While go-devil is falling, open compensator to less than mid-stroke and position bit at desired test depth.

(5) Stop pump as soon as go-devil lands, but do not bleed off pressure, to avoid allowing air back into system.

(6) Wait 15-20 minutes for recorders to establish hydrostatic baseline.

(7) When ready to inflate, start pump, pressure up, and maintain 1000-1500 psi.

(8) When weight indicator and compensator behavior show that the element is grabbing the side of the hole, stop pump and hold pressure for 5-10 minutes to test pressure integrity of drill string.

(9) Bleed off air on compensator to put 15,000 lb weight on the packer and position compensator at mid-stroke. This shifts the packer control sleeve down and isolates the inflated element while also opening the bore to the zone below the packer. This procedure should also result in a pulse test of the formation, so do not bleed off pump pressure unless instructed to do so.

(10) On instructions, pressure up rapidly to about 500-750 psi. Stop pump and hold pressure to monitor pressure decay. If the formation is as impermeable as we 
expect, and if the packer seals work properly, the decay of the pulse may require an hour or more. Do not bleed off or "adjust" pressure after stopping the pump.

(11) On further instructions, repeat pressure pulse tests, without bleeding off pressure between pulses. There may be two to four repetitions, and pressures may vary but will not exceed 1000-1500 psi.

(12) If pulse tests decay slowly, it will be time to deflate the packer and pull the go-devil. If the pulse tests decay too rapidly, we will unset and reset the packer and repeat pulse tests to check the integrity of the packer seal. If pulse tests continue to decay rapidly, measuring the formation permeability may require constant flow tests--pumping at constant rates up to 3 barrels/minute for up to an hour as pressures approach a steady-state value. Pump rates will be determined by counting barrels at the tanks, and must be kept as constant as possible by quickly switching between the two reservoirs.

(13) On completion of testing, measure flowback volume before deflating the packer.

(14) Bleed air into compensator bank to take weight off the packer and allow the control sleeve to pull up and deflate the element. Allow about 30 minutes for the packer to fully deflate before moving the pipe in the hole.

(15) Break off circulating head and retrieve go-devil with coring line.

(16) If time allows and the results of the first test warrant it, run pipe to next test depth and repeat.

\section{B . Log of Actual Events During Leg 118 Packer Measurements}

The last day of scientific operations at Hole 735B was devoted to running the drillstring straddle packer, which was configured with one element and used as a single-seal packer to isolate the zone between the bottom of the hole and the seal. Table VI-1 reproduces the shipboard log of the BHA deployed. During the packer measurements, the go-devil was deployed three times, and the packer was inflated six times at four depths to assess the variation of formation permeability (Table VI-2 and Figures VI-1, -2, and -3). Fluid pressure, flow rate, and total volume pumped were measured at the rig floor, and fluid pressure was measured in the borehole within the intervals isolated by the packer. The results of processing one of the slug tests and one of the injection tests are reproduced as the two examples in Chapter V.

Special care was taken to verify the hydraulic integrity of the testing system, which consisted of the rig pumps and lines, the drill string, and seals within the go-devil and the inflated packer. Before deploying the first go-devil, the hydraulic integrity of the rig-floor circulation system was satisfactorily tested to $10-15 \mathrm{MPa}$, over twice the pressures used to inflate the packer or test the formation. At each packer inflation, the integrity of the drill string and go-devil seals was satisfactorily tested by holding inflation pressure for 5-10 $\mathrm{min}$ before locking the packers in the inflated position. The effectiveness of the packer seal against the borehole was demonstrated by the excellent quality of the slowly decaying slug test records in relatively impermeable sections, and was directly tested in permeable zones by the method described in the following paragraphs. 
Table VI-1. Driller's log of the BHA used for the Leg 118 packer deployment.

\section{SEDCO/BP 471}

\section{BUTTOM HOLE ASSEMOLY GHANGE SHEET}

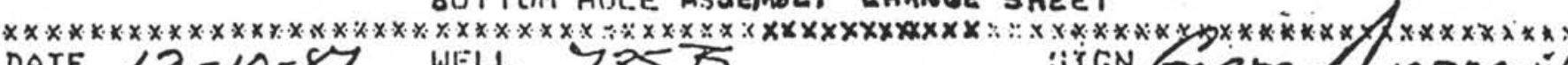
DATE $12-10-87$ WELL 73575 :ITSN

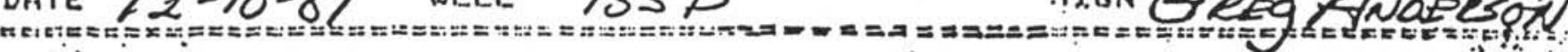

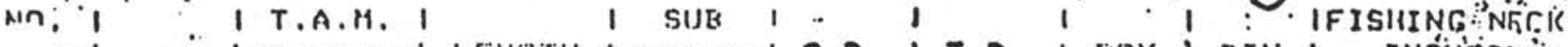

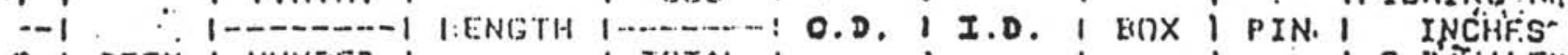

ט. 0.1 ITEM I NUMEER ।

I TUTAL I

1 0.1)

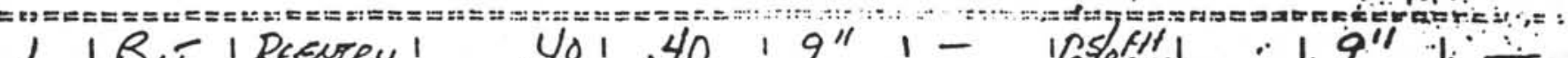

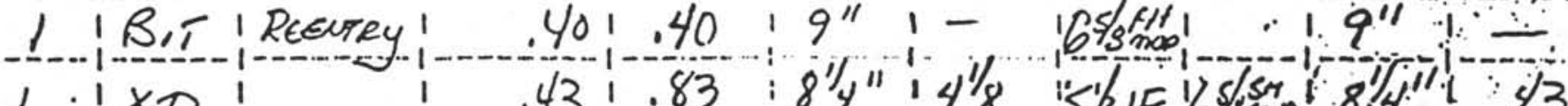

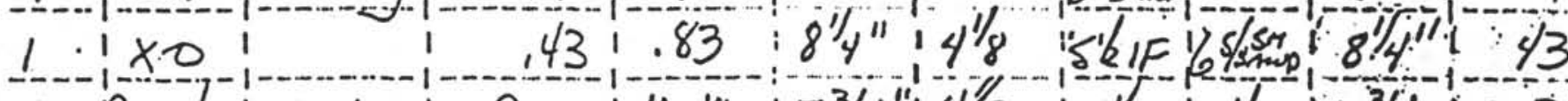

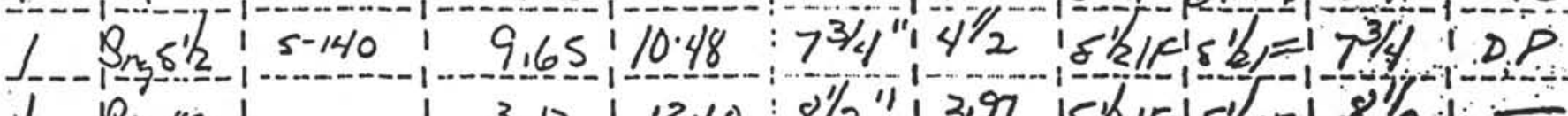
1 Pack 1

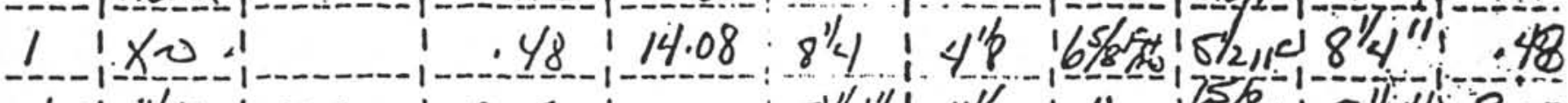

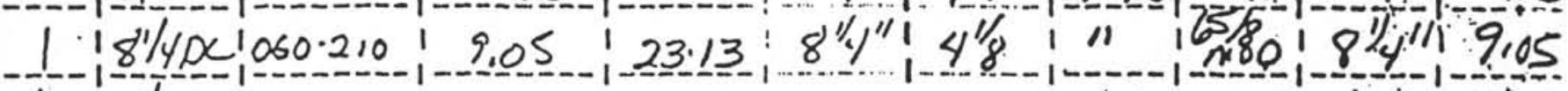

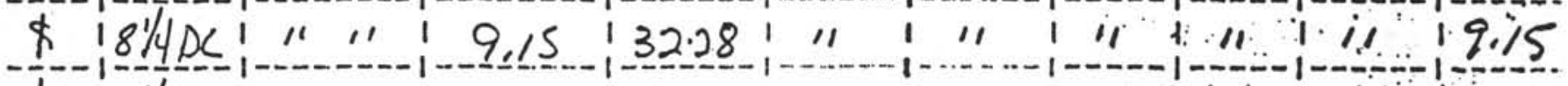

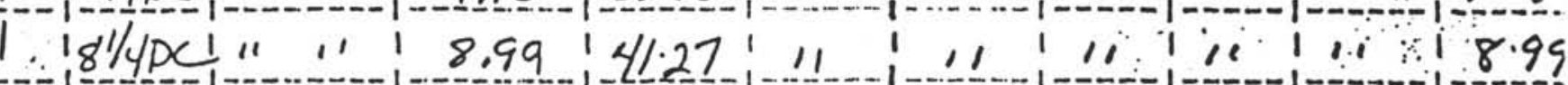

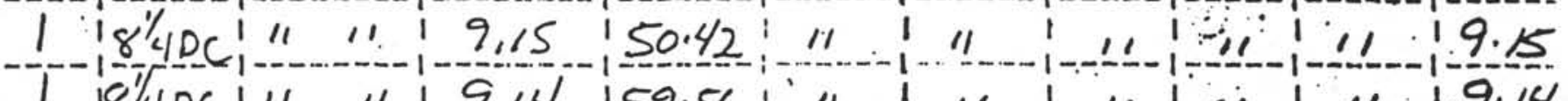

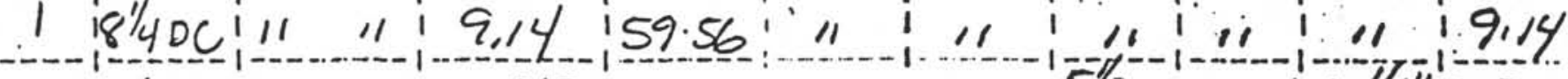

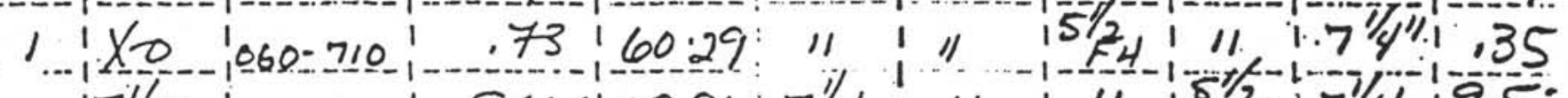

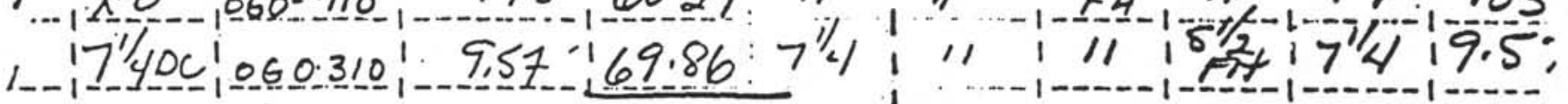
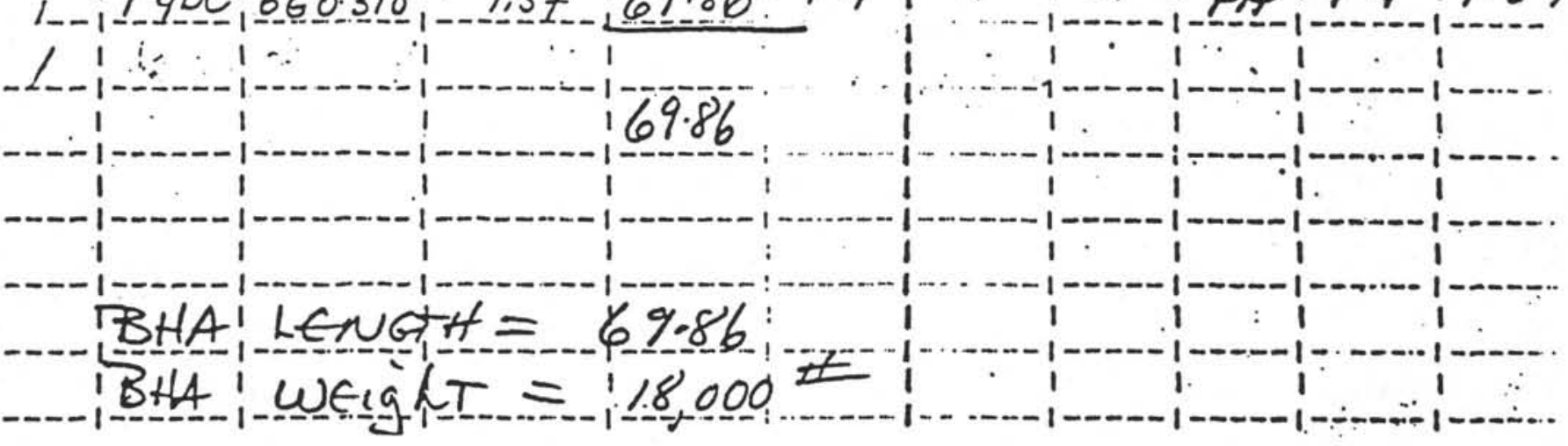
Table VI-2. Summary of events during six packer inflations, with a total of three go-devil deployments, Hole 735B, Leg 118.

\section{Go-Devil \#1}

(1) 49 m packer depth

4 pulse tests - fast decay unset with $20,000 \mathrm{lb}$

(2) $47 \mathrm{~m}$ - reset packer

2 pulse tests - fast decay

3 injection tests

100 strokes/minute (with mud slug to check seal)

50 " "

30

\section{Go-Devil \#2}

(3) $389 \mathrm{~m}$

2 pulse tests - very slow decay

(4) $299 \mathrm{~m}$

4 pulse tests - moderately slow decay

(5) $223 \mathrm{~m}$

3 pulse tests - fast decay

1 injection test - 50 strokes/minute

\section{Go-Devil \#3}

(6) $223 \mathrm{~m}$ reset

1 pulse test - fast decay

2 injection tests

30 strokes/minute

$50 \quad " \quad$ (with mud slug to test seal) 


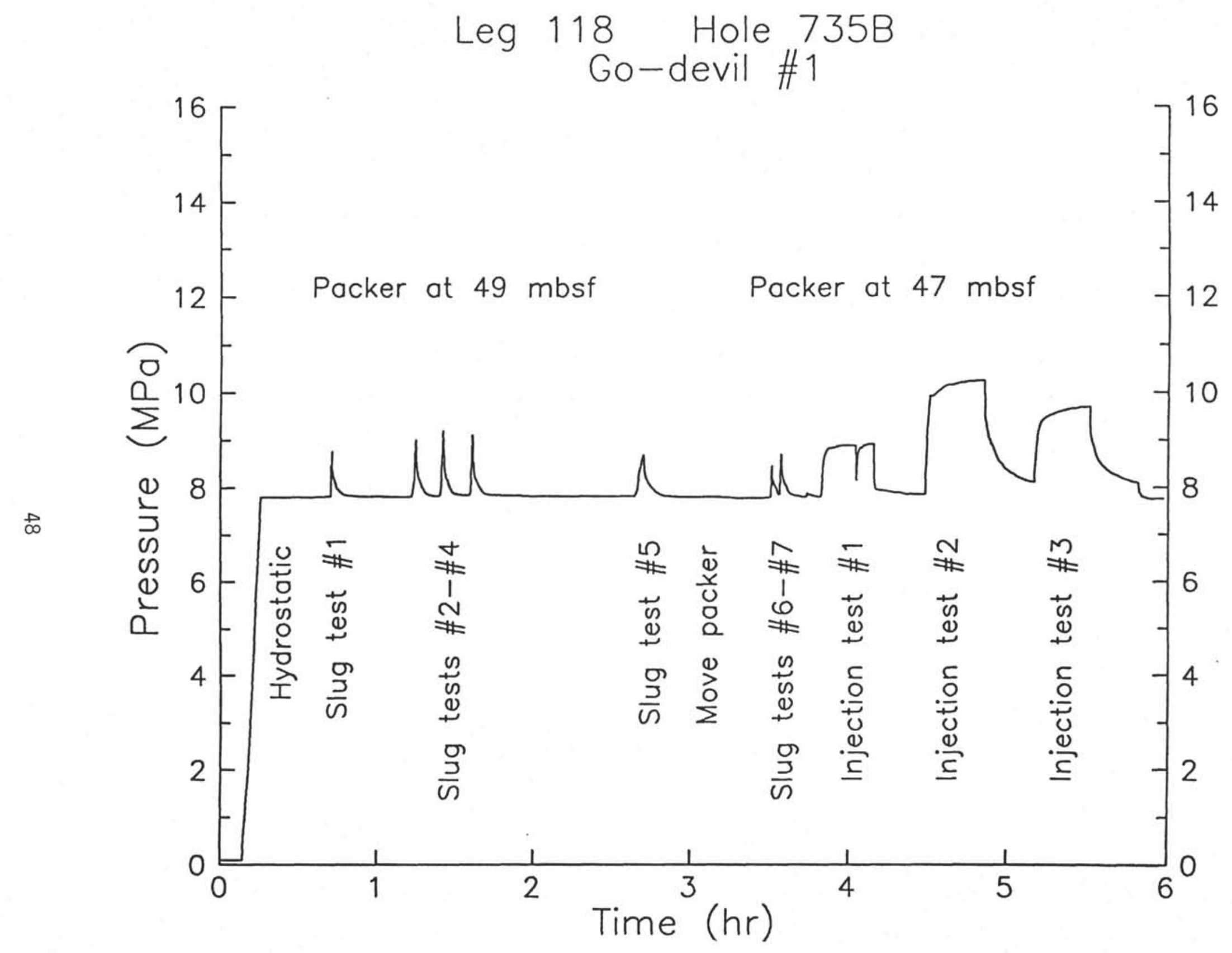

Figure VI-1. Corrected pressures versus time for the first go-devil deployed during Leg 118, encompassing the packer inflations at 49 and $47 \mathrm{mbsf}$. 


\section{Leg 118 Hole 735B \\ Go-devil \#2}

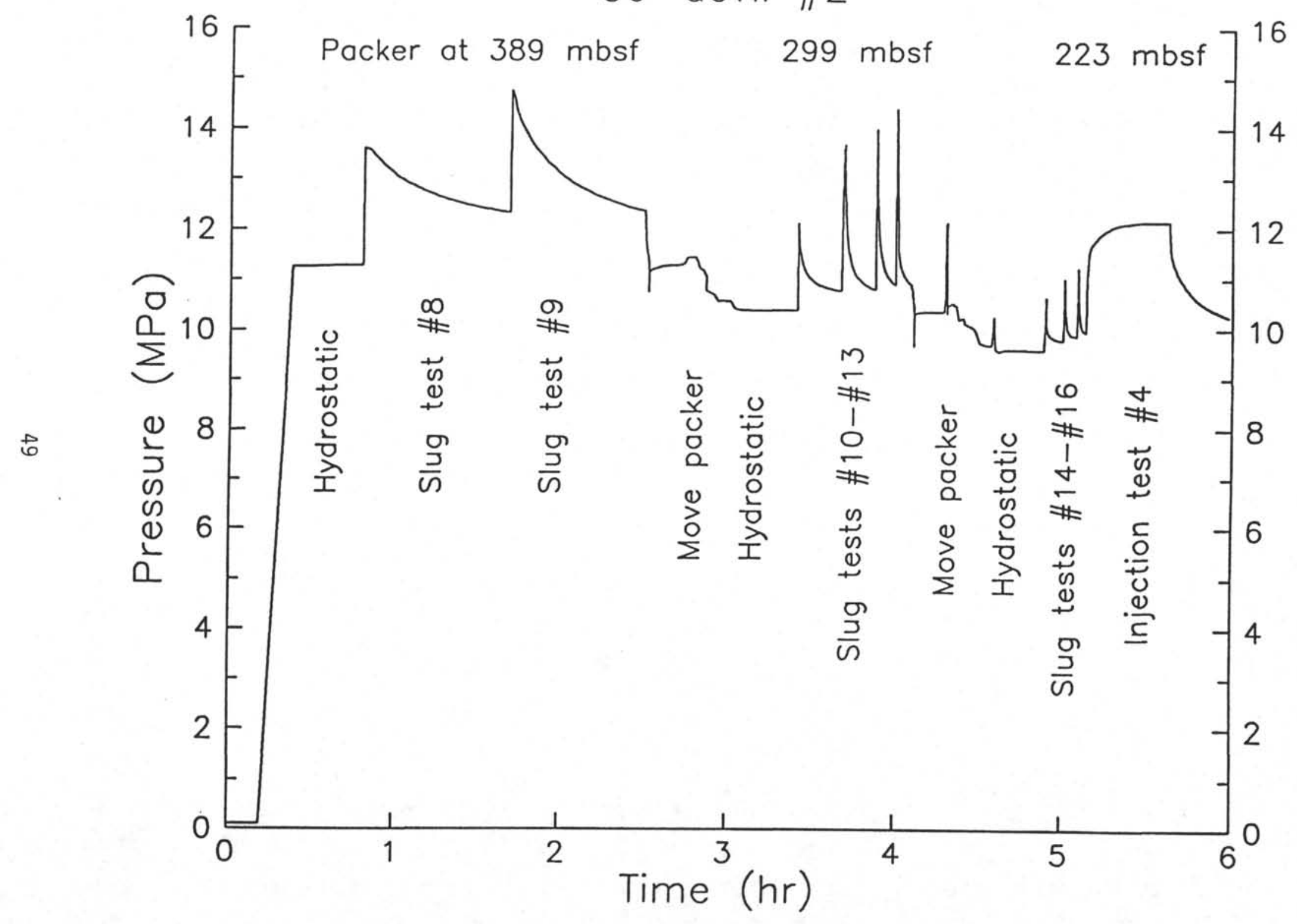

Figure VI-2. Corrected pressures versus time for the second go-devil deployed during Leg 118, encompassing the packer inflations at 389,299 , and 223 mbsf. 
Leg 118 Hole 735B

Go-devil \#3

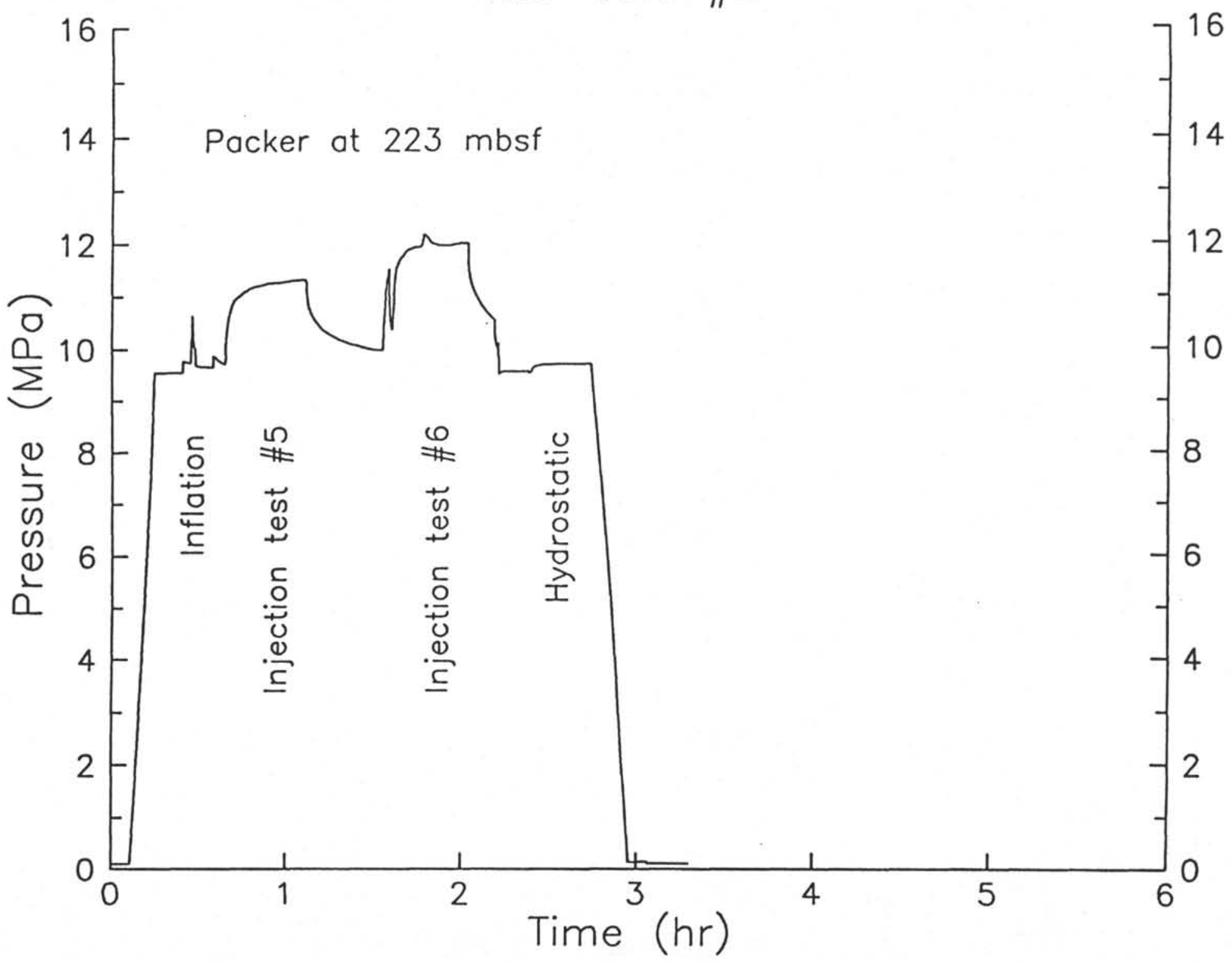

Figure VI-3. Corrected pressures versus time for the third go-devil deployed during Leg 118, for the repeated inflation at 223 mbsf. 
The depths at which the packer was set were based primarily on logging results. It was decided to set the packer first at a shallow depth because there were a number of indications (e.g., superb recovery of massive core, very high electrical resistivity values and low porosity values from the logs) that much of the cored formation might be quite impermeable. Setting the packer first as shallow as possible in the hole allowed the permeability of the entire cored section to be assessed; if the entire section had been impermeable, the remaining time on site would have been used for other purposes. However, the results at the first inflation depth showed that there was significant permeability in the hole, and the subsequent inflations were run from deep in the hole back up the hole, to determine the variation of permeability with lithology and to locate the permeable section(s).

As described in previous chapters, two kinds of experiments were used to determine the permeability of the isolated interval, pressure pulse (slug) tests and constant-rate injection tests. Injection tests generally disturb the pressure field in the formation much more than slug tests, and were therefore conducted after the slug tests at appropriate inflation depths.

The complete sequence of operations is summarized in Table VI-2, and the Kuster pressure-time records are shown in Figures VI-1 through VI-3. All operations went smoothly, except for the very first packer setting at 49 mbsf, as follows: When the pulse test results at the first setting indicated unexpectedly high permeability, it was decided to verify that the packer element was sealing properly by resetting the packer at the same depth and repeating the measurements. However, the packer could not be unset smoothly, and it required much more pull $(20,000 \mathrm{lb})$ than normal to release the pressurized fluid inside the inflation element. For a short time, the packer was actually stuck in the hole, and it was not clear whether it was working properly. Nevertheless, when the packer was moved $2 \mathrm{~m}$ shallower in the hole and pressured up, it reset smoothly and gave similar indications of high permeability somewhere in the isolated interval.

Such indications could also have been produced by a "leaky" packer seal if the element had been damaged when pulling it free. Therefore the seal was then tested by utilizing the video reentry system, which was hanging immediately above the reentry cone, as follows: A small slug of mud was pumped into the isolated interval, immediately followed by a constant-rate injection test that involved pumping seawater into the isolated interval at nearly $2000 \mathrm{~L} / \mathrm{min}$ for more than $20 \mathrm{~min}$. This amount of seawater was more than twice that required to pump the mud back out of the hole if the packer had not been sealing properly. No mud or other fluid was seen exiting the cone on the video during this or two subsequent injection tests during this inflation. Although this particular injection test was flawed as a permeability measurement because of procedures required for the mud slug, fluid pressures during the subsequent injection tests closely followed the prescribed behavior, indicating that the packer was functioning properly.

Thus we concluded that the packer was operating correctly, and there was indeed highly permeable formation in the hole. The go-devil was retrieved and redressed, and the 
packer was moved deep in the hole and set at successively shallower depths to locate the permeable zone(s). The packer and go-devil operated smoothly until the drill string had to be pulled to depart the site. At the end of the last packer setting at $223 \mathrm{mbsf}$, the mud-slug and injection test described above was repeated; no mud was seen exiting the cone, again verifying that the packer was sealing properly. When the packer was brought back on deck, the inflation element was in nearly perfect condition, in contrast to several previous examples of shredded, melted, or otherwise frazzled elements recovered from basaltic Holes 395A and 504B.

\section{Comments}

Figure VI-2 attests to the fact that the packer may be reset at several depths without retrieving the go-devil, which needs to be pulled only when the recorder must be redressed. It should be emphasized that, after the inflation pressure is released from the element(s), up to 30 minutes may be required for full deflation and retraction of the element(s) before the packer is moved to a new setting depth. Otherwise, the outer rubber cover of the element may be rubbed off, destroying the sealing capability of the element.

Several of the steps given in the plan reproduced in section A might be clarified or explained further, as follows:

Steps (8) and (9): When inflation pressure is applied to the element(s), pressures will hold perfectly stable only if the go-devil seal functions perfectly. Even if this seal is leaking, the straddle packer can be successfully inflated, simply by keeping the pumps on at a slow rate for a few minutes to maintain pressure in the elements until the control sleeve is shifted to shut the inflate/deflate port to the elements. If the packer elements are indeed inflated, the packer will hold against the borehole wall, will accept some weight, and will allow the control to shift. Once this sleeve is shifted, the go-devil seal serves no other function (unless the downhole shut-in valve is used), so it becomes immaterial whether or not it is actually sealing.

Steps (9)-(11), slug tests: When the straddle packer is set, closing the inflation sleeve applies a slug test to the formation, but it is impossible to determine what proportions of the pumped fluid are directed into the packer elements and the isolated zone. Therefore, it is impossible to measure system compressibility during the initial slug test that occurs on inflation, and at least one more slug test should be conducted at every inflation depth, during which the volume pumped for the slug is carefully recorded to determine compressibility. Before repeating a slug test, the previous slug test should be allowed to decay so that pressures reach less than $50 \%$, preferably about $20 \%$, of the initial pressure pulse.

Step (12), injection tests: If the results warrant an injection test, it should be conducted only after the second (or subsequent) slug test has been allowed to decay as completely as possible. A conservative rate of injection should be selected, or else there will be a risk of hydrofracturing the formation; in past experience in permeable sections of basement holes, 2 barrels per minute has produced good results. Keeping the rate of injection constant is 
much more important than attempting to inject exactly at a specified rate. It can be informative to repeat injection tests, at different rates, but the shut-in pressures after one period of injection should be allowed to decay as completely as possible before repeating injection. This may require waiting an hour or more, but the decay of shut-in pressures can be processed to determine permeability as well as pore pressure. It may therefore be more important to fully monitor the decay of the shut-in pressures after a single injection test than to run another injection test. 


\section{REFERENCES}

Anderson, R. N., and Zoback, M. D., 1982. Permeability, underpressures, and convection in the oceanic crust near the Costa Rica Rift, eastern equatorial Pacific. Jour. Geophys. Res., 87:2860-2868.

Anderson, R. N., Zoback, M. D., Hickman, S. H., and Newmark, R. L., 1985. Permeability versus depth in the upper oceanic crust: in situ measurements in DSDP Hole 504B, eastern equatorial Pacific. Jour. Geophys. Res., 90:3659-3669.

Becker, K., 1986. Special report: Development and use of packers in ODP. JOIDES Journal, 12(2):51-57.

Becker, K., 1988. A guide to ODP tools for downhole measurements. ODP Technical Note 10: College Station, TX (Ocean Drilling Program).

Becker, K., 1989. Measurements of the permeability of the sheeted dikes in Hole 504B, ODP Leg 111. In Becker, K., Sakai, H., et al., Proc. ODP, Sci. Results, 111: College Station, TX (Ocean Drilling Program), 317-325.

Becker, K., 1990. Measurements of the permeability of the upper oceanic crust at Hole 395A, ODP Leg 109. In Detrick, R., Honnorez, J., Bryan, W. B., Juteau, T., et al., Proc. ODP, Sci. Results, 106/109: College Station, TX (Ocean Drilling Program), 213222.

Becker, K., in press. In-situ bulk permeability of the gabbros in Hole 735B, ODP Leg 118. In Robinson, P. T., Von Herzen, R. P., et al., Proc. ODP, Sci. Results, 118: College Station, TX (Ocean Drilling Program).

Bredehoeft, J. D., and Papadopulos, S. S., 1980. A method for determining the hydraulic properties of tight formations. Water Resour. Res., 16:223-238.

Bullard, E. C., 1954. The flow of heat through the floor of the Atlantic Ocean. Proc. $R$. Astron. Soc. London, Ser. A, 222:408-429.

Carslaw, H. S., and Jaeger, J. C., 1959. The Conduction of Heat in Solids: London (Oxford University Press).

Cooper, H. H., Jr., Bredehoeft, J. D., and Papadopulos, I. S., 1967. Response of a finite diameter well to an instantaneous charge of water. Water Resour. Res., 3:267-269.

Gartling, D. K., 1977. Convective heat transfer analysis by the finite element method. Comput. Methods Appl. Mech. Eng., 12:365-382.

Hayashi, K., Ito, T., and Abe, H., 1987. A new method for the determination of in situ hydraulic properties by pressure pulse tests and application to the Higashi Hachimantai geothermal field. Jour. Geophys. Res., 92:9168-9174.

Hickman, S. H., Langseth, M. G., and Svitek, J. F., 1984. In situ permeability and porepressure measurements near the mid-Atlantic Ridge, Deep Sea Drilling Project Hole 395A. In Hyndman, R. D., Salisbury, M. H., et al., Init. Repts. DSDP, 78B:

Washington (U.S. Govt. Printing Office), 699-708.

Horner, D. R., 1951. Pressure build-up in wells. Proc., Third World Pet. Cong., II:501. Jaeger, J. C., 1958. The measurement of thermal conductivity and diffusivity with cylindrical probes. Trans. Am. Geophys. Union, 39:708-710.

Matthews, C. S., and Russell, D. G., 1967. Pressure Buildup and Flow Tests in Wells. SPE Monograph 1, Dallas: Am. Inst. Min. Met. Pet. Eng. 
Neuzil, C. E., 1982. On conducting the modified "slug" test in tight formations. Water Resour. Res., 18:439-441.

Papadopulos, S. S., Bredehoeft, J. D., and Cooper, H. H., 1973. On the analysis of "slug test" data. Water Resour. Res., 9:1087-1089.

Parsons, R. W., 1966. Permeability of idealized fractured rock. Jour. Soc. Petrol. Eng., 6:126-136.

Robinson, P. T., Von Herzen, R. P., et al., 1989. Proc. ODP, Init. Repts., 118: College Station, TX (Ocean Drilling Program).

Von Herzen, R.P., and Maxwell, A. E., 1959. The measurement of thermal conductivity of deep-sea sediments by a needle-probe method. Jour. Geophys. Res., 64:1557-1563. 


\section{APPENDIX A. \\ TAM STRADDLE PACKER \\ ASSEMBLY AND TESTING INSTRUCTIONS \\ $10 / 22 / 89$}

Refer to the assembly drawings dated $8 / 1 / 89$ (reproduced at the back of this appendix). Before beginning assembly, clean and inspect all threads and sealing surfaces. Make sure all sealing surfaces are smooth -- if not, polish off imperfections. Grease all threads as each part is assembled.

Assembly and testing should be completed in the following sequence:

(A) Assemble upper packer control assembly.

(B) Assemble upper go-devil.*

(C) Test upper control assembly with go-devil.

(D) Add packer element and complete upper packer assembly.

(E) Test inflation of upper packer in section of casing.

After a successful inflation test, set assembled upper packer aside for use in the hole. Assemble spare go-devils.*

If the straddle configuration is to be run, continue with:

(F) Assemble lower packer assembly.

(G) Test inflation of lower packer in section of casing.

(H) Assemble pressure-actuated sleeve to lower packer.

(I) Assemble lower go-devil.*

After a successful inflation test, set assembled lower packer aside for use in the hole. Depending on the length of the straddle interval, the lower packer may be assembled to the upper packer immediately and the entire straddle packer set aside for later use, or the straddle assembly may be completed on the rig floor as the BHA is made up.

When the BHA is made up for the packer measurements, continue with:

(J) Final assembly of packer into BHA.

* Note: In 1988, the go-devil was completely redesigned with a new retrieval system. The old go-devils are still usable if needed. Sections B and I (below) for assembling the upper and lower go-devils are each subdivided into instruction sets for the old design and the new design. 


\section{A. Assembly Procedure -- Upper Packer Control Assembly}

(1) Check that the $2 \mathrm{~J}$ pins (825-TJ-12) are in good condition and are securely installed in control tube (825-TJ-38). In normal use, these pins do not bear the weight of the packer, but if the packer must be rotated in an emergency, the pins bear the torque load.

(2) Check that the section of the control tube between the J pins and inset wrench surface is a smooth seal face. Check that the fluted section of the control tube extension (825-TJ-37-LK) is smooth and has no sharp edges that might cut the 6 poly-paks that the control tube slides past.

(3) Grease and install one 158 o-ring on the control tube, and assemble the control tube extension to the control tube.

(4) Place J housing (825-TJ-12) in vise, oriented with its upper end toward the tugger line, which may later be used to overcome the resistance of the poly-paks in assembling the control sub over the control tube extension. Grease and install three 357 o-rings inside upper end of $\mathrm{J}$ housing, if possible using a 90-durometer o-ring in the upper or outer position. Clean and grease slots for J pins. Slide the control tube assembly into place from the lower end, engaging the J pins in the J slots.

(5) Grease and install six poly-paks (3750-5500) in the control sub (825-TJ-32), making sure that the sealing edges are oriented as shown on the drawings: The "sharp" edges of the upper four poly-paks should point toward the top of the packer, and the "sharp" edges of the lower two poly-paks should point toward the bottom of the packer.

(6) Grease and install one 263 o-ring on the upper end of the control sub. Suspend the control sub in a chain fall, with its upper end oriented toward the lower end of the J housing. With the control tube assembly pulled into the "up" position, slide the top of the control sub over the lower end of the control tube extension. It will probably be difficult to slide past the poly-paks, and it may be necessary to use a tugger as follows: With the control sub started and supported with the chain fall, rig the tugger line through the control tube and control sub to a section of $2 \times 4$ or $4 \times 4$, and carefully pull the control sub all the way on. Make up the connection between the J housing and the control sub. Throughout this step, be as careful as possible, to avoid damage to the poly-paks.

(7) Grease and install one 357 o-ring in top connector (825-TJ-31) and make up top connector to upper end of control tube. Do not use wrench on seal surface of control tube; use the wrench cut only.

(8) Optional: If a single packer configuration is to be run, isolating sections of borehole greater than a few tens of meters long, it may be desirable to plug the four vent holes in the control sub (825-TJ-35). These vents are needed only if a short zone is isolated, to avoid applying too much pressurized fluid to the zone on inflation and possibly either hydrofracturing the 
formation or blowing past the packer seal. However, in several cases in the past the venting action has apparently resulted in irregularities in the initial slug test that occurs as the packer is inflated. If a long interval is to be isolated, it may be possible to improve the quality of the slug test obtained on packer inflation by plugging the vent holes.

The author believes that the best way to plug the vent holes is to tap them so that plugs can be inserted and removed at will. However, the packer must be disassembled before tapping the holes, so that metal shavings from the tapping procedure do not remain inside the packer, potentially causing damage to the o-ring seals. 


\section{B.1. Assembly Procedure -- Upper Go-Devil, New Design}

The new design for the go-devil replaced the unreliable fishing neck of the old design with a fishing neck with an Otis 2-5/8-in. GS profile. See the drawing (dated 8/16/88, reproduced at the back of this appendix), and note that several parts in the new design unfortunately were labeled by TAM the same as the parts in the old design that they replaced. This drawing also shows a new design for the go-devil seals, with grooves for an o-ring on the inside of the metal ring. (If necessary, the new go-devil could still be assembled with the old seals, which do not have grooves for an inside o-ring, but the old seals will have to be energized as described in B.2. step 3.)

(1) Slip onto the lock body (375-LK-53) in order:

(a) a 3.965-in.-diameter upper seal (375-LK-41) with only one o-ring installed,

(b) seal spacer (375-LK-51),

(c) another upper seal (375-LK-41) with only one o-ring installed, and

(d) a 3.99-in.-diameter no-go ring (375-LK-27).

Be careful to use the correct no-go ring and seals -- similar rings and seals for the lower godevil have slightly smaller diameters. Note that only one o-ring is required on the inside of each seal, even though two grooves are cut (to simplify the manufacturing process). Also, if downhole shut-in is not to be attempted, only the lower seal need function perfectly, so that a used seal could be used in the upper position.

(2) Make up the redesigned fishing neck (375-LK-21, with Otis GS profile) to the lock body (375-LK-53), and lock it in position with three 1/4-20 dog point set screws.

The go-devil is now ready for use in testing the operation of the control sub and packer inflation. 


\section{B.2. Assembly Procedure -. Upper Go-Devil, Old Design}

The old design for the upper go-devil can be configured in two different ways, depending on whether or not it is necessary to achieve downhole shut-in during the testing. To achieve downhole shut-in, a check valve must be included in the go-devil. The check valve allows a pressure differential to be maintained across the go-devil, and it requires the installation of dogs to lock the go-devil in place. If downhole shut-in is not required, the check valve should not be installed, and the dogs are unnecessary. The mechanism to retract the dogs is poorly designed, and it proved unreliable during Leg 109, when the retracted dogs flopped back out and dragged up the pipe as the go-devil was being retrieved. Bill Lee and Tim McCown added a spring to hold the sleeve that controls the dog retraction in place, and the go-devil was smoothly retrieved during Leg 111. Nevertheless, the dog latch should be replaced with a better latch (Z-latch?) in the future. Until then it is recommended that the go-devil be run without the check valve or dogs, which are omitted from the following instructions.

(1) Install sleeve (375-LK-24) inside go-devil body (375-LK-23) with four brass shear pins (1/8-in. diameter).

(2) Place fishing neck (375-LK-21) in position and make up cap (375-LK-22) to go-devil body. Lock cap with set screw.

(3) Slip a 3.99-in.-diameter no-go ring (375-LK-27) and 3.94-in.-diameter upper seal (375-LK-41) over lower end of go-devil body and make up lower sub (375-LK-65) to go-devil sub. Be careful to use the right no-go ring and seal -- similar rings and seals for the lower go-devil have slightly smaller O.D.s. In order to energize the seal, it needs to be squeezed a little so that its O.D. increases from 3.94 in. (unsqueezed) to $3.98 \mathrm{in}$. This is accomplished by placing spacers between the seal and the lower sub when assembling the lower sub to the go-devil body. The right combination of spacers has to be determined by trial and error. Lock this connection with set screws.

(4) Slip a second upper seal (375-LK-41) over the end of the lower sub, and make up the lower cap (lock nut 375-LK-67) to the lower sub. As in (3), be careful to use the correct seal, and use spacers to energize it to $3.98 \mathrm{in.}$ O.D. Then lock the cap in place with set screws.

The go-devil is now ready for use in testing the operation of the control sub and packer inflation. 


\section{Testing Procedure -. Control Assembly with Go-Devil}

After the upper control assembly and upper go-devil are fully assembled, they should be tested together before completing assembly of the packer, to verify that the poly-paks have survived assembly and are sealing properly. This test will run more easily if the upper control assembly is held vertical, but it can be run with the assembly horizontal.

(1) Install plugs in the four tapped inflation ports at the bottom of the control sub.

(2) Make sure the control tube is pulled into the "up" position, and install upper go-devil in its seat inside control tube.

(3) Make up 5-1/2 IF crossover (825-TJ-39) and test cap to top connector. Although there is no groove for an o-ring between the crossover and top connector, an o-ring can be inserted for testing only if desired.

(4) Fill the upper control assembly with fluid and bleed out all the air. It may take some time for all the air from the packer inflation holes to bleed off, especially if the test is run with the assembly held horizontal.

(5) Connect pump to test cap and pressure up to about 1000 psi. Check for leaks wherever there are o-rings or poly-paks. If the poly-paks are not sealing properly, fluid will leak out the bottom of the control sub or through the ports out the side of the control sub.

(6) If pressure holds steady and there are no leaks, repeat to about 2000 psi. At about 2000 psi the connection between the test cap and the top connector may begin to leak, which is OK. If nothing else leaks, the test is successful, and can be terminated.

(7) Vent the pressure, disconnect the pump, drain the fluid, remove the go-devil, and remove the four plugs from the packer inflation ports at the bottom of the control sub. If the test was successful, proceed with assembly of complete upper packer. If the test was not successful, disassemble the upper control assembly, replace the defective seals, and re-assemble and re-test upper control assembly. 


\section{Assembly Procedure -- Completion of Upper Packer}

(1) Place the assembled and tested upper control assembly in a vise. Grease and install one 263 o-ring on the outside of the lower end of the control sub.

(2) Grease and install one 251 o-ring at the upper end of the packer tube (825-TJ-34) -- this is the end without the wrench inset. Make up this end of the packer tube to the lower end of the control sub. Buck up "rig-tight."

(3) Check that the seal surface on the lower end of the packer tube is clean and smooth. Slip either end of the packer element over the packer tube and make up the packer element to the control sub. Do not twist from the rubber or the lower end of the element.

Note that the packer element bears no weight, and the connections at the ends of the element do not have to be made "rig-tight."

(4) Grease and install one 263 o-ring on the packer sub (825-TJ-35). If a straddle packer is to be run, use a packer sub that has a hole on the bottom tapped for a 3/8-in. Parker connector. If a single packer is to be run, use either packer sub, but first make sure you have pipe plugs for all holes on the bottom of the packer sub. Then slip the packer sub over the end of the packer tube and make it up to the lower end of the packer element.

(5) Grease and install three 357 o-rings around the packer tube inside the lower end of the packer sub, if possible using a 90-durometer o-ring in the lower or outer position. This step may be difficult, because the o-rings tend to seal air inside, but that air must escape for the o-ring to be properly installed. If you use something to help the o-ring into position, be careful not to damage the o-ring.

(6) When the three 357 o-rings are finally in position, slip the spacer ring (825-TJ-36) over the packer tube into position, and lock the o-rings and spacer ring in place by installing the spirolox (RRN 600).

(7) Grease and install one 251 o-ring at the end of the packer tube. Then make up the test cap for testing inflation of the packer inside a piece of casing. If the packer has already been tested, or is not to be inflation-tested, make up a crossover. If a straddle packer is to be run, use the $51 / 2$-in. IF pin crossover (825-TJ-39). If a single packer is to be run, this crossover or the $65 / 8$-in. FH crossover (825-PW-40) can be used, depending on the BHA to be run. 


\section{E. Testing Procedure -- Upper Packer Inflation}

The inflation test of the upper packer can be done either vertically or horizontally, depending on whether the casing that the packer is tested inside of can be secured vertically or horizontally. Ideally, the ability of the packer to hold inflation for several hours should be tested, but it may be inconvenient and unsafe to leave the packer inflated for this long inside a piece of casing held horizontal in the vise in the core tech shop. In the past, packer inflation has also been tested in a piece of casing secured vertically on the main deck.

(1) Make up test cap to lower end of packer tube. Plug holes in this test cap and in lower end of packer sub.

(2) Position packer within a piece of casing so that the element will remain completely within the casing on inflation.

(3) Install upper go-devil in the control tube.

(4) Fill packer with fluid and bleed air from inside the packer.

(5) Attach upper test cap and crossover to packer; attach pump to test cap. Verify that all air has been bled from the system.

(6) Pump up to inflate the element. It should start expanding at about 200 psi. Pump up to about $1000 \mathrm{psi}$ and hold full inflation. Check for leaks.

(7) If the packer holds pressure without leaks, close the control tube (if possible) to lock the packer inflated for the desired test period. Once the control tube is closed, the fluid in the elements should be isolated, and the pump pressure can be bled down. If the packer is functioning properly, it should remain inflated almost indefinitely. If it is not possible to close the control tube, leave the pump on to hold pressure inside the element for the test period. It is recommended that the inflation of the element be tested for no more than 3-6 hours, as much longer tests may introduce a set in the element that is difficult to remove on deflation except with brute force or even by disassembling the element.

(8) If the packer holds inflation for the test, it is ready to run. If the control tube has been closed, now pull it up and allow the pressure inside the elements to bleed off. When the pressure has bled off, the plugs can be opened to drain the fluid from the packer. The upper test cap and go-devil should be removed, the intended crossovers should be installed above and below the packer, and the packer should be set aside until it can be installed in the BHA. 


\section{F. Assembly Procedure -- Lower Packer}

The lower packer is a slave packer that is completely controlled by the control sub in the upper packer. Therefore, the assembly and testing of the lower packer are much simpler than the preparation of the upper packer.

(1) Place lower packer top sub (825-PW-33) in vise. Make sure you have a sub with at least one $3 / 8$-in. NPT port. (There is also a $1 / 4$-in. NPT port in the original unit.) Grease and install one 263 o-ring on the outside lower end of top sub.

If you know precisely how the packer is to be configured and deployed, the assembled pressure-actuated sleeve could be made up to the lower packer top sub now, after first installing the proper fitting in the 3/8-in. NPT port. (See section $\mathrm{H}$ for further guidance.) However, this is not necessary for testing and probably should be left until step $\mathrm{H}$, after testing the lower packer.

Proceed exactly as in steps (2)-(6) in section D above:

(2) Grease and install one 251 o-ring at the upper end of the packer tube (825-TJ-34). Make up this end of the packer tube to the top sub. Buck up "rig-tight."

(3) Check that the seal surface on the lower end of the packer tube is clean and smooth. Slip either end of the packer element over the packer tube and make up the packer element to the top sub. Twist only from the metal sleeve at upper end of packer element.

(4) Install pipe plug with teflon thread tape in the port at the bottom of the packer sub (825-TJ-35). Grease and install one 263 o-ring on the packer sub. Slip the packer sub over the packer tube and make up to the packer element.

(5) Grease and install three 357 o-rings around the packer tube inside the packer sub, if possible using a 90-durometer o-ring in the lower or outer position. Be careful not to damage the o-rings in pushing them all the way in.

(6) When the 357 o-rings are fully installed, slip a spacer ring (825-TJ-36) over the packer tube into position, and lock the o-rings and spacer ring in place by installing a spirolox (RRN 600).

(7) Grease and install one 251 o-ring at the end of the packer tube. Then make up the 6-5/8in. FH crossover (825-PW-40) to the end of the packer tube.

Proceed with testing inflation of the lower packer. 


\section{G. Testing Procedure -- Lower Packer Inflation}

As the lower packer is a slave to the top control sub, the lower packer need only be tested for inflation, and the procedure is much simpler than that used in testing inflation of the upper packer (section E above). This test is probably easiest with the lower packer inside a piece of casing that is held horizontally in the vise in the core tech shop. Note that fluid pressure is applied only within the lower packer element, and test caps are unnecessary at both ends of the lower packer.

(1) Slip casing around the lower packer so that the element will be completely contained during inflation.

(2) Attach pump via the 3/8-in. NPT port in the top sub. Fill element with fluid and bleed air from inside the packer. This will probably require that one of the plugs be removed from the lower packer sub. When the packer is full, be sure that all ports in the top sub and packer sub are plugged.

(3) Pump up to inflate the element. It should start expanding at about 200 psi. Pump up to about $1000 \mathrm{psi}$, and hold to check for leaks.

(4) If there are no leaks, the ability of the element to hold inflation should be tested for no more than 3-6 hours. Longer tests may introduce a set in the element that is difficult to remove on deflation.

(5) If the packer holds inflation for an acceptable period of time, bleed the pressure and the fluid, and proceed to section $\mathrm{H}$ to install the pressure-actuated sleeve. 


\section{H. Assembly Procedure -- Pressure-Actuated Sleeve}

If a true straddle packer configuration is to be run, the pressure-actuated sleeve must be assembled into the top of the lower packer assembly. The pressure-actuated sleeve should not be used if the two elements are to be assembled together as a double-element, double-seal single-packer with no capability to test the zone between the elements. In that case, the packer tube of the upper packer should be made up directly to the top sub of the lower packer.

If the straddle packer is to be used only to test the zone between the elements, only the body (738-PA-21) should be used. If the straddle packer is to be used to first test the zone below the lower packer and then test the straddled zone, the sleeve (738-PA-22), snap ring (738-PA-23), and snap ring cover (738-PA-24) must first be assembled to the body. The latter procedure has not been attempted as of Leg 134, and would involve a complicated and time-consuming sequence of go-devil operations, so it should not be attempted except in carefully planned situations.

(1) If you plan to use a right-angle Parker connector to attach the 3/8-in. stainless tubing between the elements, install it in the top sub of the lower packer before installing the body of the pressure-actuated sleeve to the lower packer.

(2) If only the zone between the elements is to be tested, do not assemble any small parts to the body of the pressure-actuated sleeve, and proceed to step (3). Only if the dual-test-zone straddle configuration is to be deployed, follow these steps to fully assemble the pressure-actuated sleeve:

(a) Grease and install one $256 \mathrm{o}$-ring and one $258 \mathrm{o}$-ring on the inside of the sleeve. Slide the sleeve over the lower end of the body into position. Pin the sleeve in place with $1 / 4$-in. brass pins, rated at $1000 \mathrm{psi}$ per pin.

(b) Slide the snap ring cover up the body. Install the snap ring. Slide the snap ring cover back down over the snap ring and lock in place with a set screw.

(3) Grease and install one 251 o-ring at the bottom end of the body of the pressure-actuated sleeve. Make up the body to the top sub of the lower packer.

The upper and lower packer assemblies are now ready for final assembly together, which will probably be done on the rig floor. 


\section{Assembly Procedure -- Lower Go-Devil}

Refer to section B above regarding the fact that the go-devils were redesigned in 1988 with a new fishing neck. Both the old and new designs for the lower go-devil can still be used, but the assembly instructions are different. Refer also to the drawing of the new design in section $\mathrm{B}$, and note that the redesigned go-devil unfortunately uses some of the same part numbers as the parts in the old design that were replaced. The new go-devil can still be assembled with the old seals, which do not have grooves cut for o-rings.

The lower go-devil performs one function -- to block the flow path down the pipe, so that the straddled interval can be tested. During testing, pressure will never be greater below the lower go-devil than above it, so the lower go-devil should always be run without the latching dogs and springs.

\section{I.1 Assembly Procedure, New Design}

(1) Slip onto the lock body (375-LK-53) in order:

(a) a 3.84-in. diameter lower seal (375-LK-43),

(b) a seal spacer (375-LK-51),

(c) another lower seal (375-LK-43), and

(d) a 3.89-in. or 3.90-in.-diameter no-go ring (375-LK-28 or -29).

$\mathrm{Be}$ careful to use the correct no-go rings and seals -- similar rings and seals for the upper go-devil have slightly larger diameters. Only one of the seals needs to function perfectly, so onlyrone sealnneeds to be-new and assembled with an o-ring; the other seal could be a used one and should not be assembled with an o-ring.

(2) Make up the redesigned fishing neck (375-LK-21, with Otis GS profile) to the lock body (375-LK-53), and lock it in position with three 1/4-20 dog point set screws.

\section{I.2. Assembly Procedure, Old Design}

(1) Install sleeve (375-LK-24) inside go-devil body (375-LK-23) with four brass shear pins (1/8-in. diameter).

(2) Place fishing neck (375-LK-21) in position and make up cap (375-LK-22) to go-devil body. Lock cap with set screw.

(3) Slip a 3.89-in.-diameter no-go ring (375-LK-28) and a 3.81-in.-diameter lower seal (375-LK-43) over lower end of the go-devil body. Be sure you have the right ring and seal, as the wrong ones will stop the go-devil at the upper packer, not the lower packer. Make up the lower cap (375-LK-66), using spacers to energize the seal out to 3.84 in. Lock the lower cap in place with the set screw. 


\section{J. Final Assembly Procedure -- Packer BHA}

The BHA required for running the non-rotatable (straddle) packer typically includes (up from bit):

(1) Cleanout/reentry bit

(2) Bit sub

(3) Crossover

(4) Packer

(5) Crossover

(6) Drill collars

The drill collars provide the weight used to slide the control tube down on inflation, and counteract the upward piston force due to pressures applied to the isolated interval in formation testing. The number of drill collars required depends on the anticipated pressures during formation testing (not inflation pressure): $12,000 \mathrm{lb}$ of collars per $1000 \mathrm{psi}$ test pressure.

During all rig floor operations, be very careful not to damage the seal surface on the control tube. Tape or otherwise cover it during all operations (leaving the wrench cut accessible), and remove this cover only as the packer is run below the rig floor.

For the single packer configuration, the following joints should be torqued up on the rig floor:

(1) Packer tube to lower crossover,

(2) J housing to control sub,

(3) Top connector to control tube, using only wrench cuts.

For the straddle packer configuration, the following joints should also be torqued up, before assembling the top packer into the BHA:

(4) Packer tube to crossover,

(5) Body of pressure-actuated sleeve to top sub.

Do not torque up the connections of the packer elements to control sub, lower packer top sub, or packer subs.

If both upper and lower packers are being run, connect them with 3/8-in. stainless steel tubing, after making up all connections. The tubing must be coiled at one or both ends, to allow for the upward movement of the packer sub in the upper.packer as the element inflates. Attaching the tubing will be easier if the instructions above have been followed and right-angle Parker connectors have been attached to the upper packer sub and lower packer top sub during assembly in the shop. Otherwise, straight connectors must be used and the tubing must be bent to fit. 
It is possible to have already positioned (but not attached) a pre-formed section of this tubing as the lower and upper packer are assembled together, but this tubing will probably be damaged as the packer connections are torqued up. It will probably be more convenient to attach and bend the tubing after the packer connections are torqued up, but it will take some manual effort. If a very long straddle interval is deployed, first the tubing must be attached and coiled at the lower packer, then tubing must be run alongside the drill pipe used to space the straddle, and then the upper end of the tubing must be cut, coiled, and attached to the upper packer. 


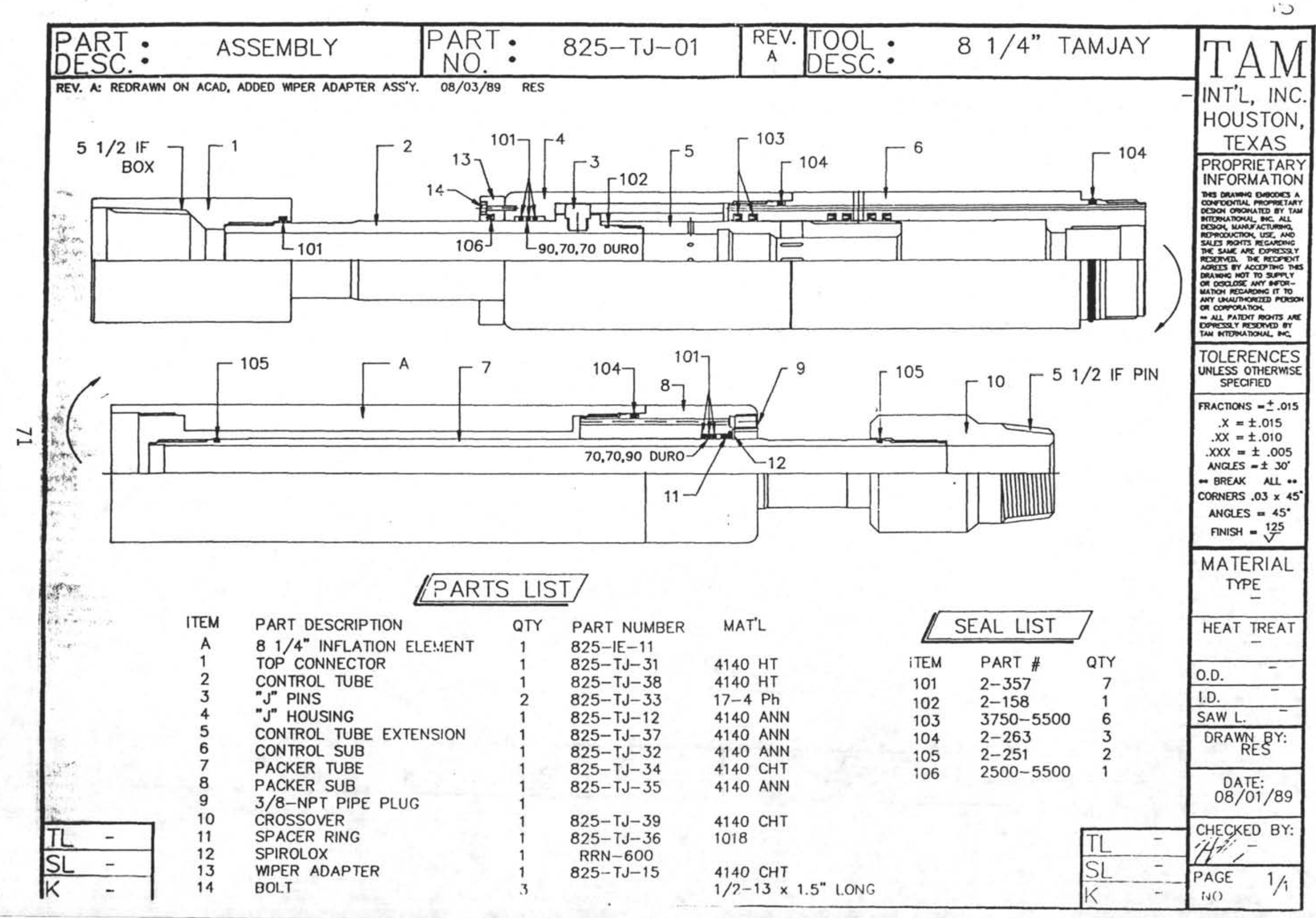




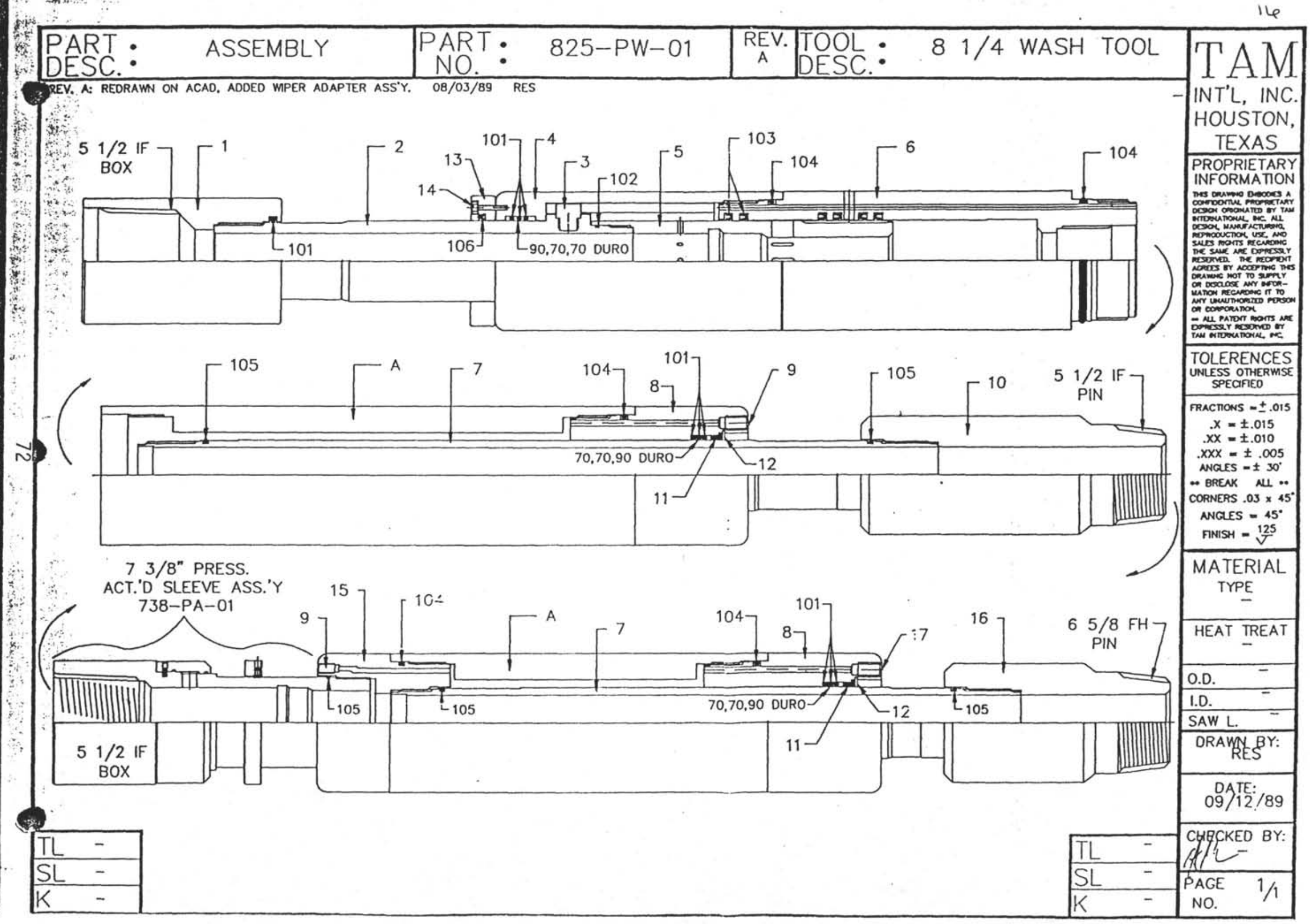




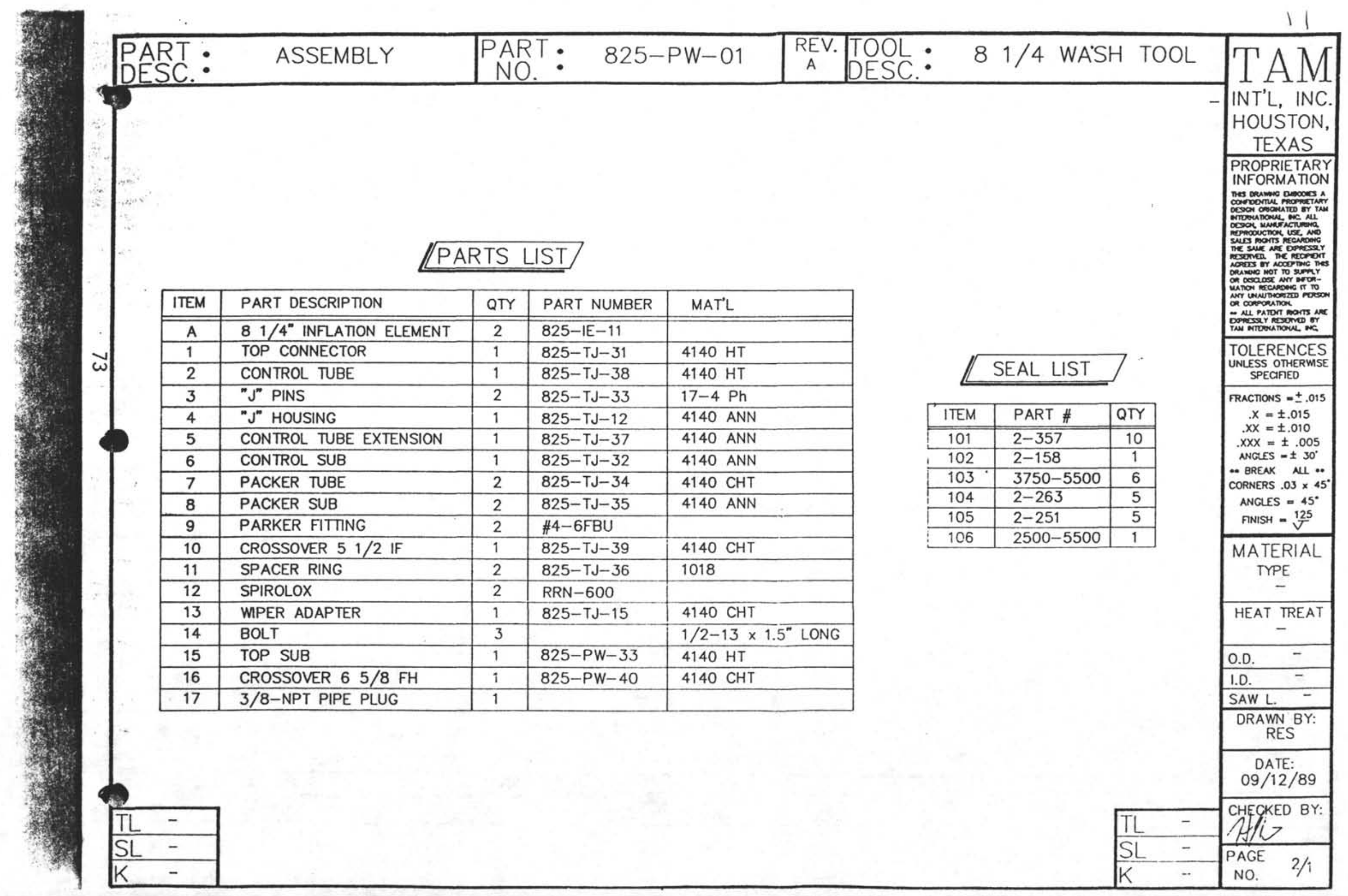




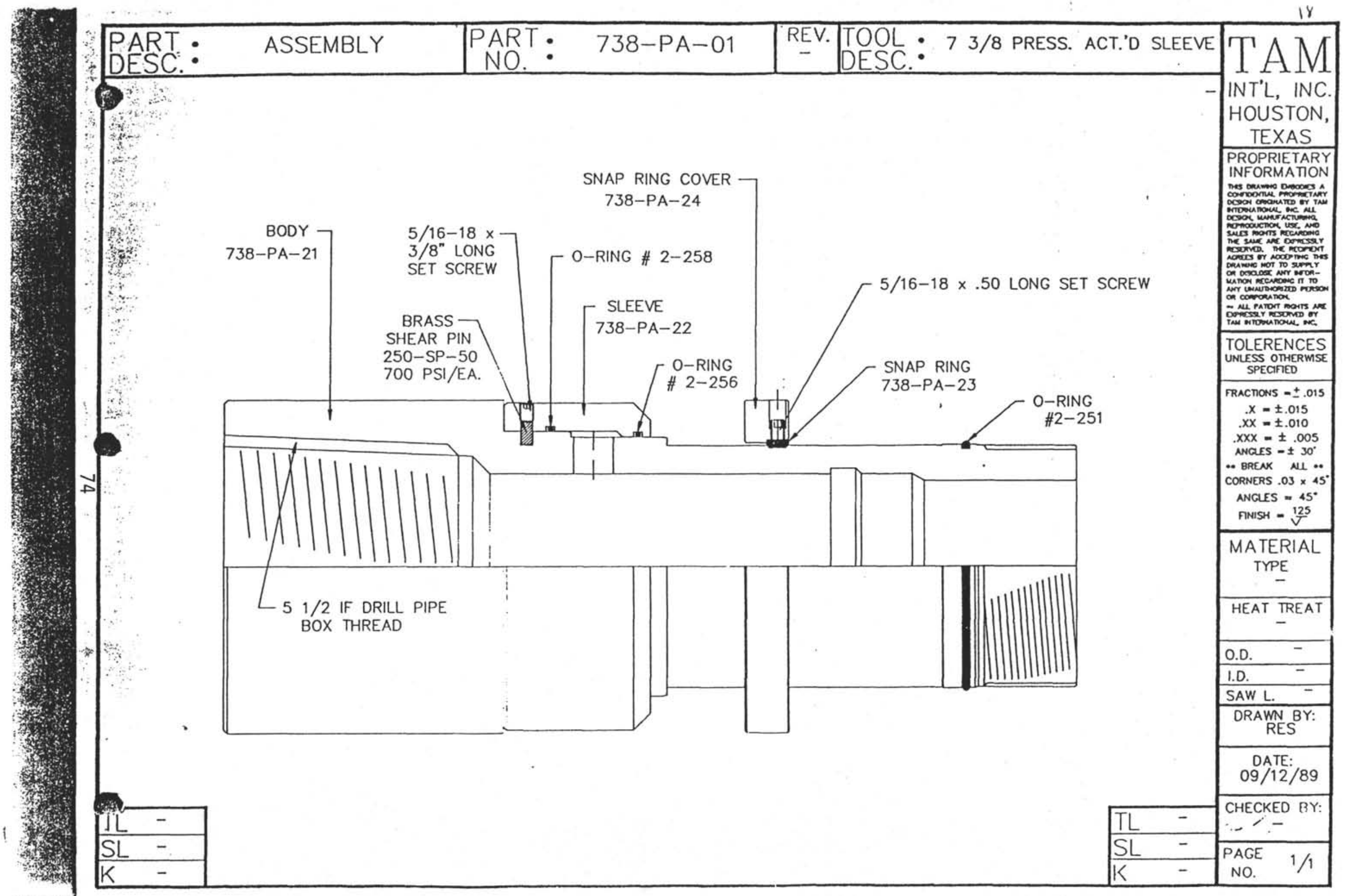




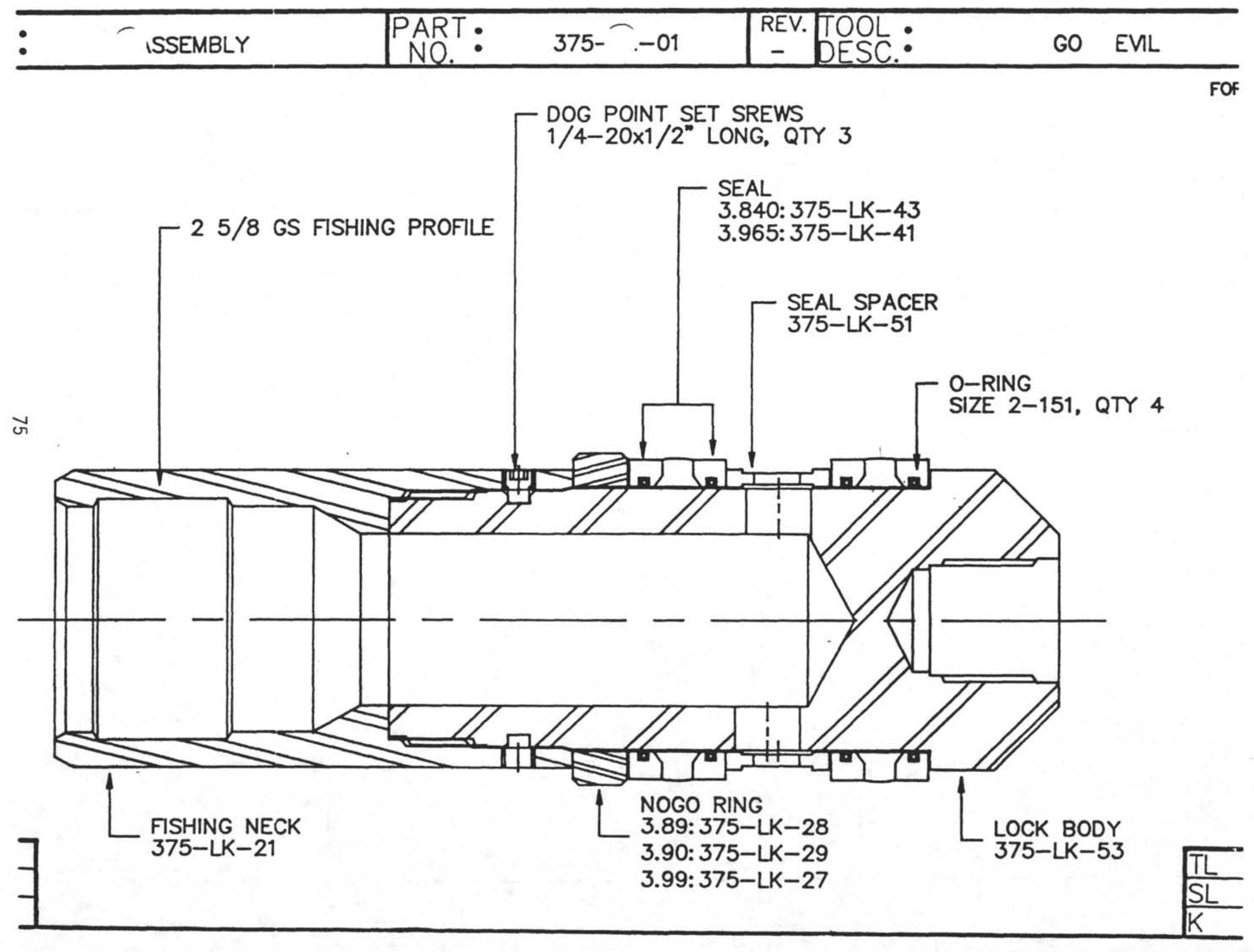




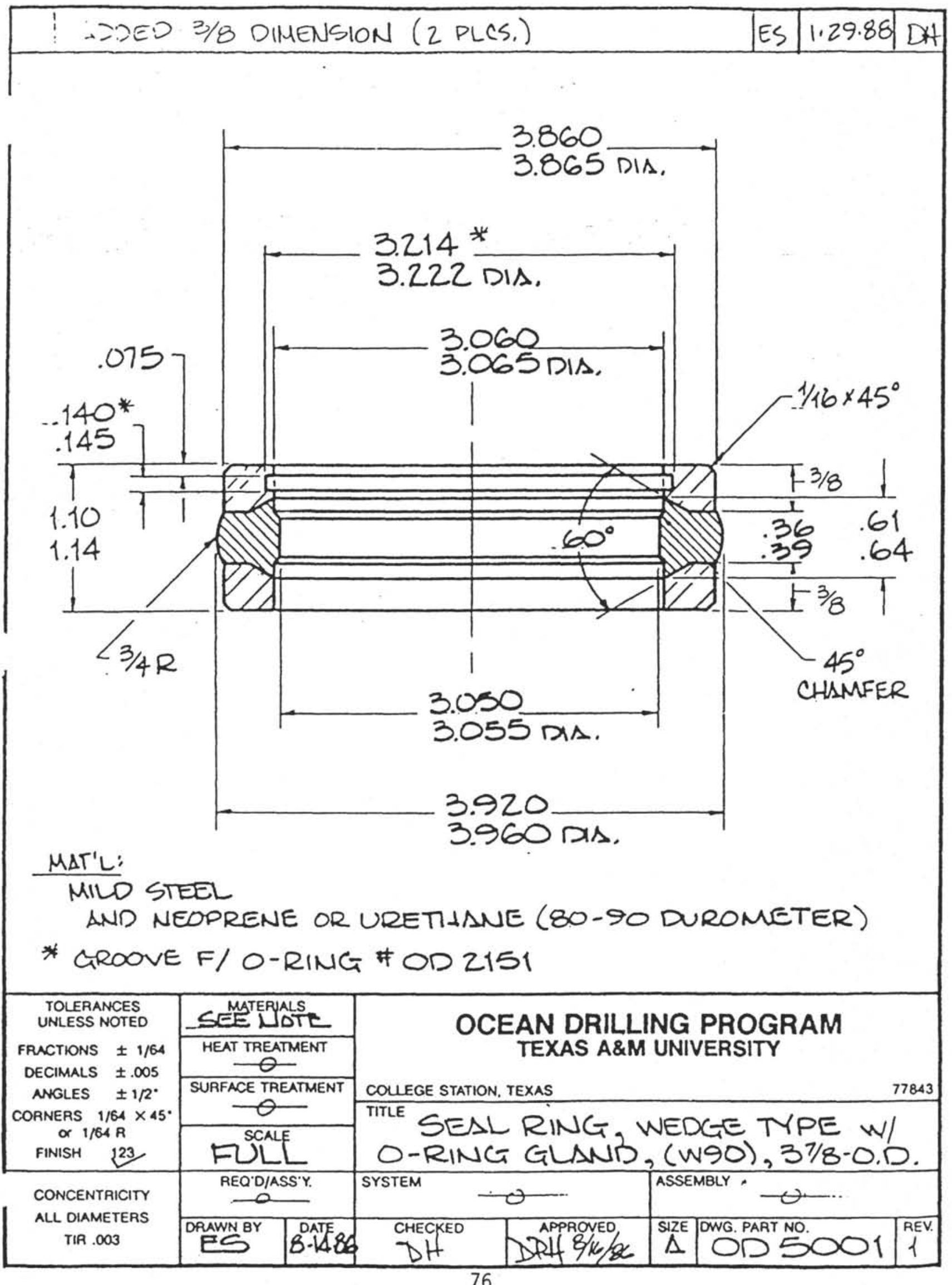




\title{
USTER
}

\begin{abstract}
Subsurface Instruments
\end{abstract}

\section{K-2 and K-3 Gauge}

Instructions

Operation

Maintenance

Drawings and Parts List

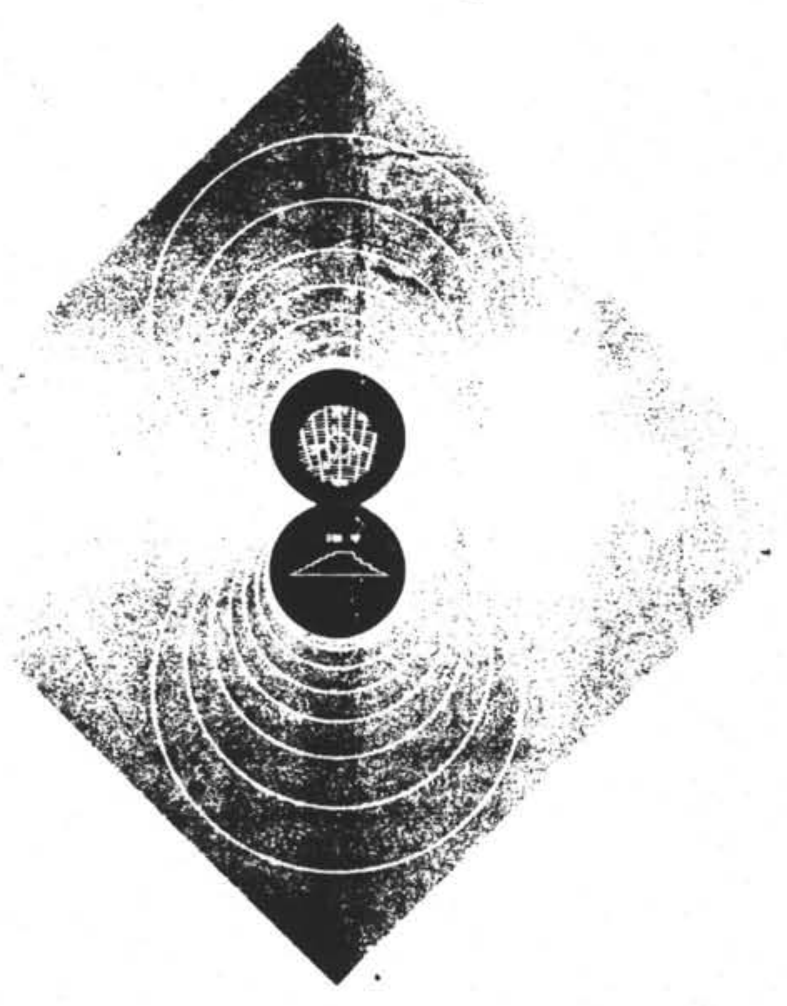




\section{TABLE OF CONTENTS}

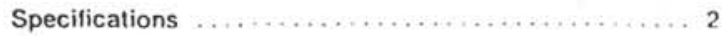

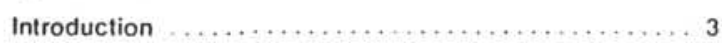

Operating Suggestions ................... 3

Important Instructions ..................... 4

Steps in Operation ....................... 5

Minor Maintenance ...................... 7

Major Maintenance ...................... 8

K-2 and K-3 Gauge Assembly Drawing ............ 9

Temperature Element Assembly Drawing ........... 10

Clock Assembly Drawing ................... 11

\section{SPECIFICATIONS}

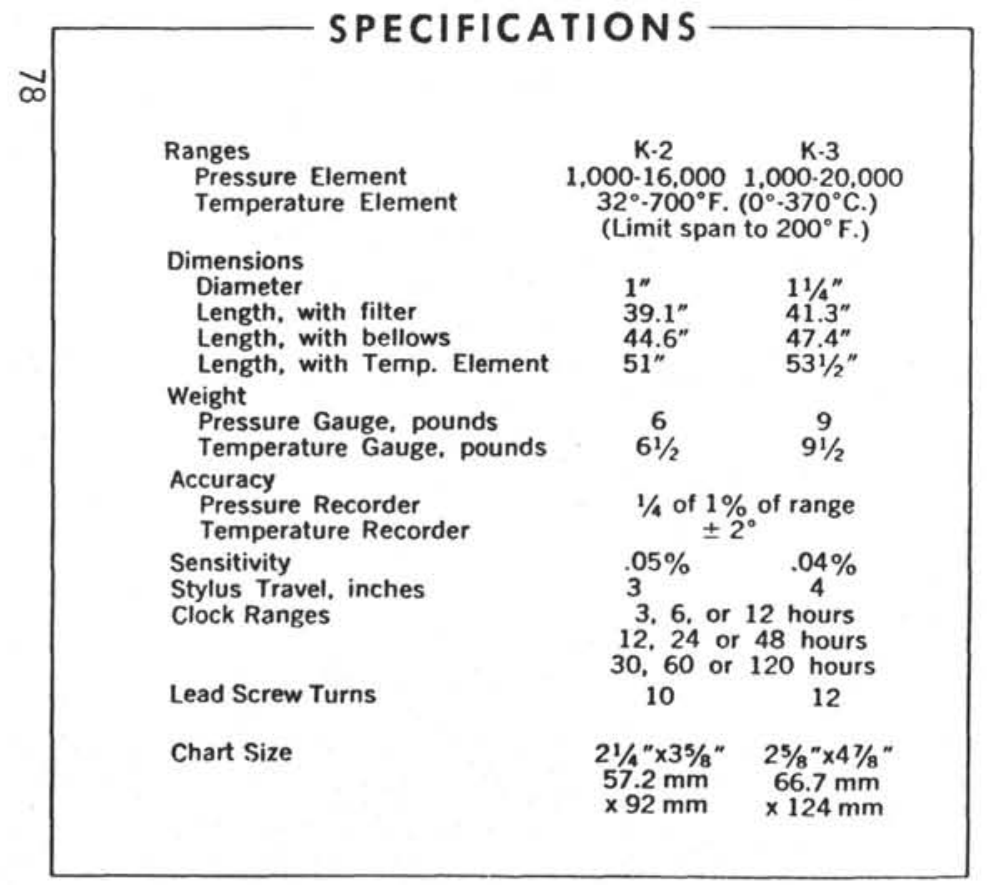

\section{$K-2$ and $K-3$ SUBSURFACE RECORDER}

\section{INTRODUCTION AND PRINCIPLE OF OPERATION}

The K-2 and K-3 gauge are completely new subsurface recording gauges with a combination of shorl length and small diameter. The gauges are rugged pressure (temperature) for long periods.

The gauge has three basic units: the pressure or temperature unit, the recording unit and the clock.

Pressure Unit. A temperature stable $\mathrm{Ni}$-Span $\mathrm{C}$ bourdon tube rotates in response to the pressure applied. A sliding spline coupling between the pressure element and the chart cup transmits the rolation.

Temperature Element. A heat sensitive fluid acted upon by the well fluid increases the vapor pressure in a closed system with a bourdon tube. The bourdon tube rotation in response to the temperature (vapor pressure change) is transmitted to the chart cup by means of the spline coupling. High temperature elements make use of a bi-metal sensor in helical form replacing bourdon tube.

Recording Unit. A precision lead screw, a bronze lead screw nut, stylus assembly, chart cup and housing make up the recorder. The clock rotation is converted to linear translation by the lead screw-lead screw nut assembly. The chart cup rotates from the bourdon tube of the pressure or temperature element. A tapered black coated chart fits into the taper of the chart guide in the chart cup. A stylus mounted on the lead screw nut marks the chart. The combination of chart cup rotation and lead screw translation produces a graph of pressure (temperature) deflection vs. time. A calibration table converts the deflection to pressure (temperature).

\section{OPERATING SUGGESTIONS}

\section{THE BASE LINE}

The base line drawn by a pressure element which has not been in use for some time will differ from the calibrated zero pressure. To correct this "zero shift" the pressure element should be flexed several times before a run. This can be accomplished with a dead weight tester or in the lubricator.

The gauge should be subjected to its maximum pressure for two minutes. then relaxed. The base line drawn after 7-10 minutes delay will agree with the manufacturers calibration. Base lines should agree within the gauge sensitivity; i.e., within .002 inch. If beyond this the gauge should be checked before use.

\section{THE CHART CUP}

The accuracy of results partially depends on the chart conforming to the chart cup. The K-2 and K-3 gauges with their tapered charts and tapered char guide eliminates any standolf at the chart edges. The chart cup itself should $b$ arc to prevent irregularitios to its circular shape. 


\section{TRAPPED INTERNAL PRESSURE}

The position of the base line is influenced by the rise in temperature of the entrapped air in the gauge housing. The entrapped air when heated causes internal pressure to develop. The gauge should be made up at room temperature. Any solvents should be thoroughly dried.

\section{READING CHARTS}

Charts can be read to approximately $.003^{\prime \prime}$ using a steel rule graduated in $1 / 100$ inch and a 4 to 6 power magnifier. Optimum accuracy and speed is obtained using a Kuster Chart Reader. In this micrometer chart reader, illuminated cross hairs are aligned through a lens system. Both pressure deflections and time can be read to .001 inch for charts up to $6^{\prime \prime} \times 6^{\prime \prime}$ on the micrometer counter.

Converting deflections to pressures (temperatures) is easily accomplished with the calibration tables supplied with your gauge. The use of a factor is not recommended; results can be in error as much as $15 \mathrm{psi}$.

\section{OPERATING PRESSURE}

Pressure element ratings are maximum. Greater accuracy and element life will result if the gauge is operated at $85 \%$ of rating or less. Over-pressured elements require recalibration.

\section{HIGH TEMPERATURE OPERATION}

When the anticipaled operating temperature is above $300^{\circ} \mathrm{F}$. it is recommended that a gauge equipped with a filter instead of a bellows be used. Erroneous pressure deflections caused by the fluid expansion in the bellows $\checkmark$ type assembly will result.

When a pressure element is converted from a bellows to a filter the bourdon tube should be filled with a clean, non-corrosive fluid, preferably by using a vacuum pump. The oil trap should also be filled with the same fluid and retained by using an oil trap plug.

The calibration of a pressure element will change slightly when the bellows is removed. A new calibration should be made when a bellows is exchanged for a filter.

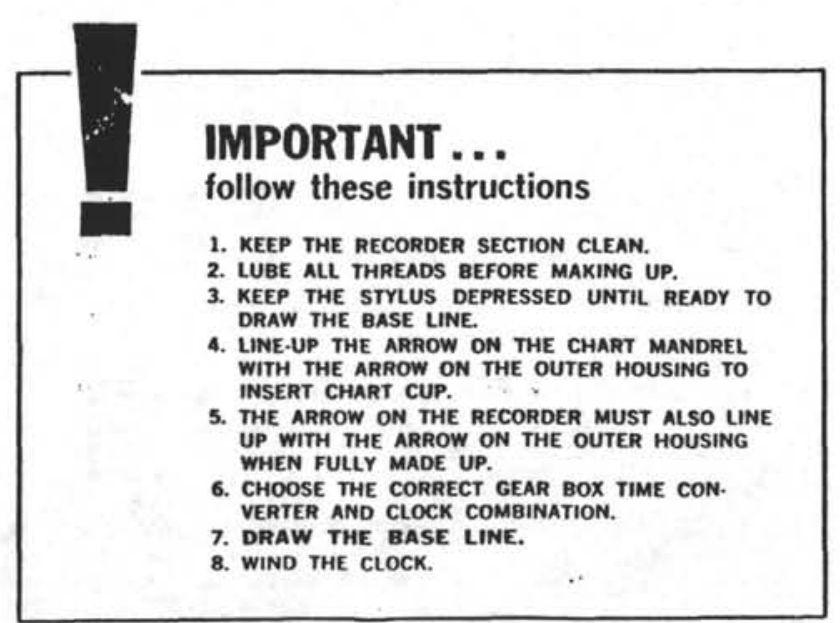

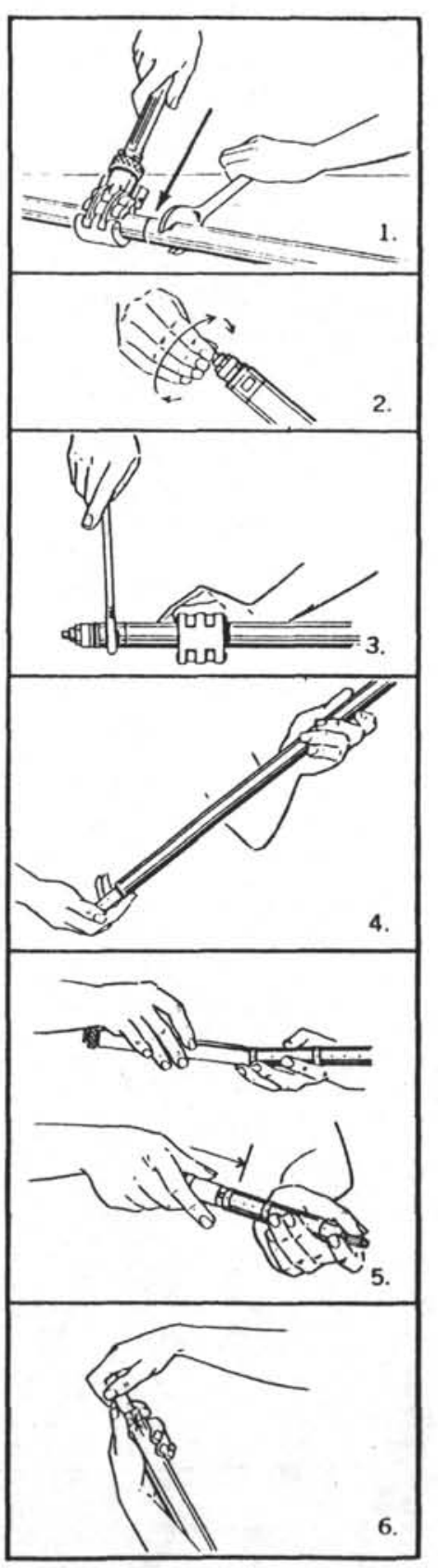

STEPS IN THE

OPERATION OF THE

K-2 AND K-3 GAUGE

1. Remove the clock

The clock is unscrewed at the join indicated, by the arrow. Use the end the points shown.

2. Depress the stylus. The stylus is placed in the "off" position by turning the gear box time converter counter.clockwise. At its extreme limit of travel the stylus is automatically depressed by the

3. Remove the recorder unit. Use the end wrench and the parma. lee wrench at the points shown.

4. Remove the chart cup. Handle the chart cup carefully. The
accuracy of the recordings are partly based on a concentric chart.

5. Install the chart in the chart cup. Place the chart mandrel on the char with the rounded ends as shown in the diagram. Holding the chart on hand tilt the chart cup withe right hand and start the insertion slight amount of rotation back and forth may be necessary for a smooth insertion. As the chart approaches bottom, more resistance is encoun. tered. This is normal. It is the taper of the guide bar forcing the chart outward inside the chart cup. Before the chart has bottomed, slide the cup, gathering the sleeve. Turn the knurled knob clock wise, locking the chart cup, chart and mandrel as one unit.

6. Replace the chart cup and chart in the pressure unit.

Whe chart man pressure unit with the arrow of the cup spline and the ring gear of the bourdon tube. Release the chart mandrel by turning the knurled knob counterclockwise. Carefully remove the chart mandrel. 
7. Install the gear box time converter in

Choose the correct time converter. Example: 12 hour run: Use 6 hour clock with $2 x$ mark on gear box out ward. 3 hour run: Use 6 hour clock with $1 / 2 \times$ mark on Wour run: Use $1 x$ gear box. are into the recorder unit. Tighten with end wrench.

8. Install the recorder unit in the pres sure unit.

unit aligned with sure unit, bring the threads together and make up. The arrows should meet in two turns. If not. repeat certain the stylus is in the correct position with respect to the chart in the chart cup.

9. Fill oil trap (for gauges with bellows) Remove the oil trap and fill $1 / 2$ ful with clean lubricating oil. Replace the oil trap hand tight. Replace the oil trap plug.

O 10. Make up all threads.

Using the end wrenches supplied, ds tight before drawing base line.

11(a). Draw the base line. PRESSURE GAUGE.

Hold the gauge (without the clock attached) in a vertical position and tap the pressure unit lightly with the hand. Turn the gear box time converter clockwise until it stops. the stylus is in pase line and start of the run. Do not alter this

(b). Draw the base line. TEMPERATURE GAUGE

Remove the bull nose at the bottom of the gauge. With the gauge held vertically (without the clock attached) tap the bourdon tube housing lightly with the hand. Turn and hold the knurled knob (ex posed when the bull hose is re feels firm against the stop. Turn the gear box time converter clock wise until it stops. This has drawn the base line. The -stylus is now in position for the start of the run. Do not alter this setting.

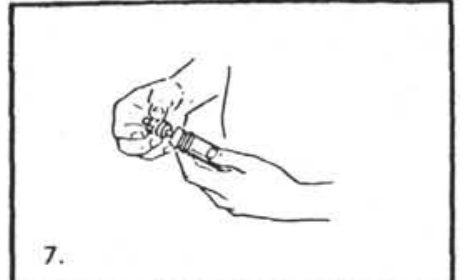

7

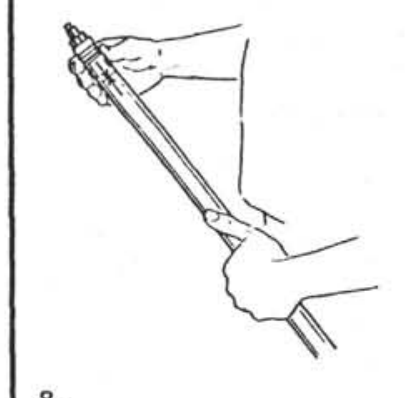

8.

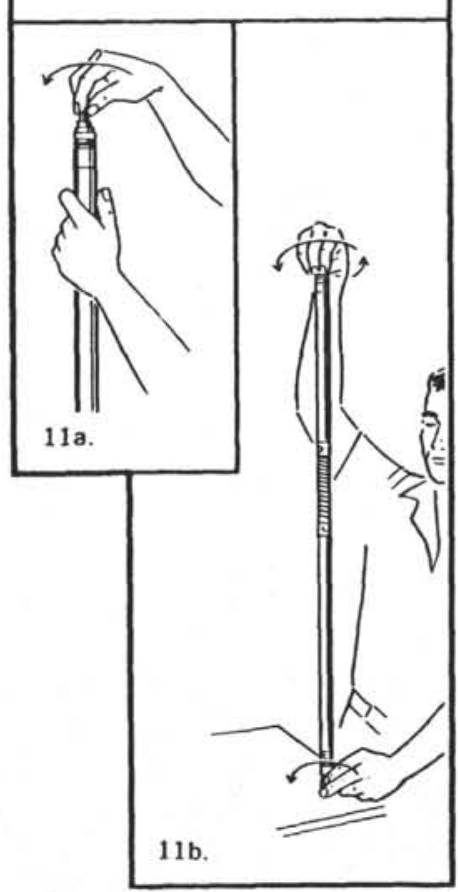

12. Install the clock.

Wind the clock with the special socket key provided. Wind counter. clockwise untit it feels wound-up. nto the pressure unit orce the start of the threads. A lip clutch engages as the clock is

13. Maximum reading thermometer. When a maximum reading ther mometer is to be used. place it in the thermoter housing. This is end) of the gauge.

14. Make up all threads tight with the end wrench and parmalee wrench place

\section{AFTER THE RUN}

15. Remove the clock.

16. Disengage the stylus.

Turn the gear box time converter shaft counter-clockwise until it stops. The stylus is now depressed and will not mark the chart.

17. Removing the chart.

Remove the recording unit. Carefully tilt the pressure unit (or tem perature unit) until the chart cup drops into the hand. Insert the chart mandrel into the chart cup. sleeve. Tighten the knurled knob. Withdraw the chart.

\section{MAINTENANCE}

\section{MINOR MAINTENANCE}

1. ALWAYS LUBRICATE ALL THREAD ED JOINTS before making up the gauge, even if only hand tight. The gauge is made of high nickel non corrosive alloys. These materials have a greater tendency to seize Temp Thread Lube is recommended. (Kuster Part No. 9510.2).

2. The K-2 and K-3 clock needs no attention in the field. Naturally they should be maintained in a clean and dry condition.

3. The Gear Box Time Converter, \#269. needs no maintenance. It should never be washed in solvent without complete drying. both inside and out. Therelore See section on major maintenance. Keep the shafts clean and smooth.
Keep

. The Recorder Unit should be washed in clean, white gasoline or solvent after first removing the Gear Box. Dry thoroughly. Make sure no film

No it is necessary for

for the lead screw bearings.

ight is adjusted as

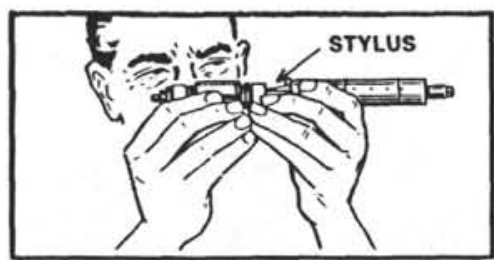


7. Check for friction and a bent stem of the Chart Cup by spinning as tion the Chart Cup should be washed in clean white gasoline or solvent and wiped with the clean. ing tool supplied.

8. The Filter and Conical Nose Piece, Piece. washed after each run to remove muds or heavy crudes.

9. If the gauge is equipped with a bellows no maintenance is reas shown in the diagram If a leak has developed the bellows will ex. tend or shorten and the convolu. tions will be distorted. The bellows should be washed in gasoline to remove any corrosive fluids.

10. O-Rings should be changed after every fifth run in temperatures below $300^{\circ} \mathrm{F}$. Change o-rings after each $r$ n in temperatures above ture o-rings for operation above $350^{\circ} \mathrm{F}$.

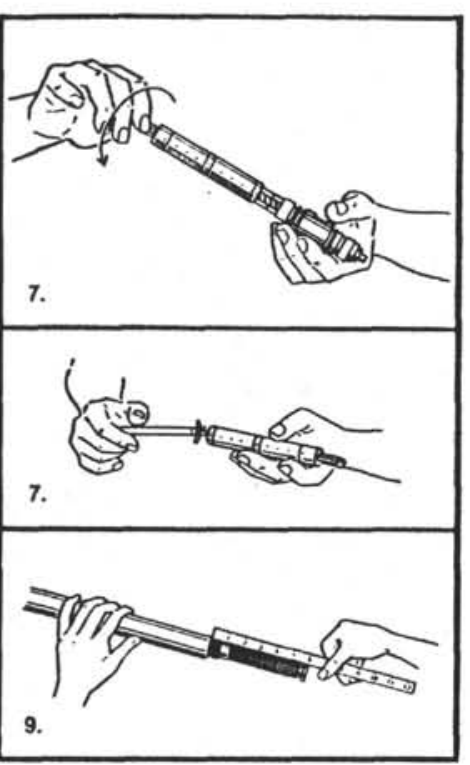

$\stackrel{\infty}{\mapsto}$

\section{MAJOR MAINTENANCE}

\section{PRESSURE UNIT}

1. Remove the recorder unit and chart cup. Remove the case (\#303) using a parmalee wrench. DO NOT USE A PIPE WRENCH ON THE CASE. Wash pling in clean solvent. Check the coil top gear (\#259-2) for wear. Re coll top if reared surface of load post (\$251).

2. If the gauge is bellows equipped, check for signs of corrosion. The indication of leakage is evident. Also see paragraph 9, Minor Main. tenance. If the bellows is replaced, the bourdon tube and bellows must be evacuated thoroughly, and the system refilled with ethylene glycol, ucon, or clean wight oil. This is

\section{RECORDER UNIT}

1. Remove the gear box from the recorder frame. With the special wrench provided, remove the ring nut (\#222-1). Remove the krinkle ring (\#222-2), the lead screw bear. ing (\#222.3) and the lead screw (1221). Wash all parts in clean sol vent and dry. Assemble. Use a frame plug (\#219) and a very small screw bearing.

2. Remove the cover on the 2:1 gear box. Wash in clean solvent and dry. Lubricate very sparingly with instru. ment oil. The $1 \mathrm{X}$ gear box needs no service except to be clean and free from excessive oil.

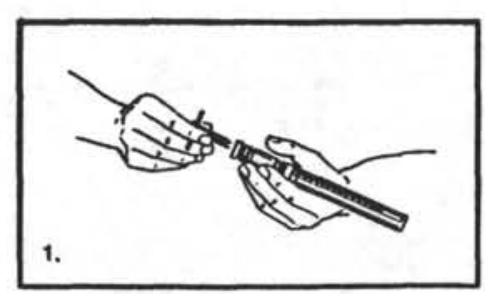
amount on the lead screw and lead
K-2(1") PRESSURE RECORDER, Part No. 201 K-3(1 1/4 ") PRESSURE RECORDER, Part No. 301

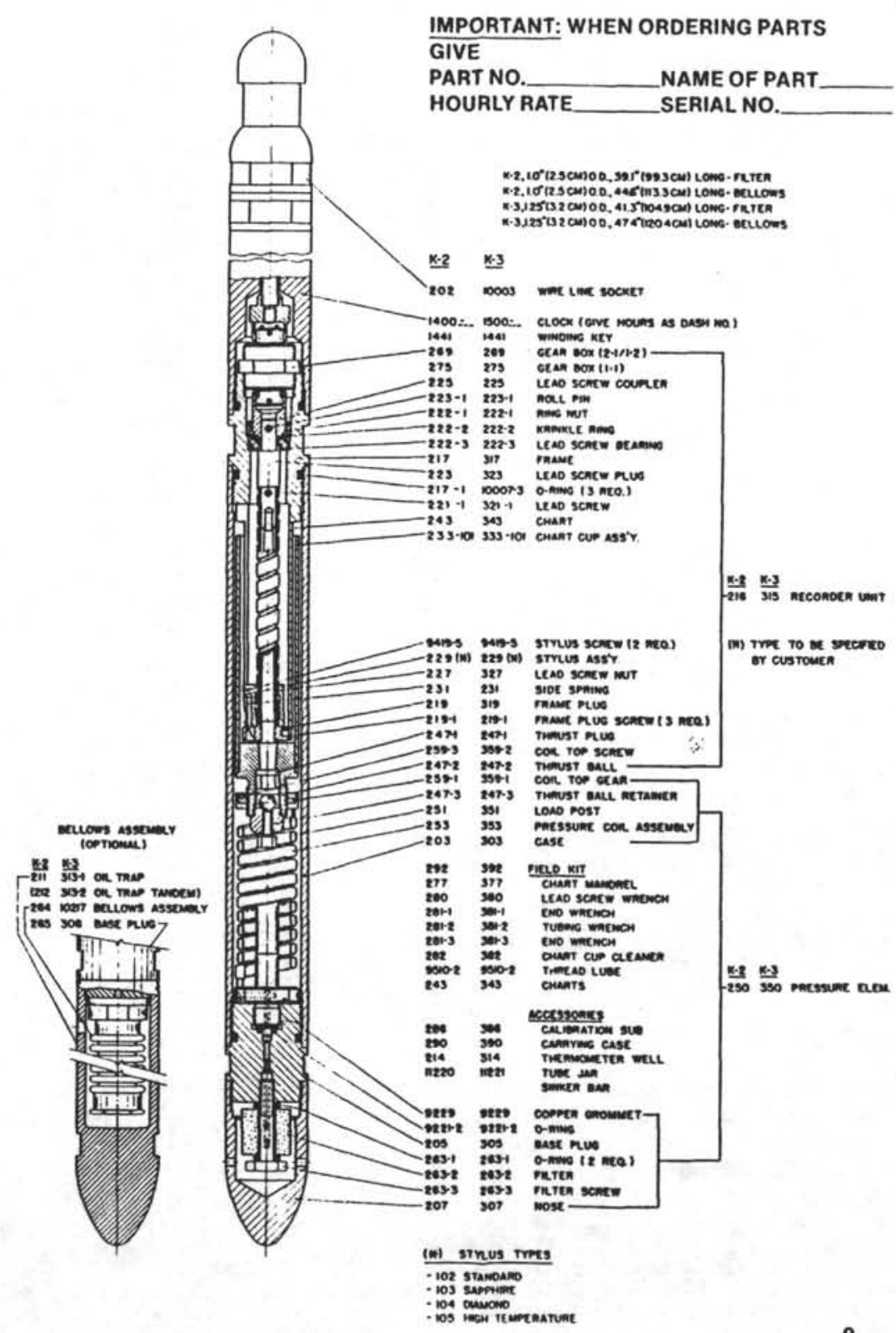


TEMPERATURE ELEMENT

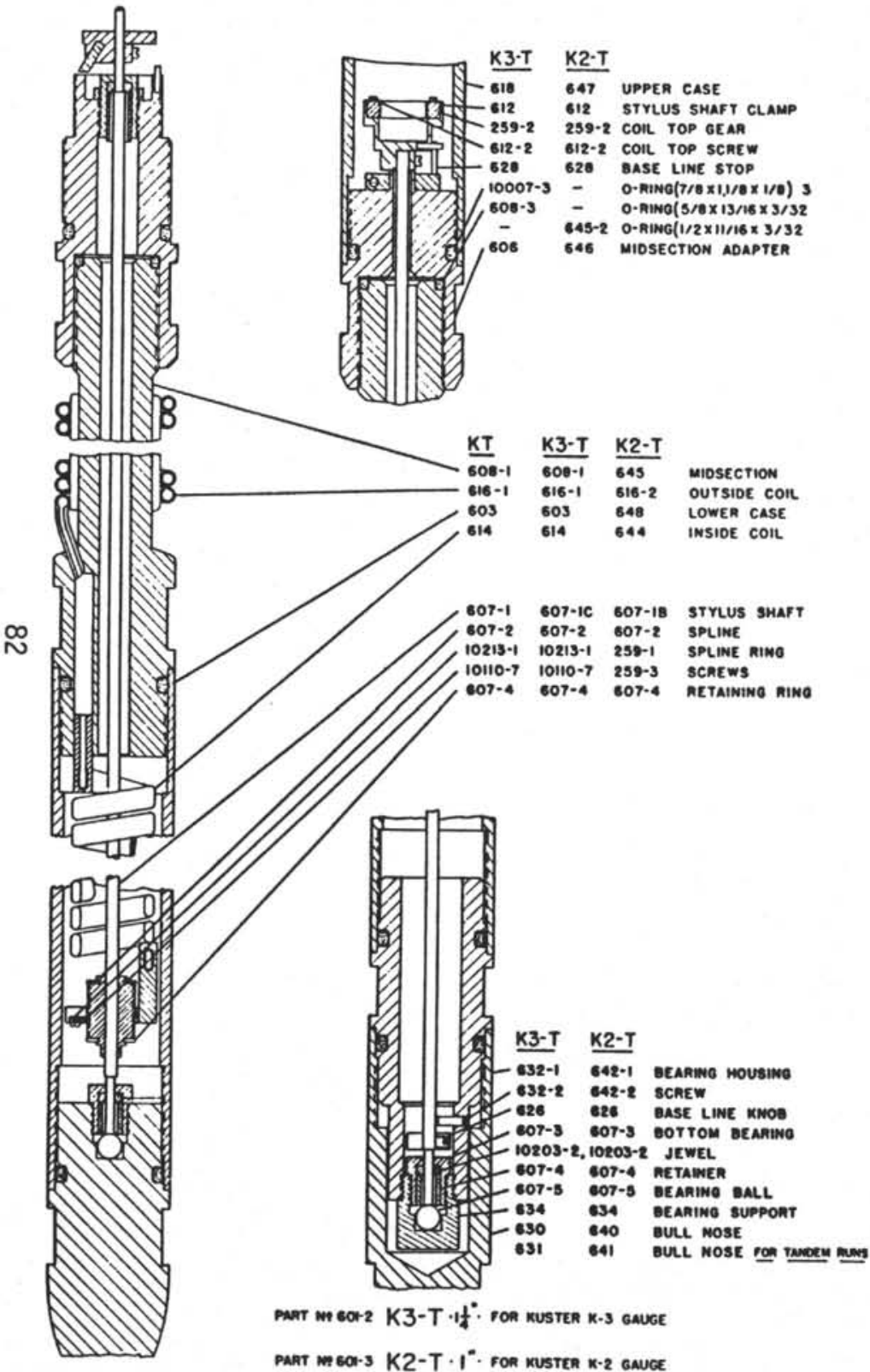

10

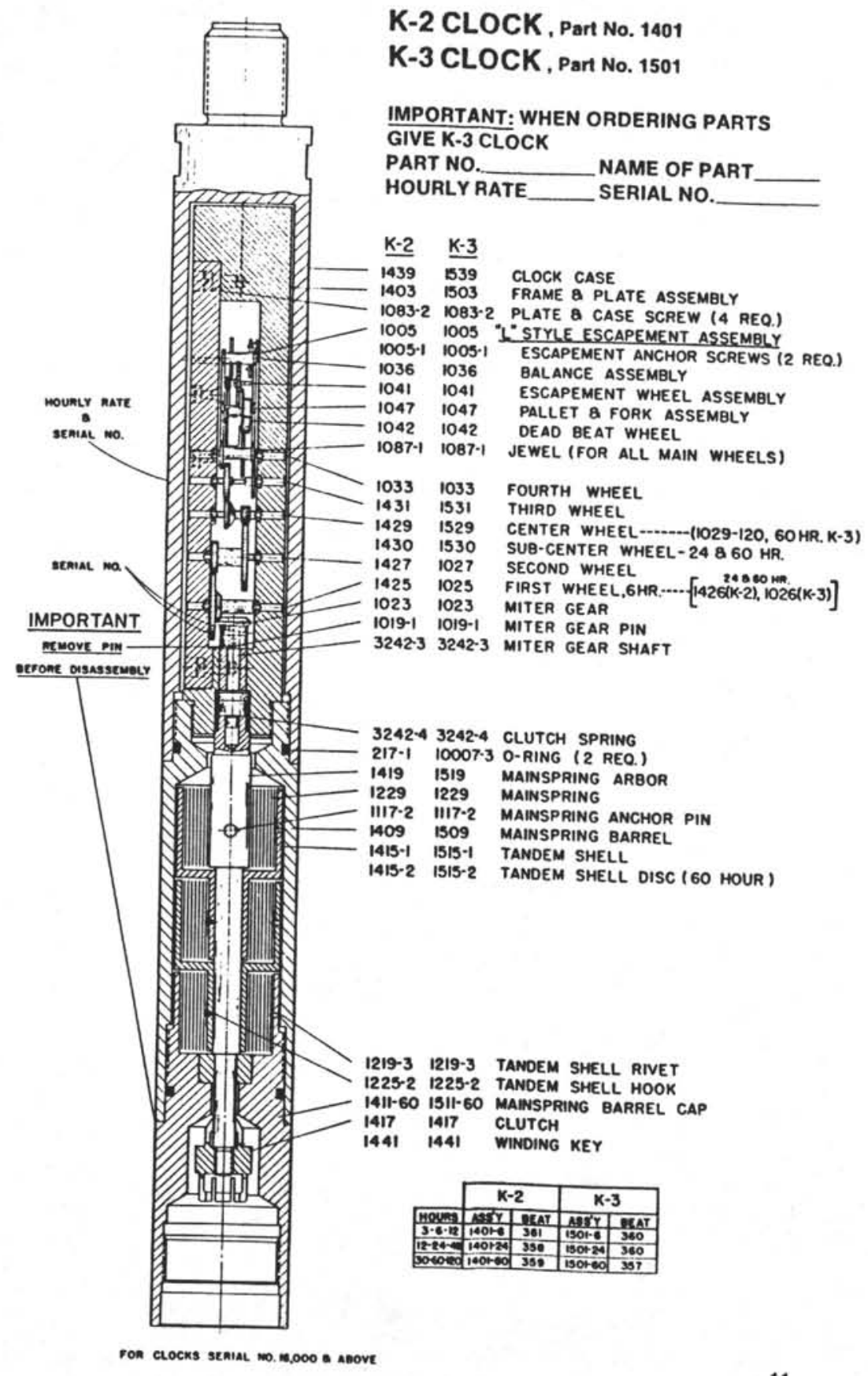




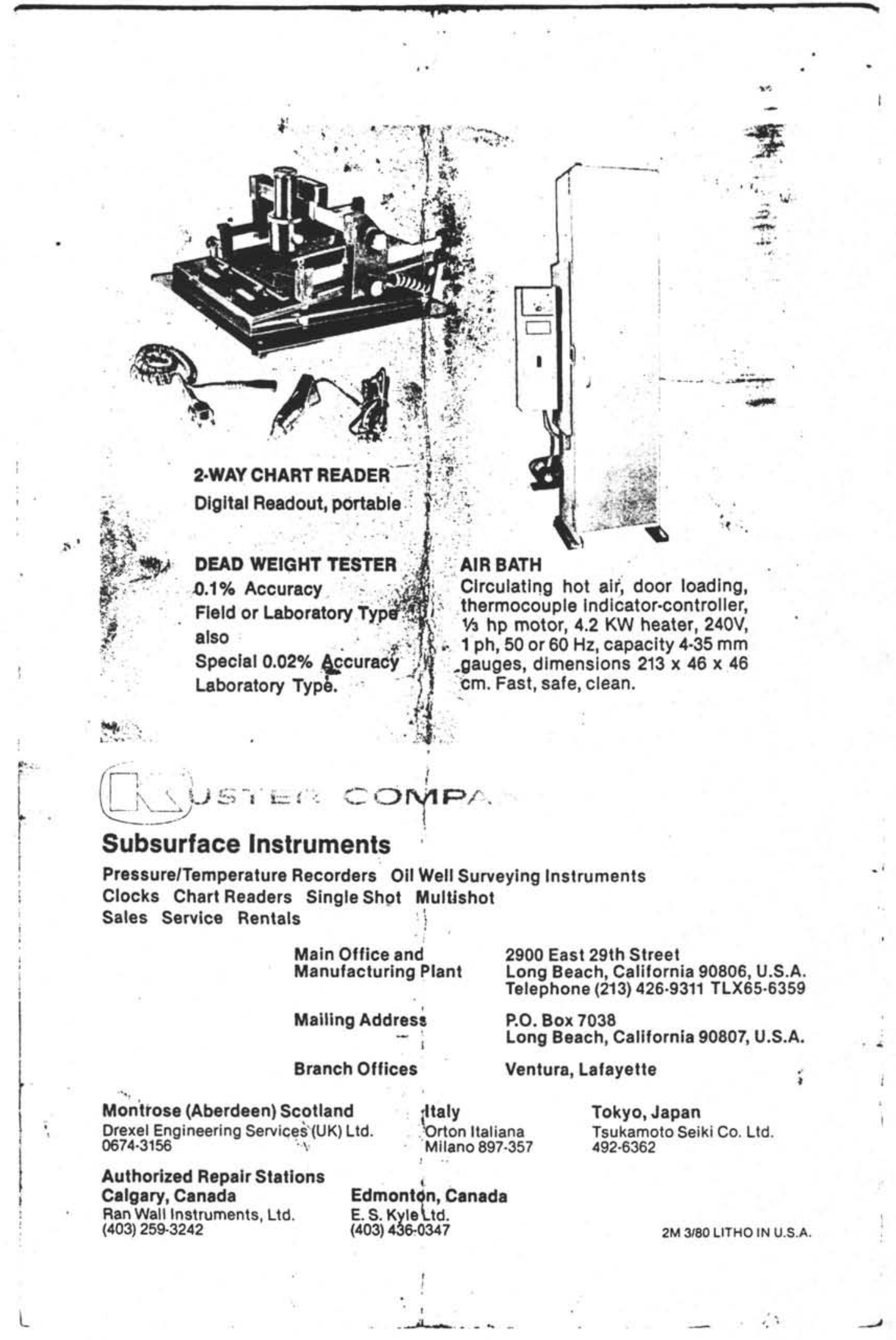




\begin{abstract}
Appendix C. Rig Floor Instrumentation Schematics
APPENDIX C-1.

Instructions for Gould PG-3000 pressure transmitter.
\end{abstract}

INDEX

SECTION 1 GENERAL DESCRIPTION AND ORIENTATION

SECTION 2 SPECIFICATIONS AND MODEL NUMBER

SECTION 3 INSTALLATION AND DIMENSIONAL DATA

SECTION 4 ELECTRICAL INSTALLATION

SECTION 5 CALIBRATION

SECTION 6 TROUBLESHOOTING

SECTION 7 WARRANTY

APPENDIX 


\section{GENERAL DESCRIPTION}

Gould PC,j000 Series Gage Pressurc Transmitters provide reliable pressure measurements in hazardous or corrosive enviroments. Zero and span are magnetically controlled in the instruments to permit simple, external screvidriver adjustments. Since these instruments are hermetically sealed field repairs should not be attempted. An instroment requiring repair should be returned to the factory.

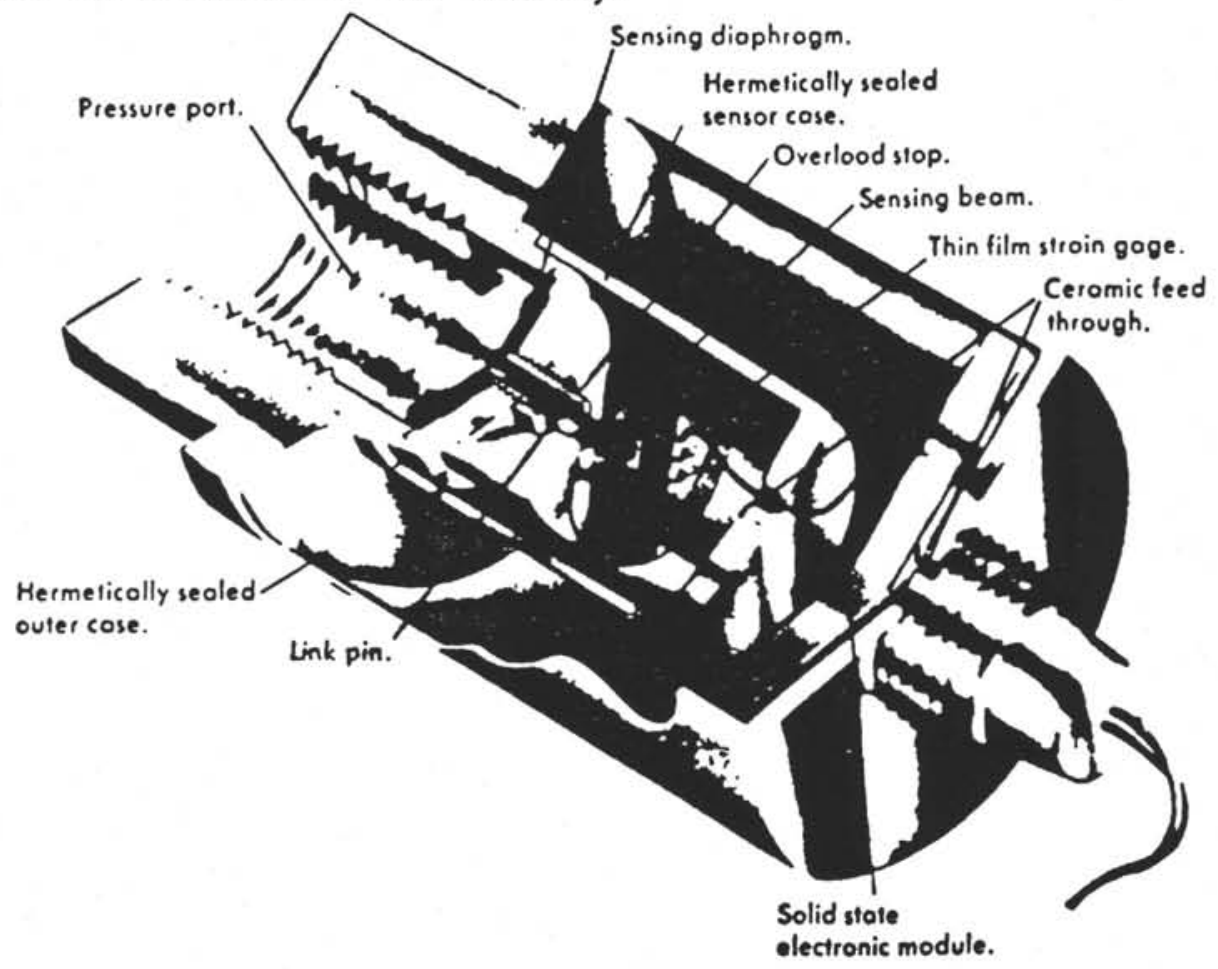

\subsection{Principle of Operation (Reference Figure 1)}

The sensor of the transmitter is Gould's time-proven strain gage beam-diaphragm assembly, which assures low volumetric displacement of less than .001 inch $^{3}$. This eliminates the requirement for seal pots. The sensing element assembly is protected from the process by an isolating diaphragm of 17-7 $\mathrm{PH}$ or Hastelloy $\mathrm{C}$. The can 
surrounding the sensing assembly is evacuated and welded, resulting in a pressure measurement referenced to full vacuum.

Electrical offsetting is utilized to produce pressure measurements referencing 14.7 psia. Since the output of the PG Series is affected by changes in atmospheric pressure, it is recommended that for lover ranges where a true gage pressure reading is required, the Gould PG3040 Series transmitter be used. For applications in which liquids corrosive to 17-7 PH diaphragms are used, the PG3000 Series may be ordered with diaphragms made of Hastelloy C. (Reference Section 2. Specifications) 


\section{Gage and Absolute Pressure Transmitters
2. Sealed Adjustable Model PG3000/PA3000 Series}

- Electronics hermetically sealed in 316 SS case

- Non-interacting, external span and zero adjustments

- Small 3-Ib design, direct pipe mounting

- $0.25 \%$ accuracy

- Reliable, proven, thin film strain gage design

- Simple DC electronics

Magnetically adjustable span and zero in a sealed transmitter

The Gould Sealed Adjustable Transmitters permit for the first time the non-interacting, external adjustments of zero and span in hermetically sealed units. The external span and zero adjustments are coupled to their corresponding internal potentiometers by magnets mounted back-10-back on the sealed transmitter housing. This permits simple screwdriver adjustments of zero and span in the field, without violation of the hermetic seal. Since zero and span are non-interacting. calibration is simplified as each adjustment is made only once.

Corrosion and moisture-resistant stainless steel housing and wetted parts

The PG3000/PA3000 Series pressure transmitters are built to stand up under the most corrosive environments. The sensor and electronics are weided shut in a stainless steel housing for protection against moisture and corrosion. Standard wetled parts are constructed of 316 stainless steel

\section{$\pm 0.25 \%$ thin film accuracy and long-term stability}

Gould's ultrastable thin film strain gage sensor assures a transmitter of having long-term stability and accuracy. The sensor consists of a beam-diaphragm assembly, with the thin film strain gage bridge circuit located on the bending beam. This strain gage offers the stability and resıstance characteristics required for high stability and dependable pertormance. No bonding agents are used, as in conventional bonded strain gage units, thereby minimizing the effects of stress and temperature.

\section{Protection against mechanical and electrical transients}

The PG3000/PA3000 Series Pressure Transmitter utilizes a revolutionary new diaphragm assembly with a rigid center plate to eliminate diaphragm damage due to water hammer and other pressure surges.

The sensing assembly is electrically isolated from the process media by a glass seal which prevents damage to the transmitter electronics caused by process borne transients.

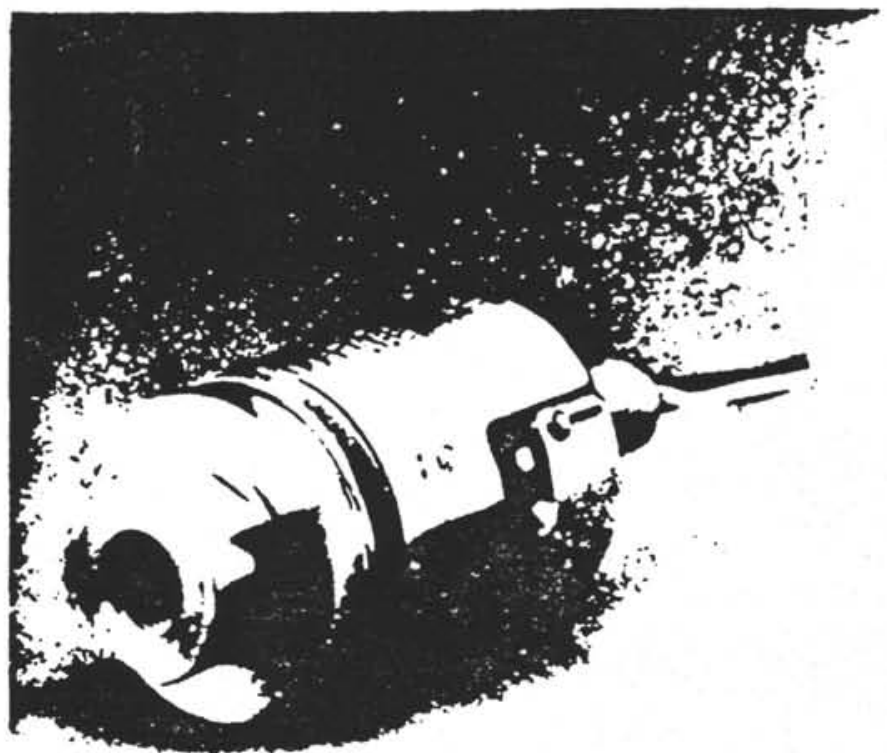

Certified intrinsically safe for hazardous locations

The PG3000/PA3000 Series transmitters are centified explosion. proof: Class I, Div. 1, Groups A, B, C.D: dustignition-proof: Class II, Div. 1, Groups E, F, G; intrinsically safe: Class I. Div. 1. Groups A. B, C \& D: CSA and FM-approved when used with approved barriers (relerence Bulletin 122)

\section{Small, lightweight, easlly mounted}

The DC electronics of the transmitter is simple and reliable, requiring less space than conventional transmitter electronics. The smaller size housing, made of stainless steel. provides a lighter and more rugged unit. This also means easy, inexpensive mounting directly on piping.

\section{For low gage and absolute pressure measurements}

For low range gage measurements, Gould offers Models LPG3040 pressure transmitters (Reference Bulletin 106/107).

For low range absolute measurements. Gould ofters Model LPA3040 pressure transmitters (Reference Bulletin 108/109) 
SPECIFICATIONS

Functional Specifications

Service

Liquid, gas or vapor

Range limits - adjustable

Output

Power Supply

Load limitations

Electrical classification Explosion-prool Dust ignition-proot. Intrinsically Sale

\section{Enclosure classification \\ Zero elevation \\ Zero suppression \\ Temperature limits Storage $\quad-65^{\circ} 10+200^{\circ} \mathrm{F}\left(-54^{*} 1093^{\circ} \mathrm{C}\right)$ Operation, electronics $-20^{\prime} 10+180^{\circ} \mathrm{F}\left(-29^{\prime}: 10+82^{\circ} \mathrm{C}\right)$ Optional, electronics $\quad-60^{\circ} 10+140^{\circ} \mathrm{F}\left(-51^{\prime} 10+60^{\circ} \mathrm{C}\right)$ Maximum process $\quad-65^{\circ} 10+250^{\circ} \mathrm{F}\left(-54^{\circ} 10+121^{\circ} \mathrm{C}\right)^{\circ}$ -Fluorolube limited to a maximum of $+160^{\circ} \mathrm{F}$ \\ Pressure limits \\ $200 \%$ of upper range limit through 5,000 psi \\ $150 \%$ of upper range limit for 10,000 psi}

\section{Specification Chart - Load Limitation}

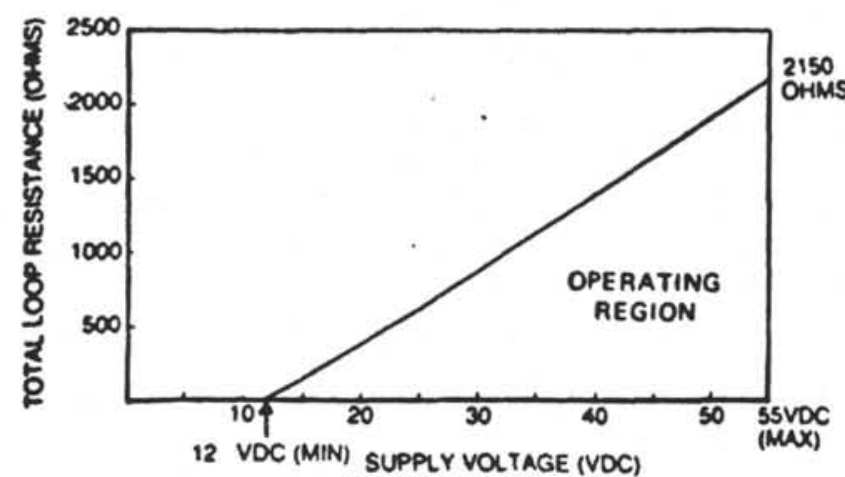

Humidity limits

$0.100 \% \mathrm{RH}$

Volumetric displacement Less than $0.001 \mathrm{cu}$ in $(0.0164 \mathrm{cc})$

Performance Specifications ( $\%$ of full range)

Accuracy

$\pm 0.25 \%$ of calibrated span. including linearity. hysteresis and repeatability

Stability

$< \pm 0.25 \%$ of upper range $\mathrm{limit} / 6$ months

Repeatability

$\pm 0.1 \%$ at maximum span

Temperature effects

$\pm 1.0 \%$ from -20 to $-180 \mathrm{~F}$

$(-29: 10-82: C)$ max span

$\pm 3.5 \%$ from -20 to $180 \mathrm{~F}$

$\left(-29^{\circ}\right.$ to -82 C) min span

Vibration effects

$\pm 0.01 \% / g$ in all ranges

RFI/EMI eflect

Negligible to $500 \mathrm{MHz}$ at 5 watts ditect contact

Power supply eflect

$0.01 \% /$ volt of power supply variation

Load eflects

$\pm 0.0002 \% / \mathrm{hm}$ of loop resistance variation

Mounting position effects None

Physical Specifications

Materials of construction Diaphragm

316 SS

Monel R (400)

NOTE: Consult factory for optional materials of construction

Other wetled parts 316 SS

Fill fluid

Silicone oil DC. 200

Specific gravity $=.873$

FS5 Fluorolube

Specific gravity $=1.86$

(measured at $25^{\circ} \mathrm{C}$ )

Electronics housing

316 stainless steel

Leads

PVC-insulated 16-gage stranded with polysultide potting White $=$ negative: Black $=$ positive : Green $=$ ground

Process connection

$1 / 2 " N P T$

Electrical connection

*4" male NPT

Weight

$4 \mathrm{lbs}(1.7 \mathrm{~kg})$ 
Collbration - Transmitters are factory-calibrated at the maximum range unless specified otherwise when order is placed.

Compensation - Transmitters are compensated for operation at $-20 * 10+180 F(-29 * 10+82 C)$. Optional compensation for low temperature operation at $-60^{\circ} 10+140^{\circ} \mathrm{F}\left(-51^{\circ} 10+60^{\circ} \mathrm{C}\right)$ may be modified at additional cost.

Tagging - Transmitters will be identified in accordance with customer requirements. (Maximum of 15 characters) Typed on calibration cover.

Accuracy - Special $\neq 0.1 \%$ of calibrated span available.
Accessorles (See Bulletins 120\& 121) Integral Meter \& Junction Box

Model 128 Linear, 0-100 scale

Transient Prolectors (Lightning)

Model TP114, */4" NPT coupling

Model TP124, Universal Junction Box mount

Mounting Bracket, Model EW3

For surface or 2" pipe

Reducing Adapter, Model RA 100

$1 / 2 "$ to $1 / 4 "$ NPT

Integral Non-indicating Junction Box - Model MA123

\section{OUTLINE DRAWINGS}

DIMENSIONS:
(Nominal) $\frac{\mathrm{mm}}{\text { inches }}$

[- 11 MINIMUMACCESSORY ENGAGEMENT

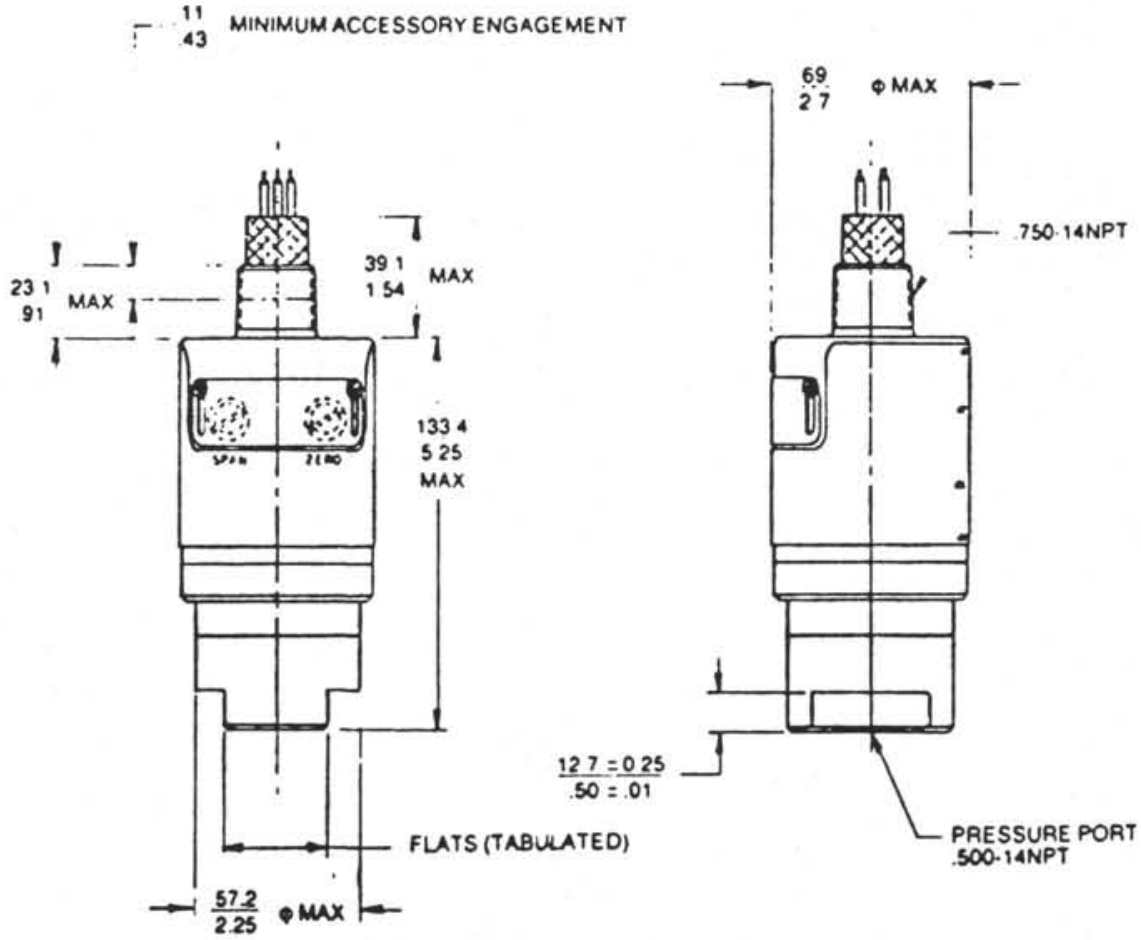

\begin{tabular}{|c|c|c|}
\hline RANGE & FLATS & $\frac{ \pm 0.25}{ \pm .010}$ \\
\hline$<2000$ PSI & \multicolumn{2}{|c|}{$\frac{28.59}{1.125}$} \\
\hline$>2000$ PSI & \multicolumn{2}{|c|}{$\frac{34.93}{1.375}$} \\
\hline
\end{tabular}




\section{INSTALLATION}

\subsection{General}

Proper installation of the transmitter has a direct effect on the quality of pressure measurement obtained. The instrument will, in many cases, be installed in an outdoor or harsh environment of a process plant. To prolong instrument service life, every effort should be made to minimize temperature fluctuation effects, vibration, and shock. Before installing the transmitter, examine the area where it is to be installed to make sure that adequate space is available for the transmitter, its accessories, and mounting bracket. Check that the anticipated measurement parameters are within the specifications called out in Section 2 .

\subsection{Mounting the Transmitter}

The PG3000 transmitter has a $1 / 2$-inch NPT process connection. It may be connected to the process piping either directly or by means of a mounting bracket.

\subsubsection{Mounting with Sensing Lines and Electrical Conduit}

Due to its light weight, the transmitter can be close-coupled to the process piping. Prior to mounting, make sure the sensing lines and conduit are firmly secured to a solid surface. Place the clamps holding them as close as possible to the transmitter to reduce bending moment.

\subsubsection{Mounting with Bracket, Model Elw3}

The Gould Model Eh'3 Mounting Bracket permits mounting the transmitter to a 2-inch pipe or a flat surface. The bracket can be used on a 
vertical or horizontal surface or pipe so that the instrument is alway's parallel to the pipe.

\section{CAUTION}

Do not use a pipe wrench on the body of the transmitter. Use the wrench flats on the transmitter for connecting piping. Using a pipe wrench on the transmitter body may result in damage and will void the warranty. 


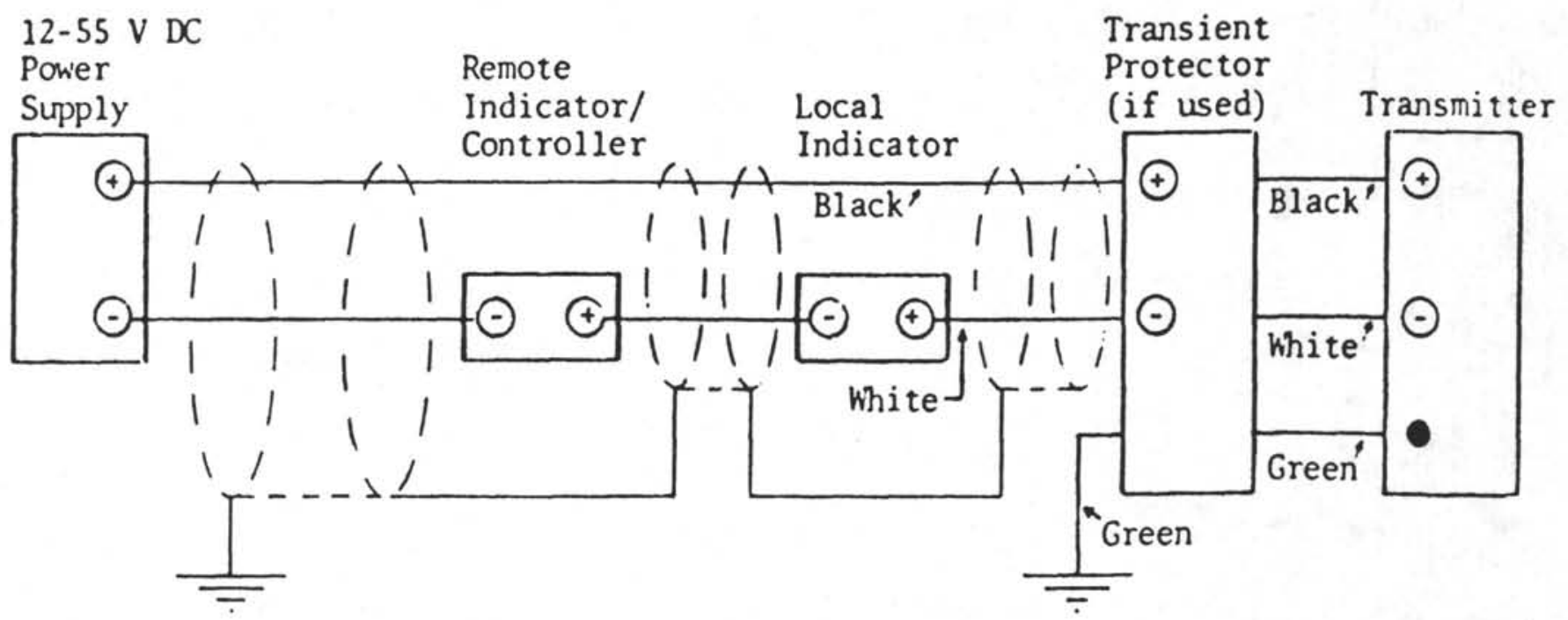

Figure 4-1. Electrical h'iring

A single transmitter or multiple transmitters may be connected to a power supply. In both cases, the negative side of the power supply or the negative side of the receiving instrument should be grounded. A block diagram of a typical multiple transmitter installation is shown in Figure 4-2.

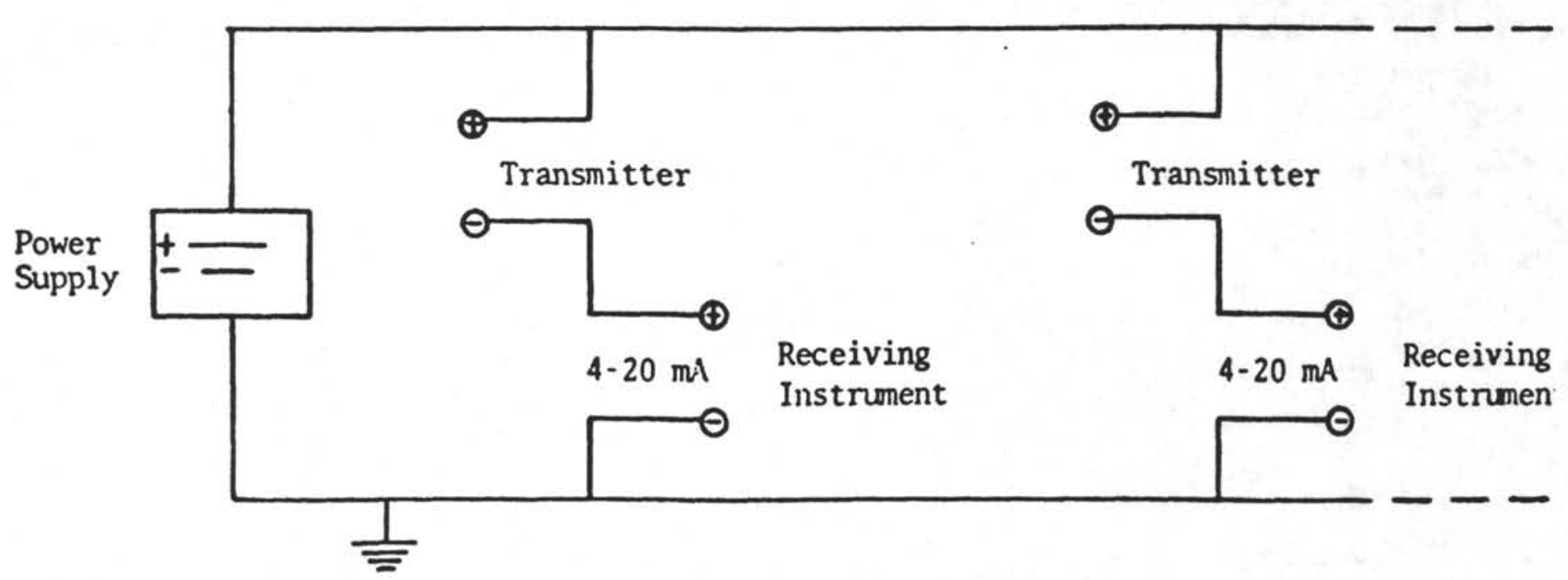

Figure 4-2. Multiple Transmitter Installation 


\section{ELECTRICAL INSTALLATION}

\subsection{Electrical Termination}

The PG3000 pressure transmitter is supplied with one of three possible terminations:

Designation 12. Three-wire No. 16 AhG, 36 inches long Black wire - positive, white wire - negative, green wire - ground

Designation 16. Integral Underwater Service Connector, threc-wire cable length up to 500 feet

Designation 18. Accessory connected to transmitter

The power supply requirements range from 12 volts $D C$ at no load to 55 volts at 2150 ohms. All power to the transmitter is supplied over the signal wiring. No additional wiring is required. Shielded wiring is not normally required, but twisted pairs should alway's be used as signal wire.

Current limiting is provided to protect the receiver. Naximum current is 25 milliamps.

\subsection{Wiring of Transmitter}

For electrical installation, refer to the Electrical Block Diagram, Figure 4-1. 


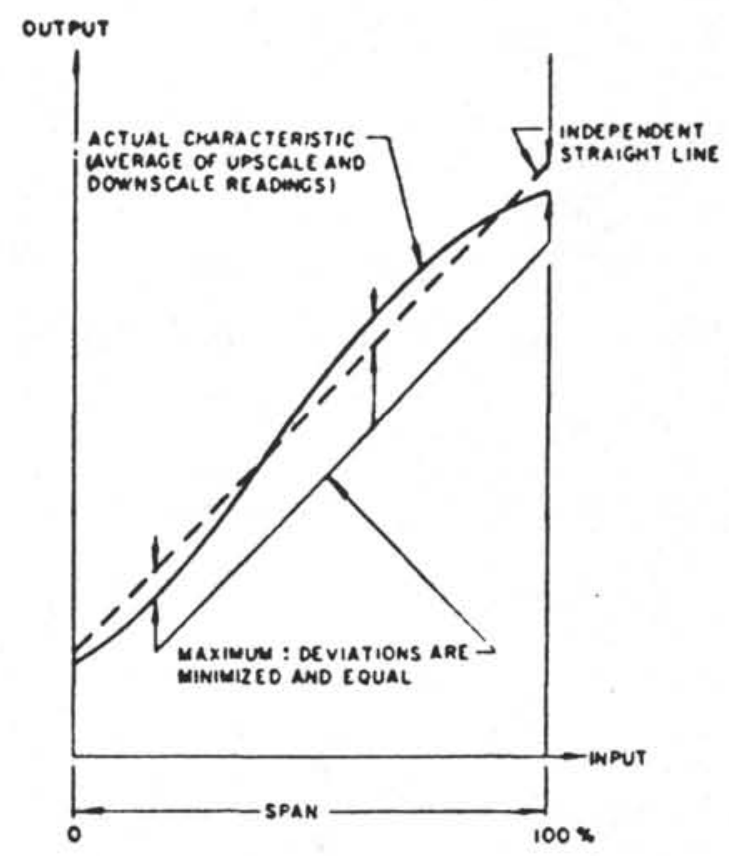

Range: The region between the limits within which a quantity is measured or transmitted. Elevated-zero range is where the zero value of the measured variable is greater than the lower range value. Suppressed zero is where the zero value of the measured variable is less than the lower range value. Lower range limit is the lowest quantity that a device can be adjusted to measure. Upper range limit is the highest quantity that a device can be adjusted to measure. Lower range value is the lowest quantity' that a device is adjusted to measure. Upper range value is the highest quantity that a device is adjusted to measure. Span: The algebraic difference between the upper and lower ranf values. 


\section{CALIBRATION}

The PG3000 transmitter is factory-calibrated to the range show on the nameplate. Since the unit is hermetically scaled, provision has becn made for zero and span adjustments through external screvidriver adjustincits. The external adjustment screws are coupled to internal zero and span potentiometers by the use of permanent magnets mounted back to back on the transmitter housing. The adjustment screw's are located under the side cover of the electronics housing. Zero and span adjustments are nonintcracting.

Turn the 2ERO screw CCli to decrease output and $\mathrm{Cl}$ to increasc output.

To decrease output, turn the SPAN screw Cli; to increase output, turn tine screw CCW.

5.1 Definition of Gould Terms (Based on SAMA Standard PAC20-1-1973 "Process Measurement and Control Terminology")

Accuracy: Conformity of an indicated value to an accepted standard value or true value. Reference accuracy is the limit that errors will not exceed when the instrument is used under reference operating conditions.

Calibration: Adjustment of the output of a device to bring it to a desired value, within a specified tolerance, for a particular value of input. Linearity: The maximm deviation of the actual characteristic (average of upscale and downscale readings) from a straight line positioned so as to minimize the maximu deviation. 
TABLE 1

ZERO ELEVATION AND SUPPRESSION

\begin{tabular}{|c|c|c|c|c|c|c|c|}
\hline \multicolumn{2}{|c|}{ Typical Ronges } & \multirow{2}{*}{$\frac{\text { Terminology }}{-}$} & \multirow{2}{*}{$\frac{\text { Range }}{010100}$} & \multirow{2}{*}{$\begin{array}{c}\begin{array}{c}\text { Lower } \\
\text { Range Volue }\end{array} \\
0\end{array}$} & \multirow{2}{*}{$\begin{array}{c}\begin{array}{c}\text { Upiser } \\
\text { Ronge Value }\end{array} \\
+100\end{array}$} & \multirow{2}{*}{$\frac{\text { Spon }}{100}$} & \multirow{2}{*}{$\begin{array}{c}\begin{array}{c}\text { Supplemeitiary } \\
\text { Duta }\end{array} \\
-\end{array}$} \\
\hline 2 & +100 & & & & & & \\
\hline 30 & מ & $\begin{array}{l}\text { Sinixersid } \\
\text { zero range }\end{array}$ & 30 to 100 & 30 & +100 & 70 & $\begin{array}{c}\text { Supipressed ratio } \\
.3\end{array}$ \\
\hline-25 & $0 \quad 25$ & $\begin{array}{l}\text { Elerstidu } \\
\text { zero trange }\end{array}$ & $-2510+25$ & -25 & +25 & 50 & - \\
\hline .50 & 0 & $\begin{array}{l}\text { Elevatcd } \\
\text { zero iange }\end{array}$ & -50100 & -50 & 0 & 50 & - \\
\hline-80 & -20 & $\begin{array}{l}\text { Elevated } \\
\text { zeroidi:g= }\end{array}$ & $-8010-20$ & -80 & -20 & 60 & - \\
\hline
\end{tabular}

\subsection{Ficld Calibration of Gould Transmitters}

1. A digital multincter or $|C| N$ is connected in series with the transritter and receiving instrument. For shop calibration, a durmy load resistor may he substituted for the recciving instrument.

2. A pressure source of inown accuracy should be connected to the process or pressure connection of the transmitter.

3. Pressure equivalent to the lolier range value should be applied to the transmitter and the zero adjusted to read $4 \mathrm{~mA}$. Pressure equivalent to the upper range value is then applied and the span adjusted for $20 \mathrm{~mA}$. Lower and upper range values should again be applied to verify the 4 and $20 \mathrm{~mA}$ readings. In the event of any change in the output readings, readjust the transmitter until the readings are correct. 


\section{TROUBLESHOOTING}

No output or low output signal:

Check for shorts and multiple grounds in loop wiring.

Check polarity of connections.

Check loop impedance.

Check for leaks or blockage in piping.

Check for entrapped gas in liquid lines.

Check transient protector (if used) for 1 megohm or greater resistance to ground from each lead.

High output:

Check output of power supply.

Check sensor connections.

Erratic output:

Check for intermittent shorts, open circuits, and multiple grounds in loop wiring.

Check piping for entrapped gas in liquid lines or for liquid in dry lines. 
APPENDIX C-2.

Control panel for Gould PG-3000 pressure transmitter.

\section{GENERAL}

The enclosed patch panel assembly can be used to monitor pressure over a range from 0 to 5000 PSI. It should be noted that this assembly is only compatible with pressure transducers that have a signal range from $4 \mathrm{~mA}$ to $20 \mathrm{~mA}$.

The transducer is driven by a power-one D.C. voltage supply which is mounted on the back of the patch panel. The supply delivers $24 \mathrm{Vdc}$ and $1.2 \mathrm{~mA}$ to the transducer.

The negative return of the transducer is connected in series with two $100 \mathrm{ohm}$ resistors. Jumpers are soldered over each resistor and connected to a pair of banana plugs and an isolated BNC connector respectively. The banana plugs can be used to transmit data to a chart recorder. The BNC is intended for use with the Masscomp. You will need to make sure that the input impedance of the chart recorder and the Masscomp is high enough so as not to induce current drain from the main series circuit.

A digital panel meter has also been connected between the resistor $\mathrm{R} 2$ and the negative return of the power supply. This meter functions as a current reciever in the circuit and will give out display readings in PSI. The current receiver has been made to read between $4 \mathrm{~mA}$ and $20 \mathrm{~mA}$ so that it will match the transducer. The meter is powered by the $24 \mathrm{Vdc}$ supply, however, it can be powered by any DC supply between $9 \mathrm{~V}$ and $32 \mathrm{~V}$. A removable splash proof cover has been mounted on the front of the meter to protect the LED display.

On the right hand edge of the patch panel, you will notice a second set of banana plugs. These are in case you need to use the panel as a spare $24 \mathrm{Vdc}$ supply. DO ${ }^{\circ} \mathrm{NOT}$ run off this set of banana plugs while monitoring pressure. A current drain will be induced and your data will be erroneous. 


\subsection{Power Supply}

The power supply generates $24 \mathrm{Vdc}$. The supply is jumpered to run off a $120 \mathrm{Vac}$ line. By changing the jumper configuration of the supply, it can also be run off $100 \mathrm{Vac}, 220 \mathrm{Vac}$ or $230 / 240 \mathrm{Vac}$. If you need to run off one of these three supplies, see the technical specs included in the manual for jumper configurations as well as A.C. application data. A fuse has also been installed on the front of the surface panel to protect the circuitry. A 1/2 AMP slow burn fuse should be used at 120 Vac.

\subsection{Diqital Panel Meter}

The digital meter is set to recleve a $4 \mathrm{~mA}$ to $20 \mathrm{~mA}$ signal. I have calibrated the meter over the range of 0 to 5000 . In the unlikely event that the meter goes out of calibration on the way out, recalibration can easily be performed. First you will need to pull the meter out of the patch panel. To do so, disconnect the D.C Input and the signal conditioner input on the back of the meter. Slide the meter out of the panel. Snap off the plastic splash proof cover assembly. Next, seperate the top plastic housing cover of the meter from the bottom housing. Slide out the red LED cover. You will now notice two potentiometers on the left side of the front panel. The top pot(RI) is used to adjust the count on the meter to $O$ (no pressure on the transducer). After having done this, you will now need to calibrate the meter at the top end(5000 PSI). Pressure the transducer to 5000 PSI. The best way to check to see if you actually have 5000 PSI is to place a voltmeter over one of the resistors on the back of the patch panel. Each resistor was measured at $100.2 \mathrm{ohms}$, thus, a voltage of $2.004 \mathrm{Vdc}$ will correspond to a current of $20 \mathrm{~mA}$. After this has been accomplished, adjust the lower pot(R2) until the digital count reads 5000. Repeat the above process until an accuracy of 1 count is attained. Reassemble the meter and place it back into the patch panel. 


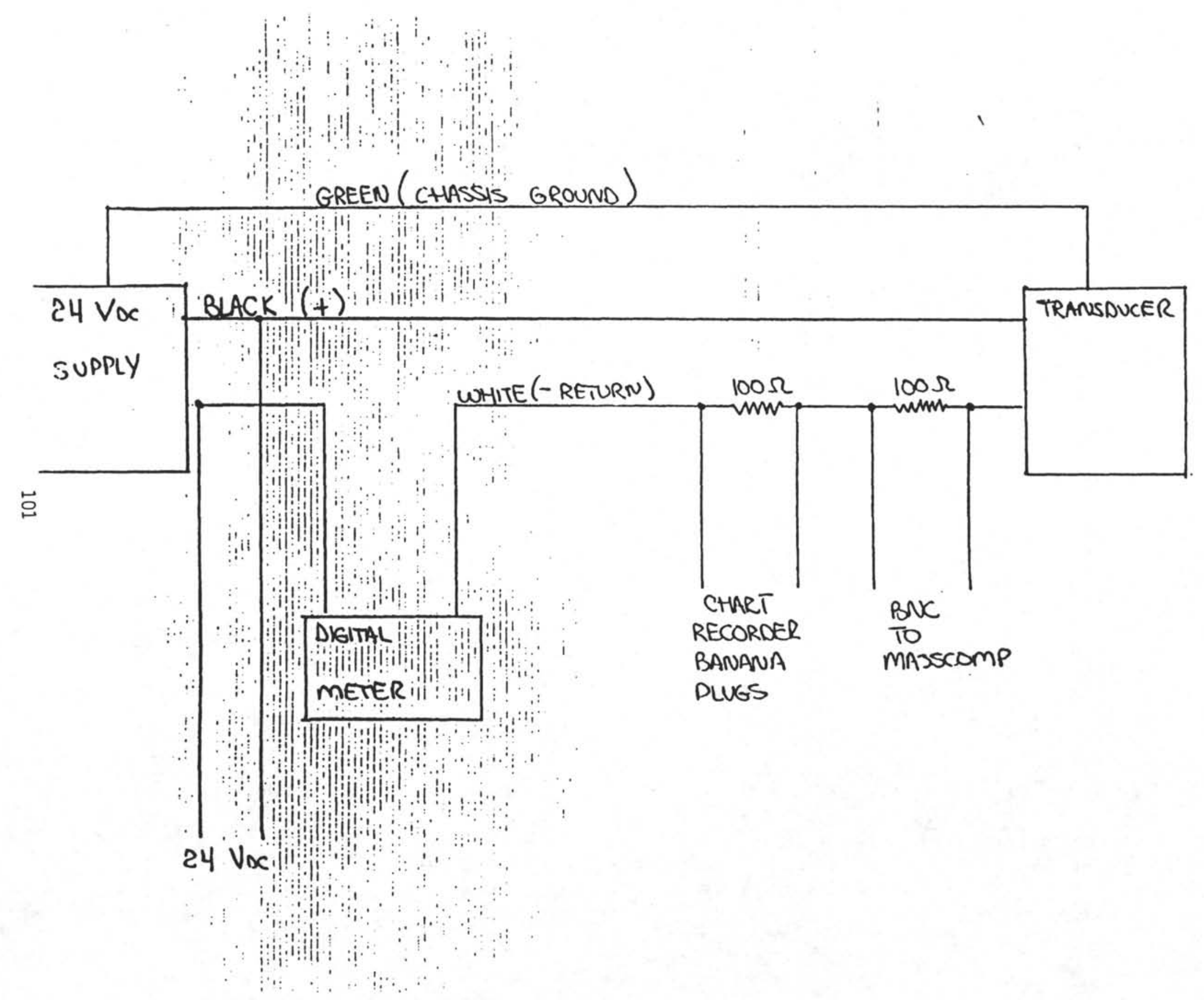




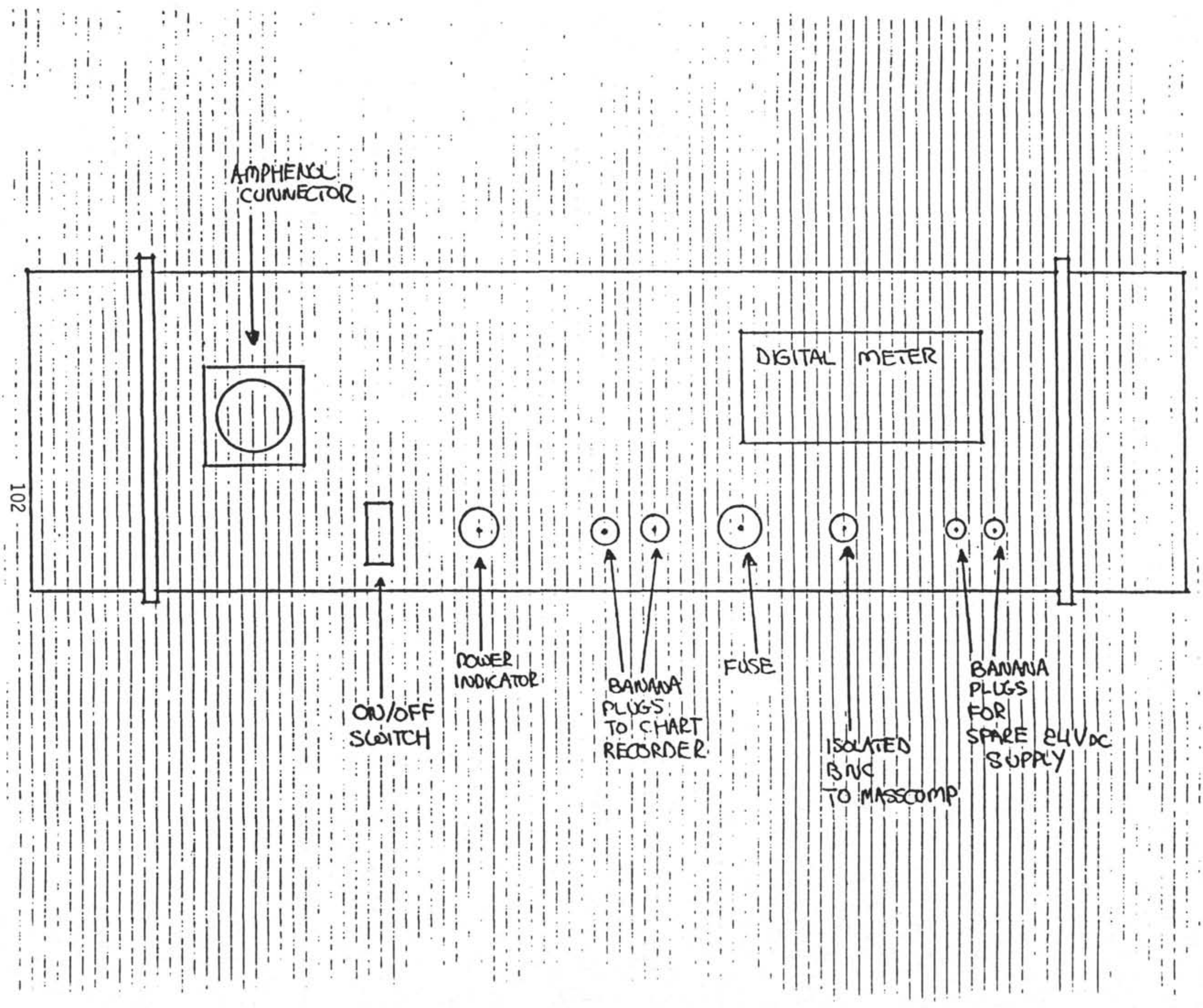




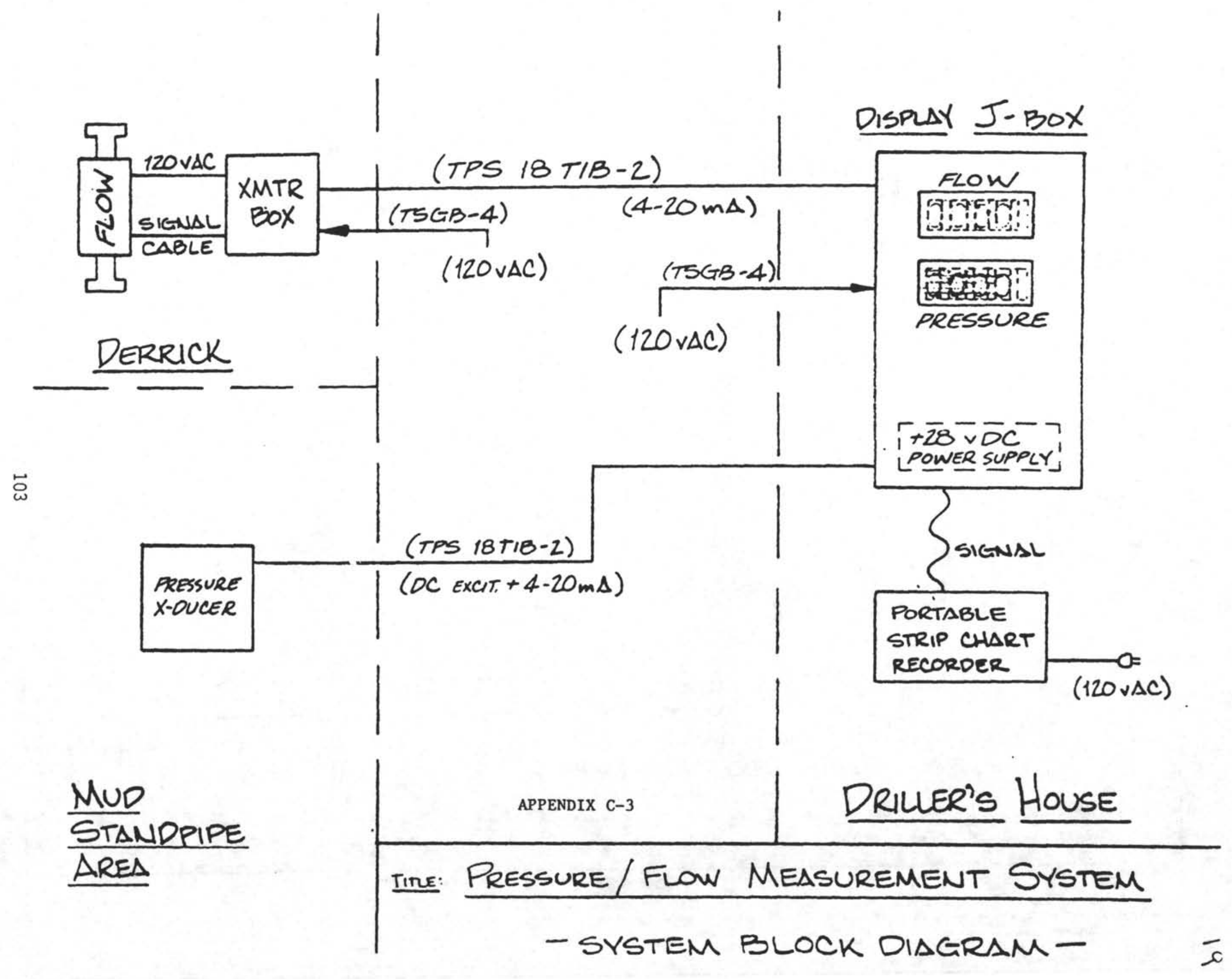




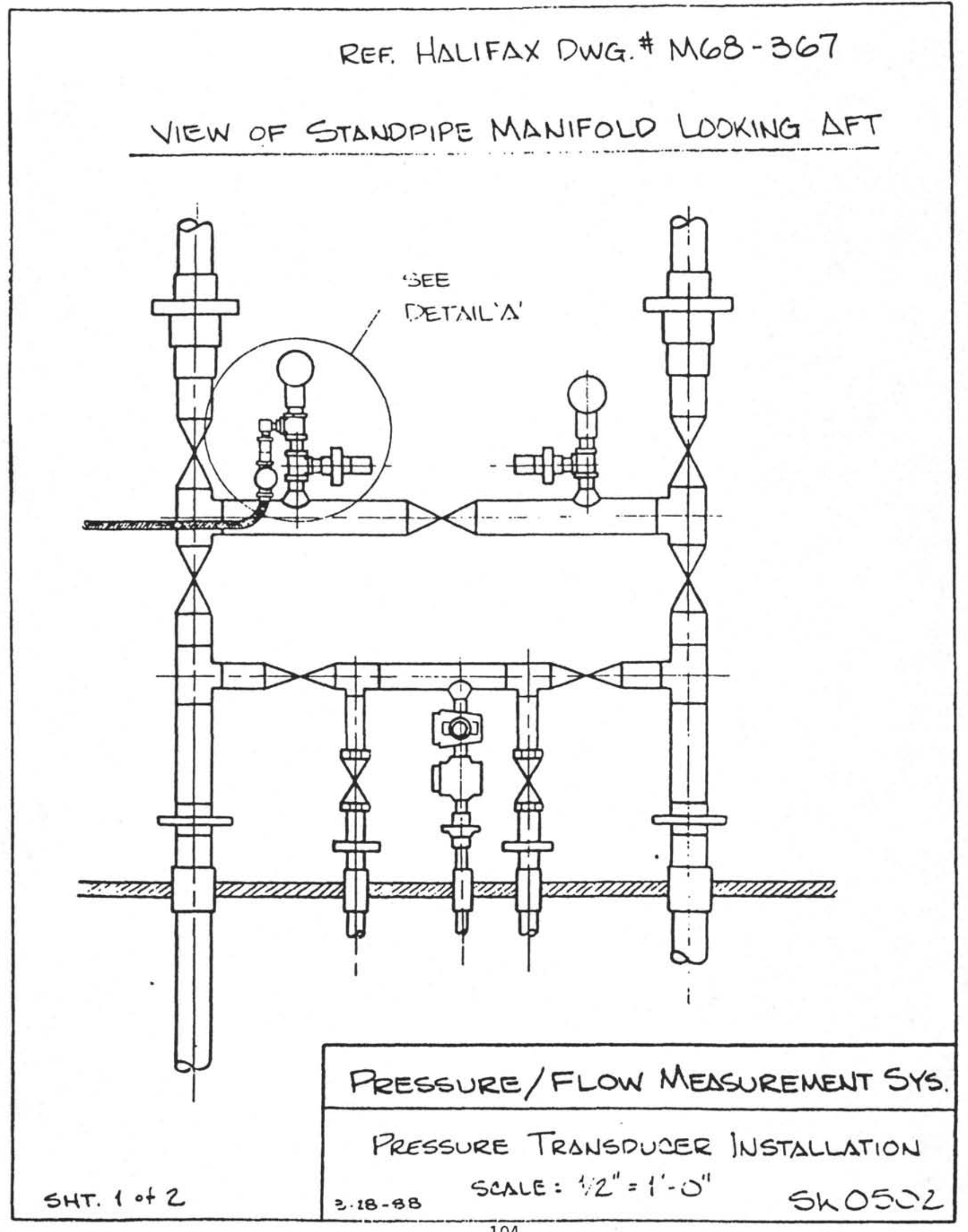


JOTES:

1) ALL NEW (N) HYDRAULIC FITTINGS $\triangle R E 6000$ PSI WIP.

2) ALL ELECTRICAL ITEMS ARE CERTIFIED SUITABLE FOR CLASS I, DIV. 1, GROUPS C AND $D$.

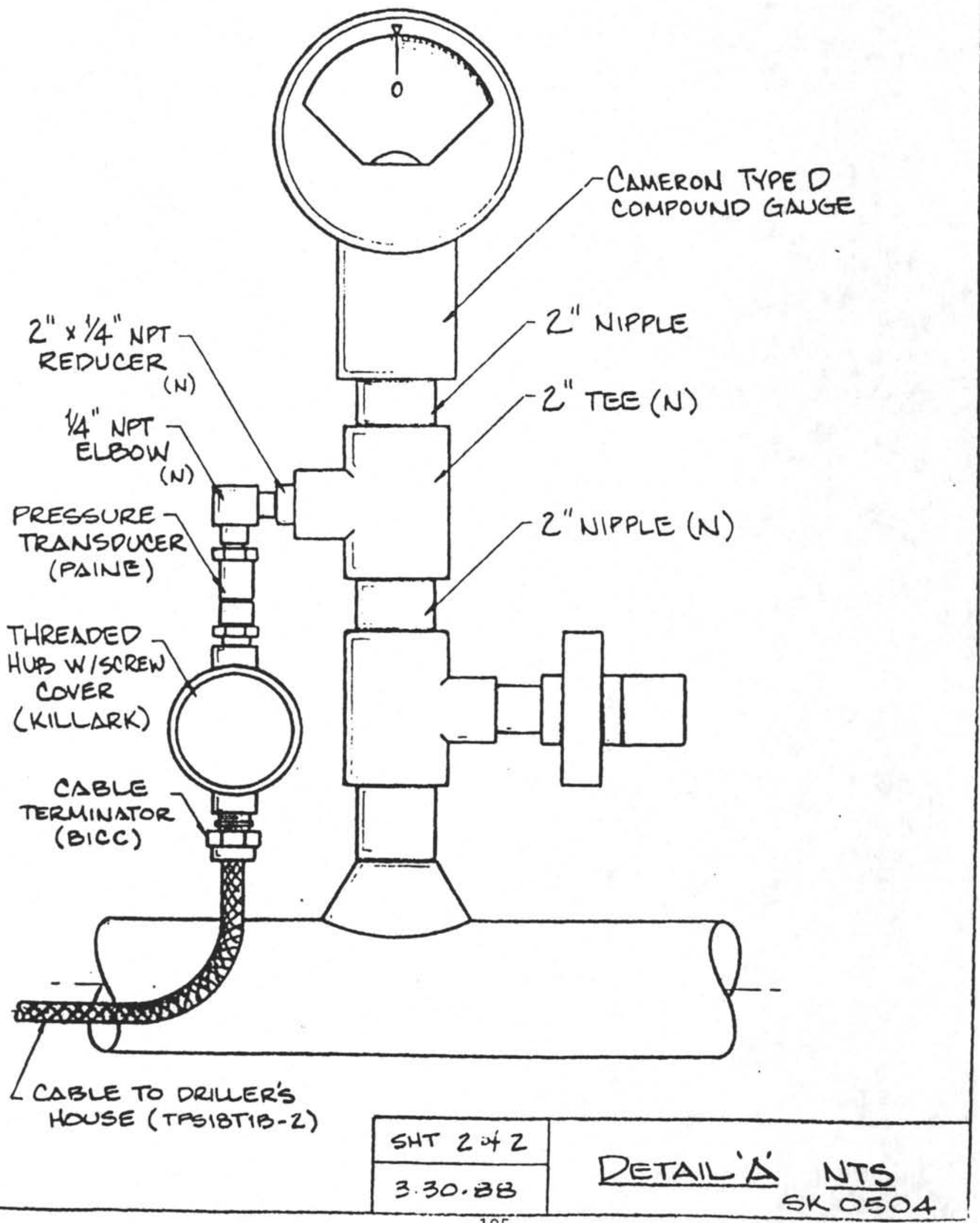




\section{APPENDIX D. INSTALLATION INSTRUCTIONS AND LISTINGS OF PACKER DATA PROCESSING PROGRAMS}

Three programs are supplied to process pressure data collected during formation testing using a packer:

(1) KUSTER.FOR -- Converts a file of up to $1000 \mathrm{x}-\mathrm{y}$ readings from a Kuster pressure recorder to a second file of time-pressure. It prompts the user for the files to use for input and output, and for the conversion factors to obtain time and pressure from $\mathrm{x}$ and y. As it ends, it calls GRAPHER for a display of time-pressure data written to a third file only for GRAPHER.

(2) SLUG.FOR -- Processes individual files containing up to 200 time-pressure readings per slug test, to estimate permeability by the type-curve-fitting method of Bredehoeft and Papadopulos (1980). It allows the data to be corrected for the effects of previous tests, and then fits the corrected data against the $\mathrm{F}$ (alpha,beta) function described by Cooper et al. (1967) and Bredehoeft and Papadopulos (1980). It uses GRAPHER for interactive curve-fitting, prompts the user for input and output filenames and all input parameters, and also writes several files used by GRAPHER to display the data.

(3) INJECT.FOR -- Processes individual files containing up to 200 time-pressure readings per constant-rate injection test, to estimate permeability from the linear segment of a semi-log plot of pressure vs. time. Like SLUG.FOR, it allows the data to be corrected for the effects of previous tests and prompts the user for input and output files and all input parameters. It also uses GRAPHER for graphic data manipulation via the LP77 toolkit CALL SYSTEM, and writes several files used by GRAPHER.

These programs were written in FORTRAN for use on IBM PC compatibles, and were compiled and linked using Lahey F77L or LP77 and the Lahey linker. The programs call the PC scientific graphics package GRAPHER, doing so via a CALL SYSTEM supplied in the LP77 toolkit. The programs and GRAPHER will run much faster with a math coprocessor; if a co-processor is not installed, it is possible that the packer programs will need to be recompiled specifying use without a co-processor. 


\section{SIMPLE INSTALLATION INSTRUCTIONS \\ (for IBM-PC-compatibles)}

Copy all of the files in the lexecute directory into the directory from which you wish to work.

There are three .EXE files -- KUSTER.EXE, SLUG.EXE, AND INJECT.EXE -- all of which contain system calls to GRAPHER. Therefore you must either:

(1) Copy GRAPHER.EXE and PLOT.EXE into the work directory, OR

(2) Change the 'PATH' statement in AUTOEXEC.BAT to include the directory in which GRAPHER.EXE resides, OR

(3) (a) Edit four FORTRAN source files -- KUSTER.FOR, VIEWTP.FOR, VIEWSLUG.FOR, and VIEWINJ.FOR -- to include the full path where the code now reads: call system ('GRAPHER').

(b) Then recompile with LP77 and relink using the *.LNK files in the lsource directory on this diskette.

Contents of lexecute directory:

\begin{tabular}{|c|c|}
\hline USTER.EXE & -- converts Kuster readings to time-pressure \\
\hline LUG.EXE & -- processes slug test data for permeability \\
\hline INJECT.EXE & -- processes injection test data for perm. \\
\hline FAB.FIL & $\begin{array}{l}\text {-- listing of F(alpha,beta) data } \\
\text {-- needed by SLUG.EXE }\end{array}$ \\
\hline LP77.CER & -- file of runtime error messages (if needed!) \\
\hline \multicolumn{2}{|c|}{ CENTERED.SYM -- GRAPHER centered symbols } \\
\hline SET1.SYM & -- GRAPHER character set (English) \\
\hline SET2.SYM & -- GRAPHER character set (Greek) \\
\hline GR_KUS.GRF & -- template for time-pressure GRAPHER graph \\
\hline GR_TP.GRF & -- template for time-pressure GRAPHER graph \\
\hline GR_TP.DAT & -- time-pressure data file written for GRAPHER \\
\hline GR_SLUG.GRF & -- template for slug test GRAPHER graph \\
\hline GR_SLUG.DAT & -- slug test data file written for GRAPHER \\
\hline GR_SHB.DAT & -- data file written for GRAPHER in GR_SLUG.GRF \\
\hline GR_SHIFT.DAT & -- data file written for GRAPHER in GR_SLUG.GRF \\
\hline GR_INJ.GRF & -- template for injection test GRAPHER graph \\
\hline GR_INJ.DAT & -- injection test data file written for GRAPHER \\
\hline GR_LINJ.DAT & $--2 n d "$ \\
\hline
\end{tabular}




\section{SIMPLE RECOMPILING/LINKING INSTRUCTIONS}

The executable files were produced using the LP77 FORTRAN compiler, the Lahey linker, and the LP77 toolkit library. If the executables need to be reconstructed, the *.FOR files in the lsource directory should be recompiled using LP77. The *.OBJ files can be linked using the Lahey linker or MS linker using the *.LNK files in the lsource directory.

$\mathrm{OR}$, the programs can be compiled and linked using F77L, which contains the required system call within its own library (i.e., toolkit is not needed).

Contents of Source directory

$\begin{array}{ll}\text { KUSTER.FOR } & \text {-- program for converting Kuster chart } x-y \text { data to time-pressure } \\ \text { KUSTER.LNK } & \text {-- linker command file to make kuster.exe } \\ \text { SLUG.FOR } & \text {-- driver program for slug test processing } \\ \text { SLUGFIT.FOR } & \text {-- main algorithms for determining permeability from slug tests } \\ \text { SLUG.LNK } & \text {-- linker command file to make SLUG.EXE } \\ \text { INJECT.FOR } & \text {-- driver program for injection test processing } \\ \text { INJFIT.FOR } & \text {-- main algorithms for determining permeability from injection tests } \\ \text { INJECT.LNK } & \text {-- linker command file to make INJECT.EXE } \\ \text { PAKRSUBS.FOR -- subroutines used by both SLUG.EXE and INJECT.EXE } \\ \text { LP77.CER } & \text {-- LP77 compiler error message }\end{array}$




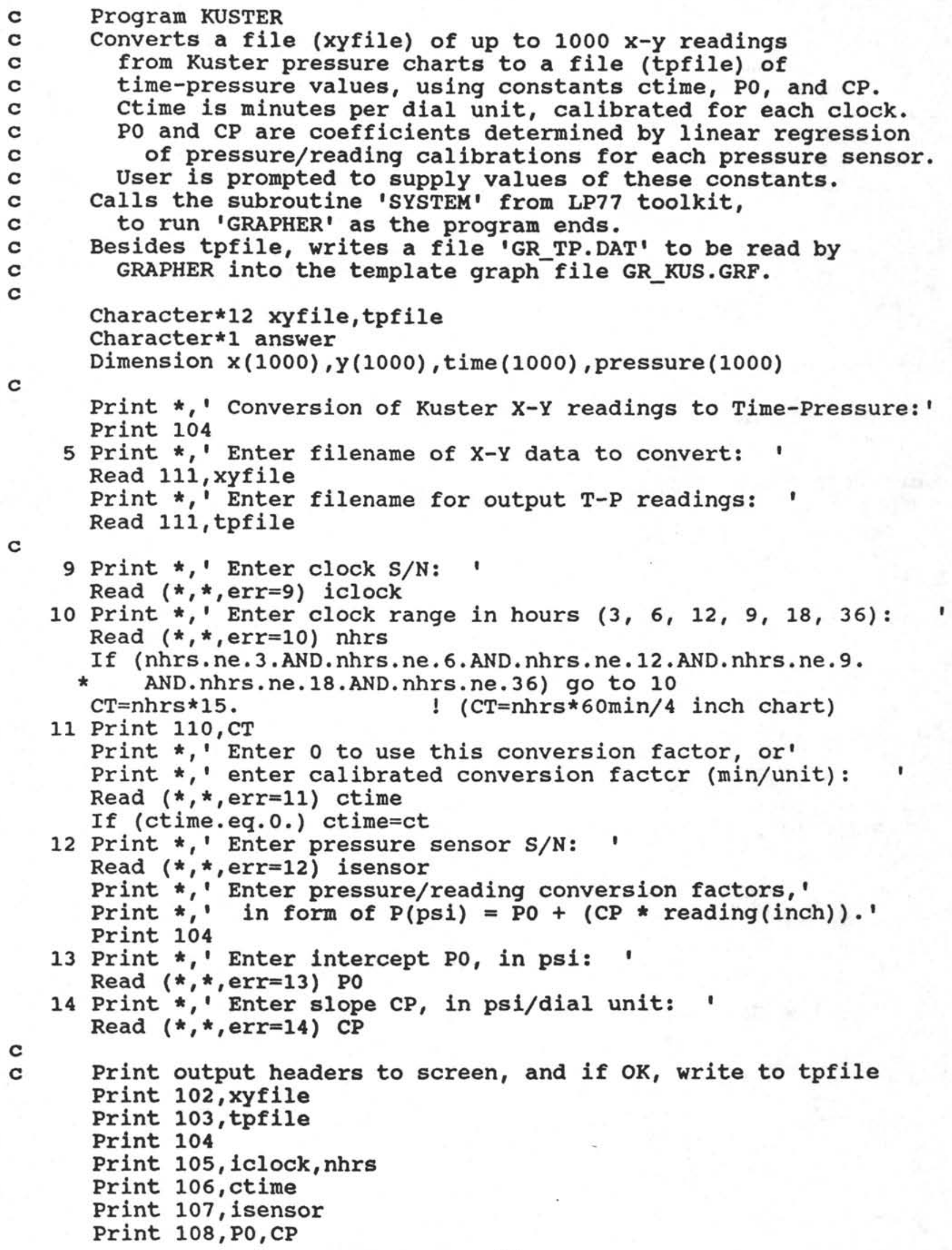


Print 104

15 Print *,' Are these parameters correct ? $(\mathrm{y} / \mathrm{n})$ '

Read 112, answer

If (answer.eq.' $n$ '.oR.answer.eq.' $N$ ') then go to 5

Elseif (answer.eq.' $y$ '.oR.answer.eq.' $y$ ') then

Else go to 18

go to 15

Endif

C

18 Print *,' Now converting Kuster $x-y$ data to time-pressure...' Print 104

19 Open $(2$, file=tpfile, status=' new' , err=21) Go to 25

21 print *,' WARNING -- ',tpfile,' already exists and will be lost!'

22 print *,' Write over ',tpfile,' ? (y/n) ' read 112 , answer

if (answer.eq.' $y$ '.oR.answer.eq.' $Y$ ') then open $(2, f i l e=t p f i l e)$ go to 25

elseif (answer.eq.'n'.oR.answer.eq.'N') then print *,' Enter new output filename: ' read 111, tpfile

else go to 19

go to 22

endif

C

25 Write $(2,102)$ xyfile

Write $(2,104)$

Write $(2,105)$ iclock, nhrs

Write $(2,106)$ ctime

Write $(2,107)$ isensor

Write $(2,108)$ PO, CP

Write $(2,104)$

Write $(2,109)$

Write $(2,104)$

C

C

Convert $x-y$ data and write $x, y, t$, and $p$ to two files,

(1) tpfile and

(2) gr_tp.dat, a headerless copy for display with Grapher

26 Open $(1, \bar{f}$ ile $=x y$ file, status $=$ 'old', err $=27)$ go to 28

27 print *,' WARNING -- ',xyfile,' does not exist !' print *,' Enter name of input time-pressure data file: ' read 111, tpfile

go to 26

28 Open $(3$, file='gr_tp.dat')

ndata $=0$

Do $30 I=1,1000$

Read $(1, *$, end $=35) \times(i), y(i)$

C

Convert $x$ (dial reading) to time (hrs) 


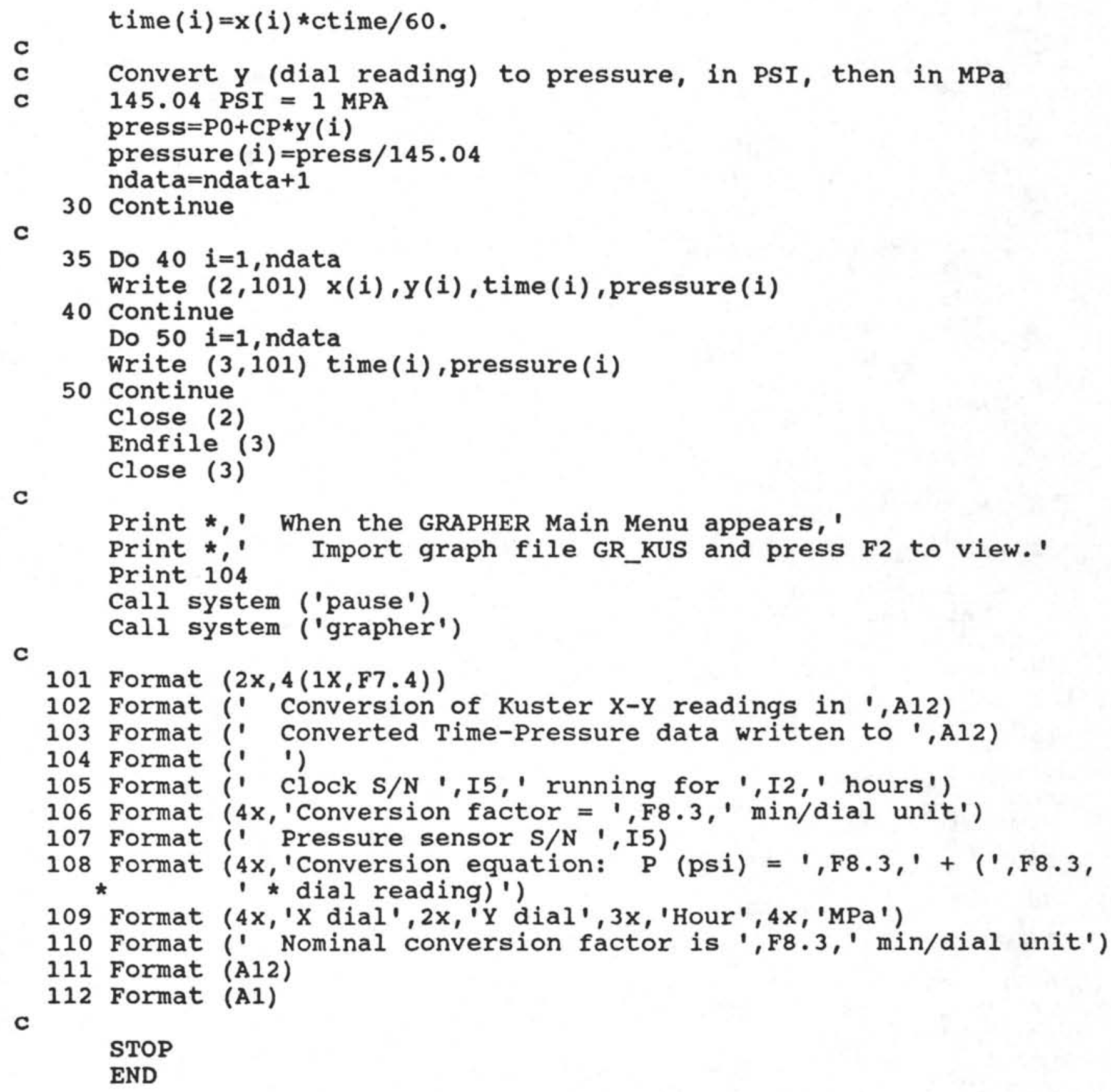




\section{program SLUG}

$c$

c C C c

Driver program for processing slug test data to determine permeability by method of Bredehoeft and Papadopulos (1980). Prompts user for all necessary input data, with error control. Reads input file tpfile with up to 200 time-pressure data, and writes processing results to outfile (unit 3 ).

\section{CALLS :}

CORRECTP, which calls:

READFAB (an entry point in GETFAB) SPLINE

EVAL (function)

VIEWTP, which calls:

SYSTEM (from LP77TOOL.LIB) to rUn PAUSE and GRAPHER

SLUGFIT, which calls:

GETFAB

SPLINE

EVAL (function)

VIEWSLUG, which calls

SYSTEM (from LP77TOOL.LIB) to rUn PAUSE and GRAPHER

Programmed by Keir Becker, summer, 1989.

As installed in June 1989, all the required subroutines (except SYSTEM) are in two files: SLUGFIT.FOR and SLUGSUBS.FOR. To make SLUG.EXE, compile SLUG.FOR, SLUGFIT.FOR, and SLUGSUBS.FOR with LP77, and link SLUG+SLUGFIT+SLUGSUBS with LP77TOOL.LIB.

character*1 answer

character* 4 hole

character $* 12$ tpfile, outfile

dimension time (200), pressure (200), corpress (200)

dimension pscale(200), tlog(200)

Get initial parameters

Tpfile is input file of slug test time-pressure data.

newfile $=1$

print $*, '$ print 101 print *, print *, print $*, "$ print $*, "$ print $*, '$ print 101 print *,' print 101 print *,' Now recording basic information needed' print $*, '$ to reduce slug test pressure-time data.' print 101

\section{$\star \star \star \star * \star$ Slug Test Processing $* * \star \star *$ '}

Before running this program:'

(1) convert Kuster $x-y$ data to time-pressure,' by running KUSTER program, and'

(2) edit time-pressure data to individual files' each containing data from a single slug test.'

To abort this program, enter ctrl-c at any prompt.'

10 print *,' Enter leg number: ' read $(*, *$, err $=10)$ leg print *,' Enter hole number: ' 
read 91 , hole

11 npermcalc $=0$

12 print *,' Enter slug test number: ' read $(*, *$, err $=12)$ ntest

print *,' Enter name of input time-pressure data file: ' read 92, tpfile

if (newfile.eq.0) go to 13

print *,' Enter filename for processed slug test data: '

C

read 9.2 , outfile

13 print 101

print 93, leg, hole

print 97, ntest

print 94,tpfile

print 95 , outfile

print 101

14 print *,' Are these parameters correct ? $(\mathrm{y} / \mathrm{n})$ '

read 96 , answer

if (answer.eq.' $Y$ '.OR.answer.eq.' $Y$ ') then go to 20

elseif (answer.eq.'n'.oR.answer.eq.'N') then

else go to 10

endif

c

C

c

c

Read input time-pressure data from tpfile, checking that it actually exists.

20 open $(1$, file=tpfile, status='old', err $=24)$

$n t p=0$

do $22 i=1,200$

read $(1, *$, end $=25)$ time(i),pressure (i)

corpress $(i)=$ pressure $(i)$

$n t p=n t p+1$

22 continue

go to 25

24 print *,' WARNING -- ',tpfile,' does not exist !'

print *,' Enter name of input time-pressure data file: '

read 92, tpfile

go to 20

25 close (1)

C

C

C

C

if (newfile.eq.0) go to 27

26 open $(3$, file=outfile, status ='new', err $=28)$

27 write $(3,101)$

write $(3,120)$ leg, hole, ntest

write $(3,101)$

go to 30

28 print *,' WARNING -- ',outfile,' already exists and will be lost!'

29 print *,' Write over ',outfile,' ? $(y / n)$ 


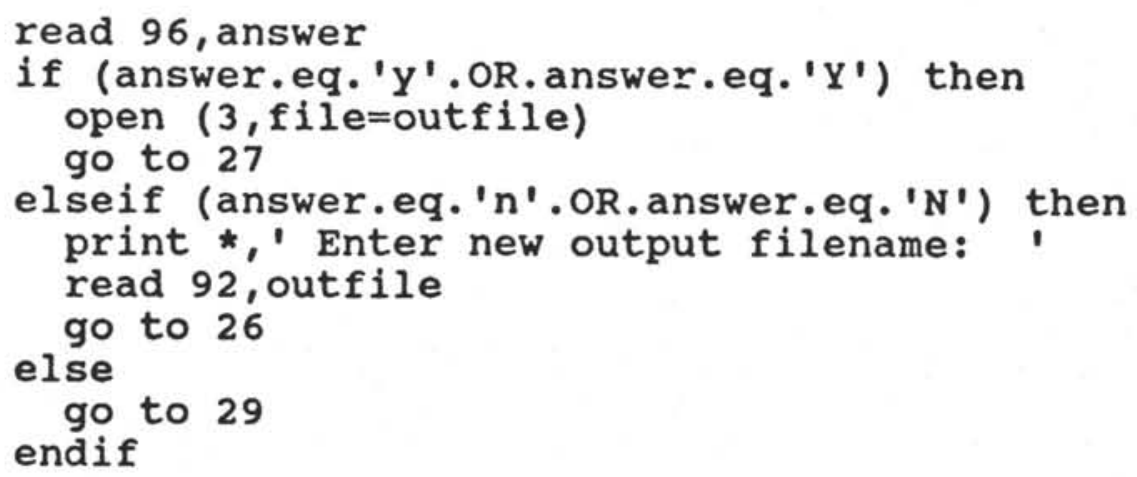

C

C

C

C

C

C

C

C

Correct measured pressures for hydrostatic and previous testing. $30 \mathrm{Call}$ correctp (ntp,time, corpress)

Pick a tentative origin (time(ito)) and end (time(its)) for the slug test. Pick the origin as the latest time at which the maximum corrected pressure occurs, and pick the end time as the latest time after the slug at which the minimum corrected pressure occurs.

pressmax $=0$.

pressmin $=10$.

do $32 j=1$, ntp

if (corpress $(j) \cdot g e \cdot p r e s s m a x)$ then

it $0=j$

pressmax $=\operatorname{corpress}(j)$ endif

continue

do $33 j=1$, ntp

if (j.gt.ito.AND.corpress $(j) \cdot l e \cdot p r e s s m i n)$ then it $s=j$

pressmin $=$ corpress $(j)$

endif

C

C

C

C

C 


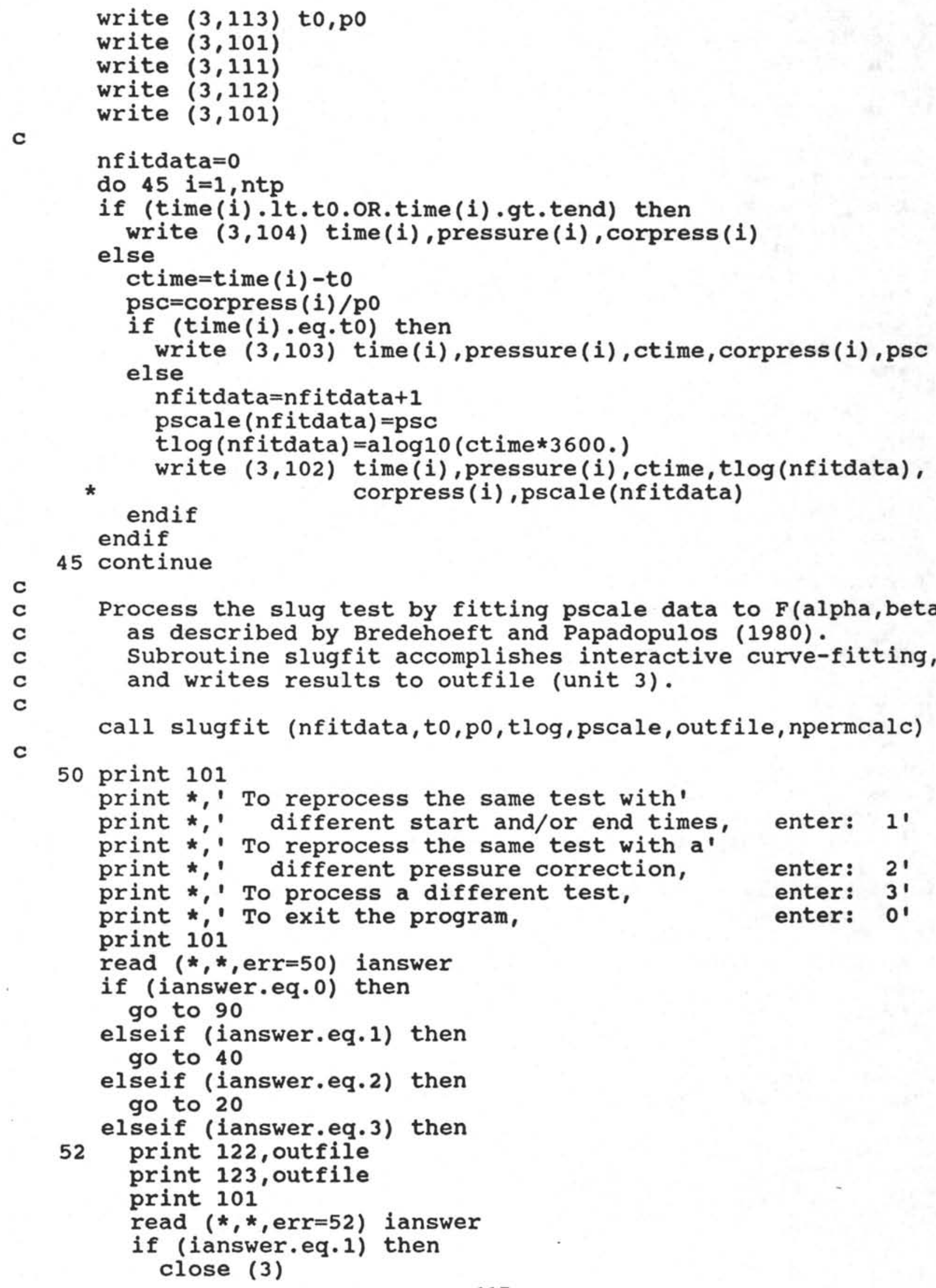

C

C

C

c

C

C

C

50 print 101

print *,' To reprocess the same test with'

print *,' different start and/or end times, enter: 1'

print *,' To reprocess the same test with a'

print *, different pressure correction,

print $*, '$ To process a different test,

print *,' To exit the program,

print 101

read $(*, *$, err $=50)$ ianswer

if (ianswer.eq.0) then go to 90

elseif (ianswer.eq.1) then go to 40

elseif (ianswer.eg.2) then go to 20

52 print 122, outfile

print 123, outfile

print 101

read $(*, *$, err $=52)$ ianswer

if (ianswer.eq.1) then

close (3) 


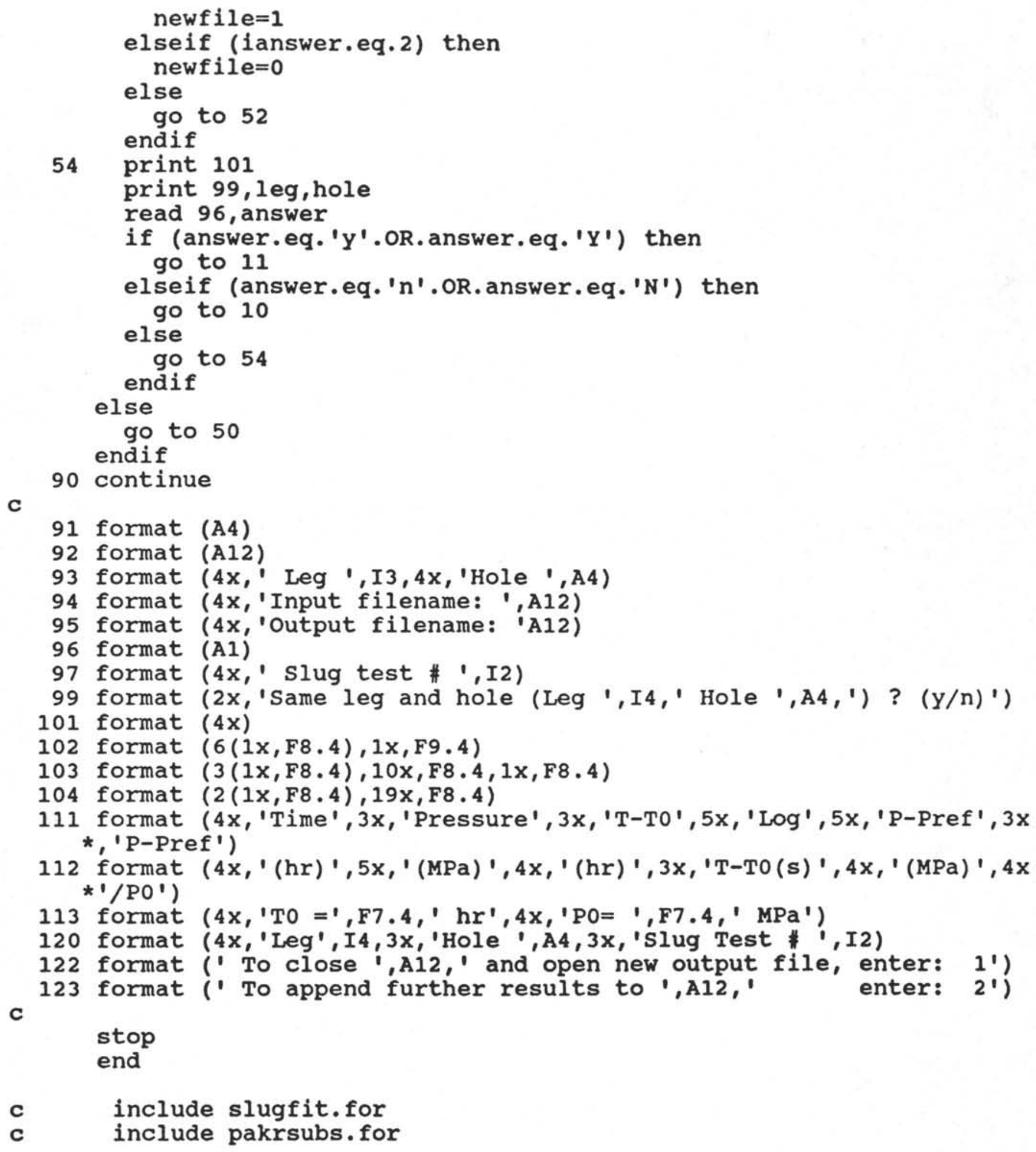


subroutine slugfit (nfit,to,po,tlog,pscale, outfile, ncalc)

Fits scaled pressure data from slug test to Bredehoeft and Papadopulos (1980) F(alpha, beta) function, and then calculates permeability and transmissivity. Prompts user for all necessary input, with error control.

CALLS:

GETFAB

SPLINE

EVAL (function)

VIEWSLUG, which calls:

SYSTEM (from LP77TOOL.LIB) to run GRAPHER

character*1 answer

character*12 outfile

dimension pscale(nfit), tlog(nfit)

dimension beta(49), fab(49), s(49), a (49)

c

C

C

C

C

C

C

C

C

C

C

C

C

c

c

c

C

c

c

C

c

c

C

Permeability calculation parameters (used after 75): comp = compressibility of fluid in pressurized zone $(m * * 2 / \mathrm{N})$

visc $=$ viscosity of fluid in pressurized zone $(\mathrm{N}-\mathrm{s} / \mathrm{m} * * 2)$

grav = gravitational acceleration $(\mathrm{m} / \mathrm{s} * * 2)$

dens $=$ density of fluid in pressurized zone $(\mathrm{kg} / \mathrm{m} * * 3)$

trans $=$ transmissivity of formation $(m * * 2 / s)$

perm $=$ permeability of formation $(m * \star 2)$

data grav $/ 9.81 /$, dens $/ 1045 . /, \mathrm{csw} / 4.2 \mathrm{E}-10 /, \mathrm{pi} / 3.1415962 /$

print *,' Now beginning iterative, graphic fitting of '

print *,'scaled slug test data to F(alpha,beta) type curves,' print $*, '$ by shifting the type curve along the log beta axis.' print 101

First choose the value of alpha

alpha $=0$.

58 call getfab (alpha, beta, fab)

print 101

print $\star, '$ Finding time shift for best curve fit,'

print $*$, and preparing to plot best fit...'

Then calculate the time shift that brings the dimensionless type curve to the best fit with the data. The calculated transmissivity and permeability are directly proportional to this shift.

Set up cubic spline interpolation

Interpolation of $F$ over 6 orders of magnitude in beta is more convenient and accurate in log beta coordinates.

do $59 i=1,49$

$\operatorname{beta}(i)=\operatorname{alog} 10(\operatorname{beta}(i))$

59 continue 
C

61

63$$
\text { C }
$$

call spline $(49$, beta, fab, s, a)

Scan through possible values of shift to find the value that minimizes the residual error between data and shifted fab. (With time converted to seconds, shift always positive, <6.) Finds shift to nearest hundredth.

referror $=10$.

do $62 i=1,51$

shift $1=(i-1) * 0.1$

error $=0$.

do $61 j=1$, nfit

shtlog=tlog $(j)-$ shift 1

efab=eval (shtlog, 49 , beta, fab, s)

error $=\operatorname{error}+(\operatorname{pscale}(j)-e f a b) * \star 2$

continue

if (error.lt.referror) then

referror=error

shift2=shift 1

endif

62 continue

do $64 i=1,41$

shift $3=\operatorname{shift} 2+(i-21) * 0.01$

error $=0$.

do $63 j=1$, nfit

sht $\log =t \log (j)-\operatorname{shift} 3$

efab=eval (shtlog, 49 , beta, fab, s)

error $=$ error $+($ pscale $(j)-e f a b) * \star 2$

$$
\text { continue }
$$

if (error.1t.referror) then

referror=error

shift=shift 3

endif

64 continue

view the curve fit.

70 call viewslug (nfit,beta, fab,tlog,pscale, shift)

If curve fit is acceptable, calculate permeability.

otherwise, adjust parameters for better fit.

print 114 , alpha

print 115, shift

print 101

71 print *,'To accept this fit and calculate permeability,

72 print *,'To change the shift of the type curve,

print *,'To change the type curve, i.e. alpha,

print *,'To quit curve-fitting these data, and either'

print $*, "$ reprocess this slug test or process another, enter: $0^{\prime}$ print 101

read $(*, *$, err $=71)$ ianswer

if (ianswer.eq.1) then

enter: 1'

enter: 2' enter: $3^{\prime}$ 


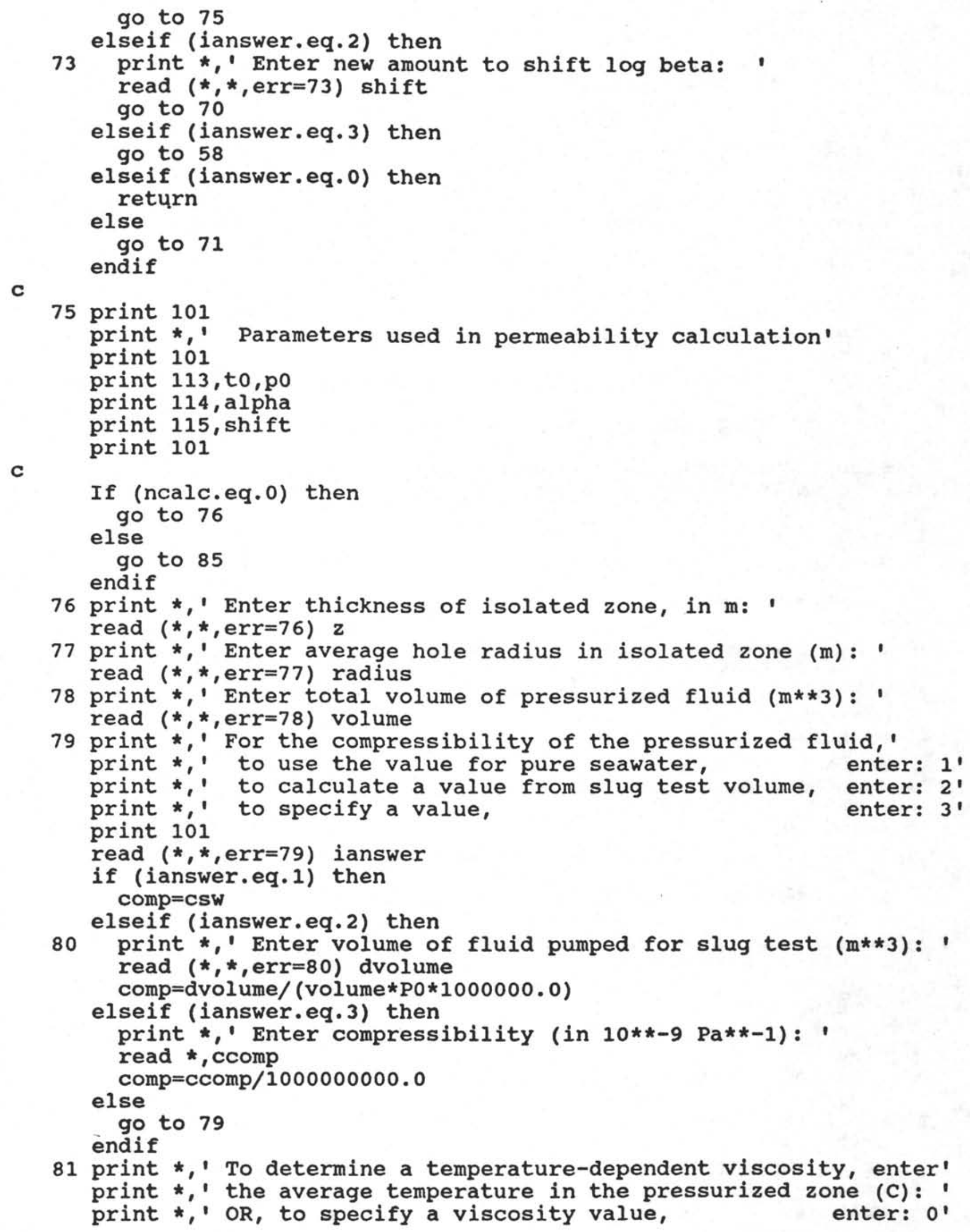

77 print *,' Enter average hole radius in isolated zone (m): ' read $(*, *$, err $=77)$ radius

78 print *,' Enter total volume of pressurized fluid $(m * * 3)$ : ' read $(*, *$, err $=78)$ volume

79 print *,' For the compressibility of the pressurized fluid,'

print *,' to use the value for pure seawater, enter: 1' print *,' to calculate a value from slug test volume, enter: $2^{\prime}$ print *,' to specify a value, enter: $3^{\prime}$ print 101

read $(*, *$, err $=79)$ ianswer

if (ianswer.eq.1) then comp $=c s w$

elseif (ianswer.eq.2) then

80 print *,' Enter volume of fluid pumped for slug test (m**3): ' read $(*, *$, err $=80)$ dvolume comp $=$ dvolume $/($ volume* $P 0 * 1000000.0)$

elseif (ianswer.eq.3) then

print *,' Enter compressibility (in 10**-9 $\mathrm{Pa} *-1$ ): ' read *, ccomp

else comp $=$ ccomp $/ 1000000000.0$

endif

81 print *,' To determine a temperature-dependent viscosity, enter' print $*, '$ the average temperature in the pressurized zone (C): ' print *,' OR, to specify a viscosity value,

enter: $0^{\prime}$ 
print 101

read $(*, *, e r r=81)$ temp

if (temp.eq.0.) then

82 print *, Enter viscosity, in $\mathrm{Pa}-\mathrm{s}$ : ' read $(*, *, e r r=82)$ visc

else

visc $=0.01668 /$ temp $* * 0.8987$

endif

85 print 101

print $116, \mathrm{z}$

print 117 , radius

print 118 , volume

print 119, comp

if (temp.ne.0) print 120,temp

print 121, visc

86 print 101

print *,' Use these values to calculate permeability ? $(\mathrm{y} / \mathrm{n})$ ' read 100 , answer

if (answer.eq.' $Y$ '.OR.answer.eq.' $Y$ ') then go to 90

elseif (answer.eq.'n'.OR.answer.eq.' $N$ ') then

else

go to 76

go to 86

endif

C

C

C

90 timeshift $=10 . * *$ shift

trans $=$ volume $*$ comp $*$ dens $* g r a v /(p i * t i m e s h i f t)$

perm $=$ volume*comp*visc/ $(z * p i * t i m e s h i f t)$

ncalc $=$ ncalc +1

print 101

print 122 , trans

print 123, perm
C

91 print 101

print $*, '$ Write these results to file ',outfile,' ? ( $y / n)$ ' read 100 , answer

if (answer.eq. ' $Y$ '.oR.answer.eq.' $Y$ ') then go to 92

elseif (answer.eq.'n'.OR.answer.eq.'N') then

print 114, alpha

print 115, shift

print 101

go to 72

else

go to 91

endif

92 write $(3,101)$

write $(3,101)$

write $(3,124)$ ncalc

write $(3,101)$

write $(3,113)$ to,po 


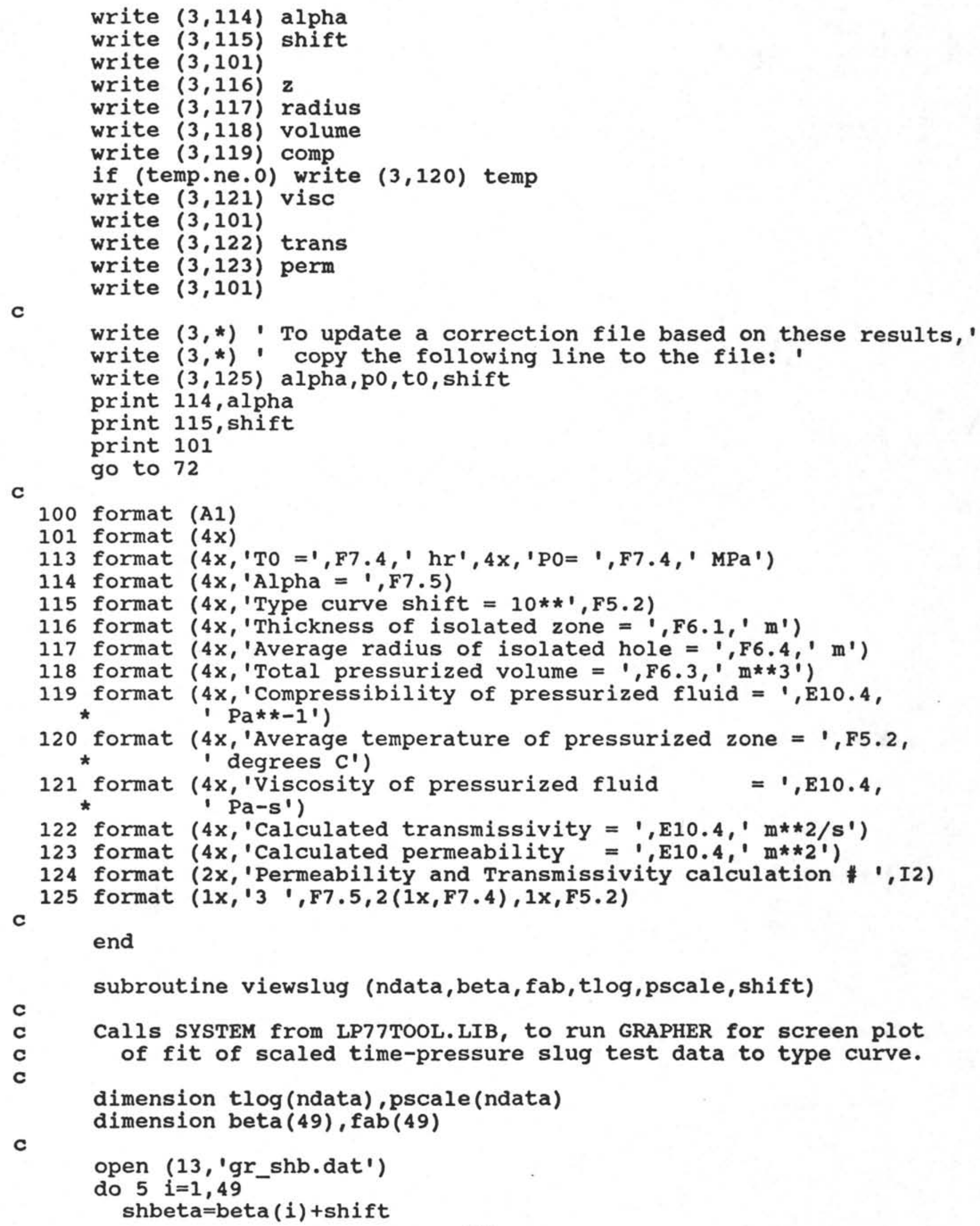




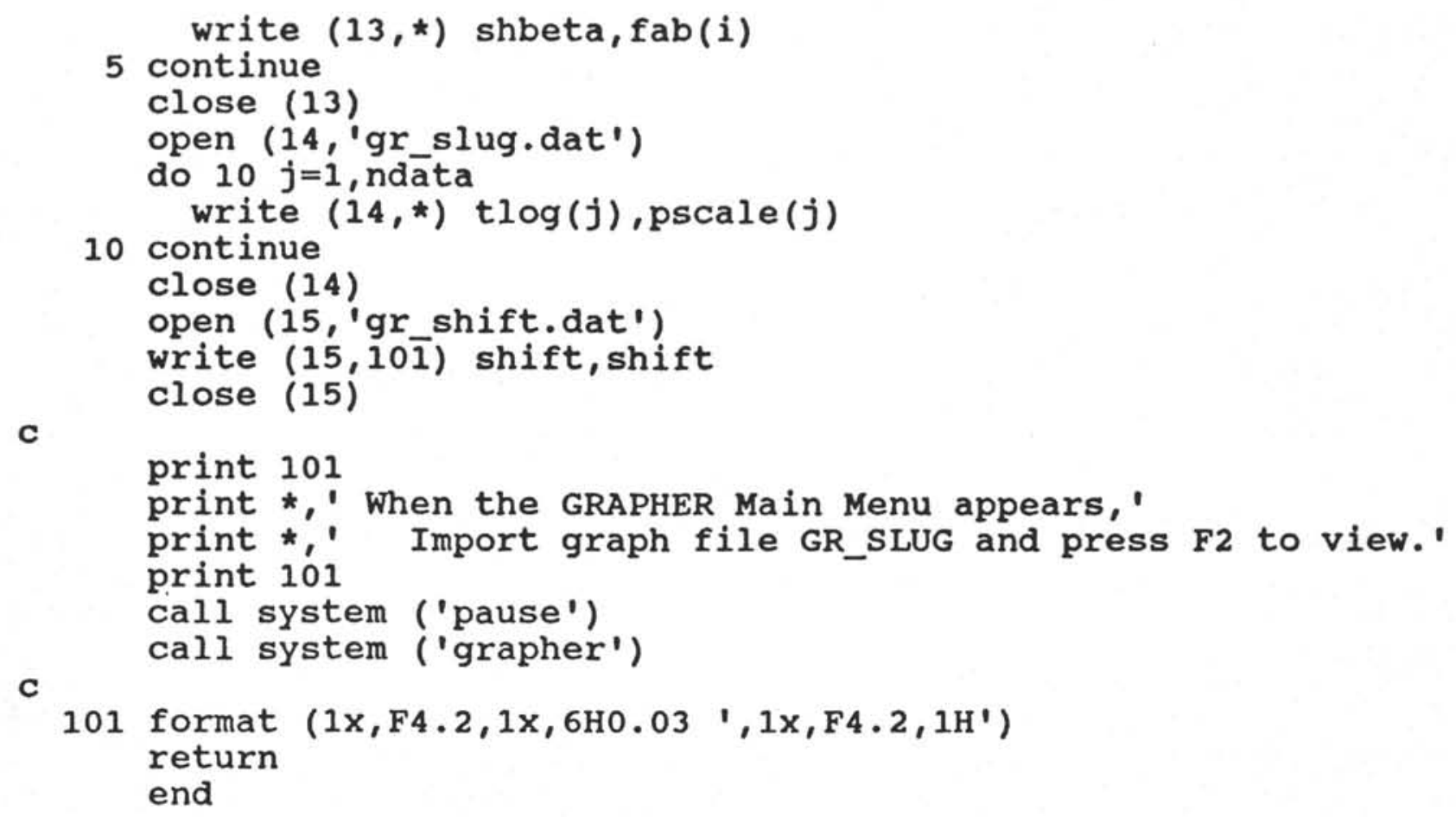




\section{program INJECT}

C

C

C

C

C

C

C

C

C

C

C

C

c

c

c

C

C

C

C

C

C

C

C

C

C

C

Driver program for processing injection test data as an infinite line source to determine permeability.

Prompts user for all necessary input data, with error control.

Reads input file tpfile with up to 200 time-pressure data, and writes processing results to outfile (unit 3 ).

\section{CALLS :}

CORRECTP, which calls:

READFAB (an entry point in GETFAB)

SPLINE

EVAL (function)

VIEWTP, which calls:

SYSTEM (from LP77TOOL.LIB) to run PAUSE and GRAPHER

INJFIT, which calls: VIEWINJ, which calls

SYSTEM (from LP77TOOL.LIB) to rUn PAUSE and GRAPHER LINREG

Programmed by Keir Becker, summer, 1989.

As installed in June 1989, all the required subroutines (except SYSTEM) are in two files: INJFIT.FOR and PAKRSUBS.FOR.

To make SLUG.EXE, compile INJECT.FOR, INJFIT.FOR, and PAKRSUBS.FOR with LP77, and link INJECT+INJFIT+PAKRSUBS with LP77TOOL.LIB.

character*1 answer

character* 4 hole

character*12 tpfile, outfile

dimension time (200), pressure (200), corpress (200)

dimension prinj(200), tscale(200), tlog(200)

Get initial parameters

Tpfile is input file of injection test time-pressure data.

newfile $=1$

print $*, 1$

print 101

print *,

print $\star$,

print $*, 1$

print *,

print $*, 1$

print 101

print $*, 1$

print 101

print $*, 1$ Now recording basic information needed'

print $*, 1$ to reduce injection test pressure-time data.'

10 print 101

$\star * * * *$ Injection Test Processing $* * * * * !$

Before running this program:'

(1) convert Kuster $x-y$ data to time-pressure,' by running KUSTER program, and'

(2) edit time-pressure data to individual files' each containing data from one injection test.'

To abort this program, enter ctrl-c at any prompt.'

11 print $*, 1$ Enter leg number: ' read $(*, *, e r r=11)$ leg

12 print *,' Enter hole number: ' read 91 , hole

13 nkcalc $=0$ 
14 print *,' Enter injection test number: ' read $(*, *$, err $=14)$ ntest

15 print *,' Enter name of input time-pressure data file: ' read 92 , tpfile

if (newfile.eq.0) go to 17

16 print *,' Enter filename for processed injection test data: ' read 92 , outfile

C

17 print 101

print 93,leg, hole

print 97 , ntest

print 94, tpfile

print 95 , outfile

print 101

18 print *,' Are these parameters correct ? $(\mathrm{y} / \mathrm{n})$ '

read 96 , answer

if (answer.eq.' $y$ '.OR.answer.eq.' $Y$ ') then go to 20

elseif (answer.eq.'n'.OR.answer.eq.'N') then

else go to 10

endif

Read input time-pressure data from tpfile, checking that it actually exists.

20 open $(1$, file=tpfile, status='old', err=23)

ntp $=0$

do $22 i=1,200$

read $(1, *$, end $=25)$ time (i),pressure (i)

corpress $(i)=$ pressure $(i)$

$n t p=n t p+1$

22 continue

go to 25

23 print *,' WARNING -- ',tpfile,' does not exist !'

24 print *,' Enter name of input time-pressure data file: ' read 92, tpfile

go to 20

25 close (1)

C

C

Check that output file won't erase an old file, and write headers in output file.

if (newfile.eq.0) go to 27

26 open $(3$, file=outfile, status='new' , err $=28$ )

27 write $(3,101)$

write $(3,120)$ leg, hole, ntest

write $(3,101)$

go to 32

28 print *,' WARNING -- ',outfile,' already exists and will be lost!'

29 print *,' Write over ',outfile,' ? (y/n)

read 96 , answer

if (answer.eq.' $y$ '.oR.answer.eq.' $y$ ') then 


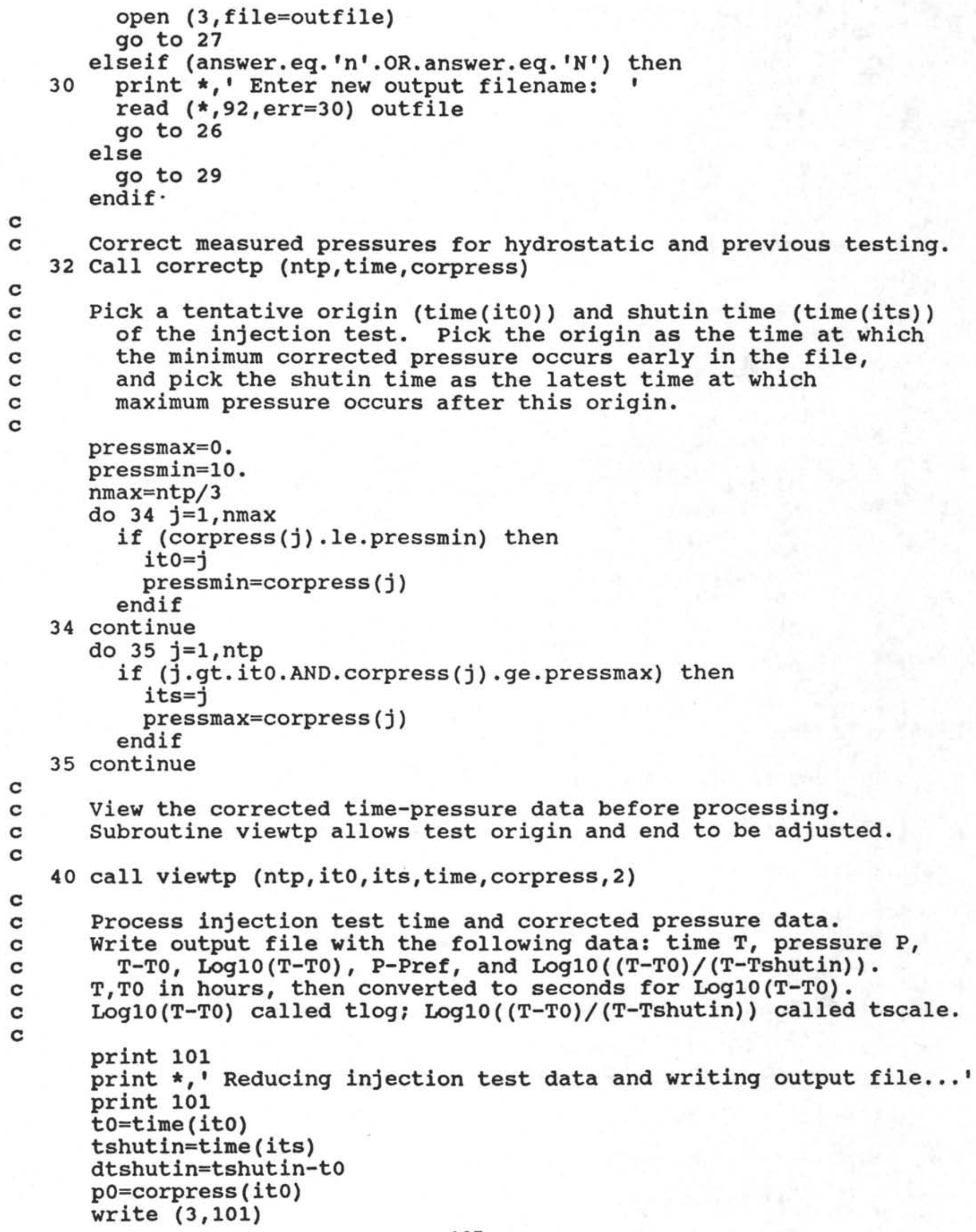

C

C

C

C

c

C

Correct measured pressures for hydrostatic and previous testing.

32 Call correctp (ntp, time, corpress)

Pick a tentative origin (time(ito)) and shutin time (time(its))

of the injection test. Pick the origin as the time at which

the minimum corrected pressure occurs early in the file, and pick the shutin time as the latest time at which maximum pressure occurs after this origin.

pressmax $=0$.

pressmin $=10$.

$n \max =n t p / 3$

do $34 j=1, \operatorname{nmax}$

if (corpress $(j) \cdot$ le.pressmin) then

it $0=j$

pressmin $=$ corpress $(j)$

endif

View the corrected time-pressure data before processing.

subroutine viewtp allows test origin and end to be adjusted.

40 call viewtp (ntp, ito, its, time, corpress, 2 )

Process injection test time and corrected pressure data. Write output file with the following data: time $T$, pressure $P$, $\mathrm{T}-\mathrm{T0}, \log 10(\mathrm{~T}-\mathrm{T} 0), \mathrm{P}-\mathrm{Pref}$, and $\log 10((\mathrm{~T}-\mathrm{T} 0) /(\mathrm{T}-\mathrm{Tsh}$ tin $))$. $\mathrm{T}, \mathrm{TO}$ in hours, then converted to seconds for Log10(T-T0). Log10 (T-T0) called tlog; Log10 ((T-T0)/(T-Tshutin)) called tscale.

print 101

print $\star, '$ Reducing injection test data and writing output file...' print 101 to $=$ time (ito)

tshutin=time (its)

dtshut in=tshutin-to

po $=$ corpress $($ ito $)$

write $(3,101)$ 


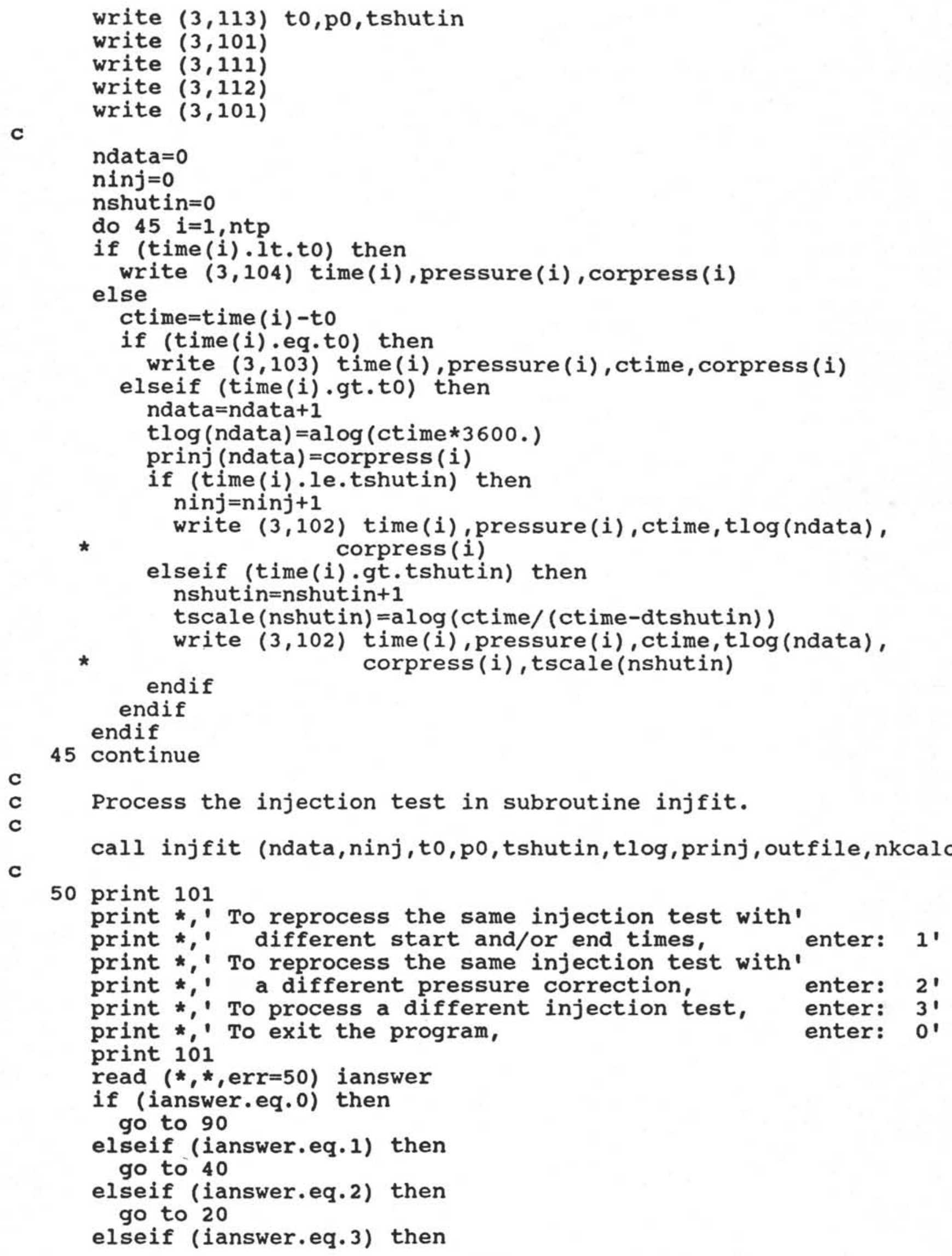

c

c

50 print 101

print *,' To reprocess the same injection test with' print *,' different start and/or end times, enter: 1 ' print *,' To reprocess the same injection test with' print $\star^{\prime}$, a different pressure correction, enter: 2' print *,' To process a different injection test, enter: 3 ' print *,' To exit the program, enter: 0 ' print 101

read $(*, *$, err $=50)$ ianswer

if (ianswer.eq.0) then

go to 90

elseif (ianswer.eq.1) then go to 40

elseif (ianswer.eq.2) then go to 20

elseif (ianswer.eq.3) then 
print 122 , outfile

print 123 , outfile

print 101

read $(*, *$, err $=52)$ ianswer

if (ianswer.eq.1) then

close (3)

newfile $=1$

elseif (ianswer.eq.2) then

newfile $=0$

else

go to 52

endif

54 print 101

print 99, leg, hole

read 96 , answer

if (answer.eq.' $y$ '.OR.answer.eq.' $Y$ ') then go to 13

elseif (answer.eq.'n'.oR.answer.eq.'N') then go to 10

else

go to 54

endif

else

go to 50

endif

C

90 continue

91 format (A4)

92 format (A12)

93 format ( $4 x$, ' Leg ', I3, $4 x$, 'Hole ', A4)

94 format ( $4 \mathrm{x}$, 'Input filename: ',A12)

95 format ( $4 \mathrm{x}$, 'Output filename: 'A12)

96 format (A1)

97 format (4x,' Injection test \# ',I2)

99 format $(2 \mathrm{x}$,' 'Same leg and hole (Leg ', I4,' Hole ', A4,') ? (y/n)')

101 format $(4 \mathrm{x})$

102 format $(6(1 \times, F 8.4))$

103 format $(3(1 \mathrm{x}, \mathrm{F} 8.4), 10 \mathrm{x}, \mathrm{F} 8.4,1 \mathrm{x}, \mathrm{F} 8.4)$

104 format $(2(1 \mathrm{x}, \mathrm{F} 8.4), 19 \mathrm{x}, \mathrm{F} 8.4)$

111 format (4x, 'Time', 3x, 'Pressure', 3x, 'T-TO', 5x, 'Log', 5x, 'P-Pref', 6x *, 'Log')

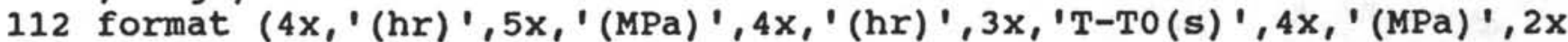
*, ' (T-TO)/(T-Ti)' )

113 format $\left(4 \mathrm{x},{ }^{\prime} \mathrm{TO}={ }^{\prime}, \mathrm{F7} .4,{ }^{\prime} \mathrm{hr} \mathrm{hr}^{\prime}, 4 \mathrm{x},{ }^{\prime} \mathrm{PO}={ }^{\prime}, \mathrm{F7} .4,{ }^{\prime} \mathrm{MPa}{ }^{\prime}, 4 \mathrm{x},{ }^{\prime}\right.$ Shutin $=$ '

*,F7. $\left.4,{ }^{\prime} \mathrm{hr}^{\prime}\right)$

120 format ( $4 \mathrm{x}$, ' 'Leg', I4, 3x, 'Hole ',A $4,3 \mathrm{x}$, 'Injection Test \# ', I2)

122 format ('To close ', A12,' and open new output file, enter: 1')

c

123 format (" To append further results to ', A12,"

enter: $\left.2^{\prime}\right)$

stop

end

c

c include injfit.for

c include pakrsubs.for 
subroutine injfit (ndata, ninj,to,po,tshutin, tlog, prinj, outfile, ncalc)

C

c

C

C

C

C

C

C

C

C

C

C

C

C

c

c

C

C

C

15

Fits scaled pressure-log time injection test data to a line source solution, and then calculates permeability and transmissivity.

Prompts user for all necessary input, with error control.

CALIS :

VIEWINJ, which calls:

SYSTEM (from LP77TOOL.LIB) to run PAUSE and GRAPHER LINREG

character*1 answer

character*12 outfile

dimension tlog(ndata), prinj (ndata)

dimension tfit(200),pfit(200)

data $\mathrm{pi} / 3.1415962 /$,grav/9.81/,dens/1045./

First view injection data vs log time, interactively adjusting the endpoints of the

linear segment of the semi-log plot.

(Permeability is calculated from slope of linear segment.)

linest $=1$

linend=ninj

10 call viewinj (ndata,tlog,prinj,linest,linend)

If linear fit is acceptable, calculate permeability.

otherwise, readjust parameters for better fit.

nfit $=0$

do $15 \mathrm{i}=1$ inest, $l$ inend

nfit=nfit+1

tfit (nfit) $=t \log (i)$

pfit (nfit) $=\operatorname{prinj}(i)$

continue

call linreg (nfit,pfit, tfit, a,b, se)

print 101

print *, Intercept $=1, a$

print $\star, '$ slope $=$ ', b

print *,' Standard error $=$ ', se

print 101

50 print *,'To accept this fit and calculate permeability,

52 print *, 'To readjust the endpoints of linear segment,

print *, 'To quit line-fitting these data, and either'

print $*, "$ reprocess this test or process another,

print 101

read $(*, *, e r r=50)$ ianswer

if (ianswer.eq.1) then

go to 55

elseif (ianswer.eq.2) then

go to 10

elseif (ianswer.eq.0) then enter: 1'

enter: 2 '

enter: $0^{\prime}$ 


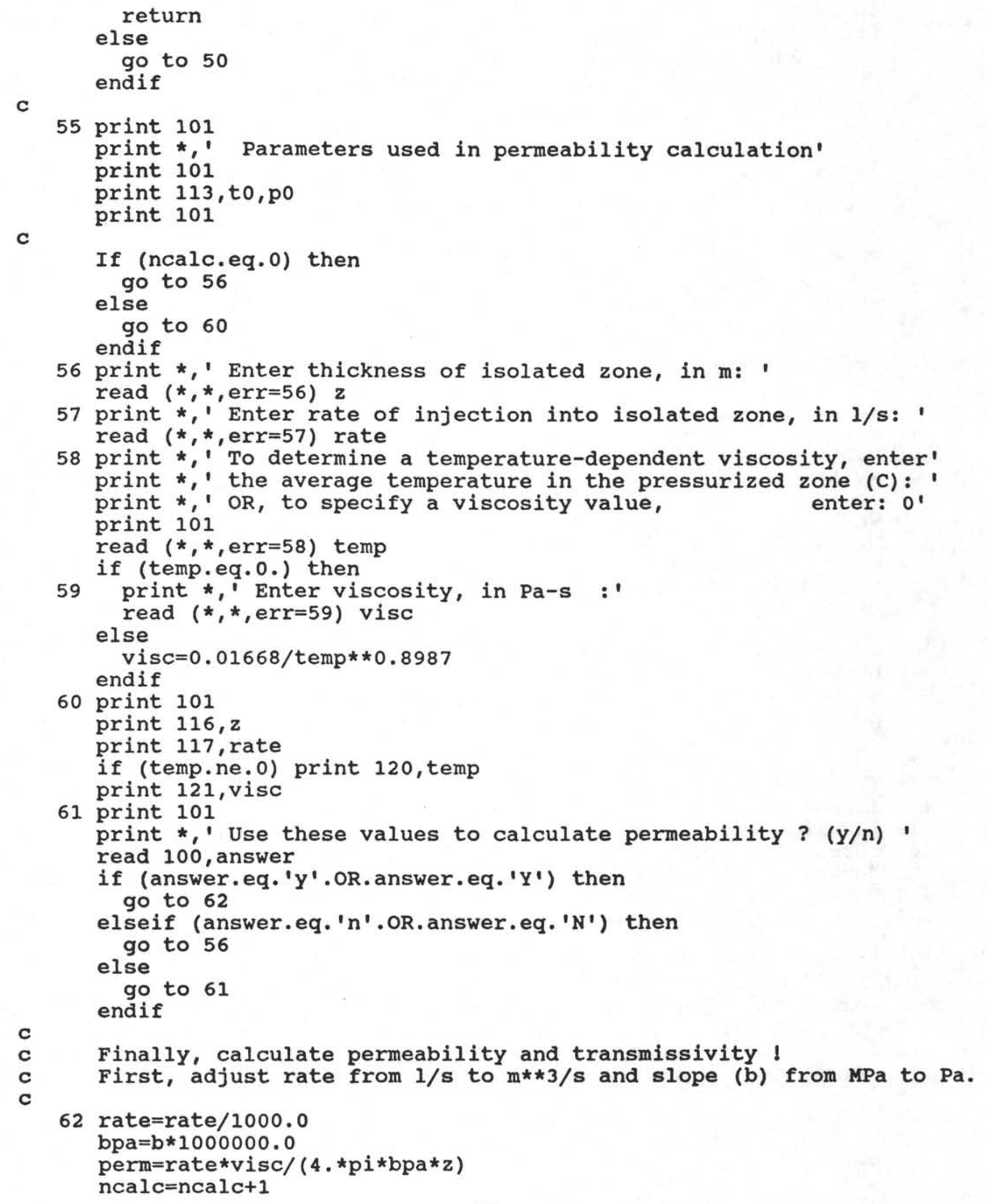


trans $=$ perm* $z$ *dens $* g r a v / v i s c$

print 123, perm

print 122 , trans

C

80 print 101

print *,' Write these results to file ',outfile,' $(\mathrm{y} / \mathrm{n})$ ? ' read 100 , answer

if (answer.eq.' $y$ '.OR. answer.eq.' $Y$ ') then go to 82

elseif (answer.eq.' $n$ '.oR.answer.eq. ' $N$ ') then

else go to 52

go to 80

endif

82 write $(3,101)$

write $(3,101)$

write $(3,124)$ ncalc

write $(3,101)$

write $(3,113)$ to,po

write $(3,101)$

write $(3,116) \mathrm{z}$

write $(3,117)$ rate

if (temp.ne.0) write $(3,120)$ temp

write $(3,121)$ visc

write $(3,101)$

write $(3,123)$ perm

if (trans.ne.0.) write $(3,122)$ trans

write $(3,101)$

c

c

c

100 format (A1)

101 format $(4 x)$

113 format $\left(4 \mathrm{x},{ }^{\prime} \mathrm{TO}={ }^{\prime}, \mathrm{F} 7.4, \mathrm{\prime}^{\prime} \mathrm{hr} \mathrm{C}^{\prime}, 4 \mathrm{x},{ }^{\prime} \mathrm{PO}=\mathrm{I}^{\prime}, \mathrm{F} 7.4, \mathrm{\prime}^{\prime} \mathrm{MPa} \mathrm{\prime}^{\prime}\right)$

116 format $\left.\left(4 \mathrm{x},{ }^{\prime} \text { Thickness of isolated zone }=1, \mathrm{~F} 6.1, \mathrm{I}^{\prime} \mathrm{m}\right)^{\prime}\right)$

117 format $\left(4 x\right.$, 'Average injection rate $\left.=1,510.4,11 / s^{\prime}\right)$

118 format $\left(4 \mathrm{x},{ }^{\prime}\right.$ Total pressurized volume $\left.=', \mathrm{~F} 6.3, \mathrm{I}^{\prime} \mathrm{m} * 3^{\prime}\right)$

119 format ( $4 \mathrm{x},{ }^{\prime}$ Compressibility of pressurized fluid $=1$, E10.4, *

120 format $(4 \mathrm{x}$, 'Average temperature of pressurized zone $=$ ',F5.2, * $'$ degrees $\left.C^{\prime}\right)$

121 format ( $4 \mathrm{x}$, 'viscosity of pressurized fluid $=$ ', E10.4, * ' $\left.\mathrm{Pa}-\mathrm{s}^{\prime}\right)$

122 format $\left(4 \mathrm{x},{ }^{\prime}\right.$ Calculated transmissivity $\left.=', \mathrm{E} 10.4, \mathrm{I}^{\prime} \mathrm{m} * 2 / \mathrm{s}^{\prime}\right)$

123 format $\left(4 \mathrm{x},{ }^{\prime}\right.$ Calculated permeability $=$ ', E10.4,' $\left.\mathrm{m} * 2^{\prime}\right)$

124 format $(2 x$, 'Permeability calculation $\#$ ',I2)

c

125 format (1x,'2 ',F8.5,2(1X,F7.4),1X,F5.2)

end 
subroutine viewinj (ndata,tlog,prinj,linest, linend)

C
c
C
C
c
c
C

Calls SYSTEM from LP77TOOL.LIB to run GRAPHER for semi-log plot of pressure-time during an injection test.

Allows the user to adjust the circled endpoints of the linear section of this plot, from which permeability is calculated.

dimension tlog (ndata), prinj (ndata)

46 open $(13$, 'gr_inj.dat')

do $47 j=1$, ndāta

if (j.eq.linest) then

write $(13,124)$ tlog $(j), \operatorname{prinj}(j), \operatorname{prinj}(j)$

elseif (j.eq.linend) then

write $(13,125) t \log (j), \operatorname{prinj}(j), \operatorname{prinj}(j)$

else

write $(13,126) t \log (j), \operatorname{prinj}(j)$

endif

47 continue

close (13)

open (14,'gr_linj.dat')

do $48 j=1$, ndāta

if (j.ge.linest.AND.j.le.linend) then

endif

48 continue

close (14)

print 101

print *,' When the GRAPHER Main Menu appears,'

print *,' Import graph file GR_INJ and press F2 to view.'

print 101

call system ('pause')

call system ('grapher')

50 print 101

print *,' To accept the two circled points as the'

print *,' endpoints of the linear segment, and'

print *,' calculate permeability accordingly, enter: 0 '

print *,' To change one or both of the endpoints, enter: 1 '

print 101

read $(*, *$, err $=50)$ ianswer

if (ianswer.eq.0) then return

elseif (ianswer.eq.1) then

else continue

go to 50

endif

51 print 101

print *,' To accept the first circled point as the'

print *,' beginning of the linear segment, enter: 0 '

print *,' To choose a different beginning, enter the'

print *,' number of data points to move the circle (+/-)' print 101

read $(*, *$, err $=51)$ ianswer 
if (ianswer.ne.0) then

maybe $=l$ inest $+i$ answer

if (maybe.1t.1.OR.maybe.gt.ndata) then

print *,' This value would move the circled point'

if (maybe.1t.1) then

print *,' earlier than the first data point !'

elseif (maybe.gt.ndata) then

print $\star, '$ later than the last data point !'

endif

go to 60

else

linest=maybe

endif

endif

C

52 print 101

print *,' To accept the second circled point as the'

print *,' end of the linear segment, enter: 0 '

print *,' To chose a different end, enter the'

print *,' number of data points to move the circle $(+/-)$ '

print 101

read $(*, *, \operatorname{err}=52)$ ianswer 2

if (ianswer2.ne.0) then

maybe $=1$ inend + ianswer 2

if (maybe.le.linest.oR.maybe.gt.ndata) then

print *,' This value would move the circled point'

if (maybe.le.linest) then

print $*, '$ earlier than the start of the linear segment !' elseif (maybe.gt.ndata) then

print $*, '$ later than the last data point !' endif

else

go to 60

linend=maybe

endif

endif

C

if (ianswer.ne.0.0R.ianswer2.ne.0) go to 46

return

c

60 print 101

print $*, '$ Now preparing to review plot ...'

C go to 46

101 format (4x)

124 format $(3(1 \mathrm{x}, \mathrm{F} 8.5), 1 \mathrm{x}, 14 \mathrm{H}$ 'START LINE ?')

125 format $\left(3(1 \mathrm{x}, \mathrm{F} 8.5), 1 \mathrm{x}, 12 \mathrm{H}^{\prime}\right.$ END LINE ?')

c

126 format $(2(1 \times, F 8.5))$

end

SUBROUTINE LINREG (N, Y, X, A, B, SE)

DIMENSION $X(N), Y(N)$

$\mathrm{SX}=0$. 


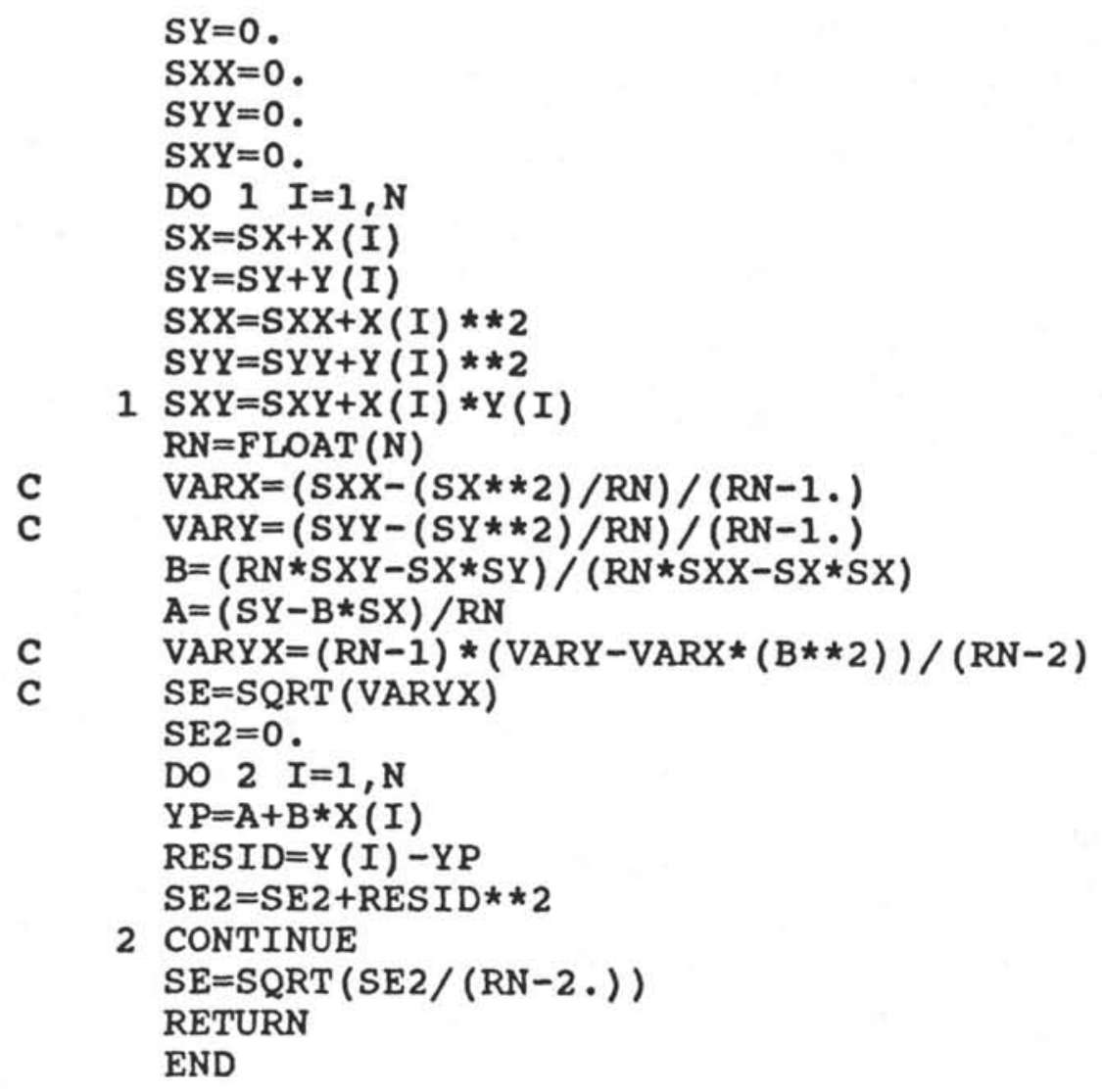


SUBROUTINE CORRECTP (ntp,time, corpress)

C

C

C

C

C

C

C

C

C

C

C

C

C

C

Corrects ntp time-pressure data points to a reference pressure that includes hydrostatic pressure plus the superimposed effects of previous pressure tests.

\section{CALLS :}

READFAB (an entry point in GETFAB)

SPLINE

EVAL (function)

character*12 corrfile

dimension time (ntp), corpress (ntp)

dimension icorr $(20)$, correctn $(20,4)$

dimension beta (49), fab(49), s(49), a (49)

Corrfile is file of corrections for hydrostatic pressure and extrapolations of previous slug and injection tests.

Read up to 20 separate correction lines, for superposed events.

In each line, icorr(i) denotes the kind of correction: icorr $(i)=1$ means constant correction, e.g. hydrostatic icorr $(i)=2$ means correction for shutin after injection test $i \operatorname{corr}(i)=3$ means $P O * F(a l p h a$, beta), after slug test calls SPLINE and EVAL for slug test corrections

correctn $(i, j)$ are the coefficients for corrections, some of which are not used depending on value of icorr(i)

do $10 i=1,20$

$i \operatorname{corr}(i)=0$

do $10 j=1,4$ $\operatorname{correctn}(i, j)=0$.

\section{print 101}

print *,' Correction of Time-Pressure data'

print 101

15 print *,' For full processing with a correction file, enter: 1' print *,' To correct only for hydrostatic pressure, enter: $2^{\prime}$ print 101

read $(*, *$, err $=15)$ ianswer

If (ianswer.eq.1) then

print *,' Enter name of reference pressure correction file: ' read 92 , corrfile

write $(3,95)$ corrfile

open $\left(2\right.$, file $=$ corrfile, status $={ }^{\prime}$ old', err $\left.=80\right)$

ncordata $=0$

do $25 i=1,20$

$\operatorname{read}(2, *, \operatorname{end}=26)$ icorr $(i),(\operatorname{correctn}(i, j), j=1,4)$

ncordat $a=$ ncordat $a+1$

25 continue

26 close (2)

print *,' Number of corrections to data $=1$, ncordata

Elseif (ianswer.eq.2) then ncordata $=1$ 
$i \operatorname{corr}(1)=1$

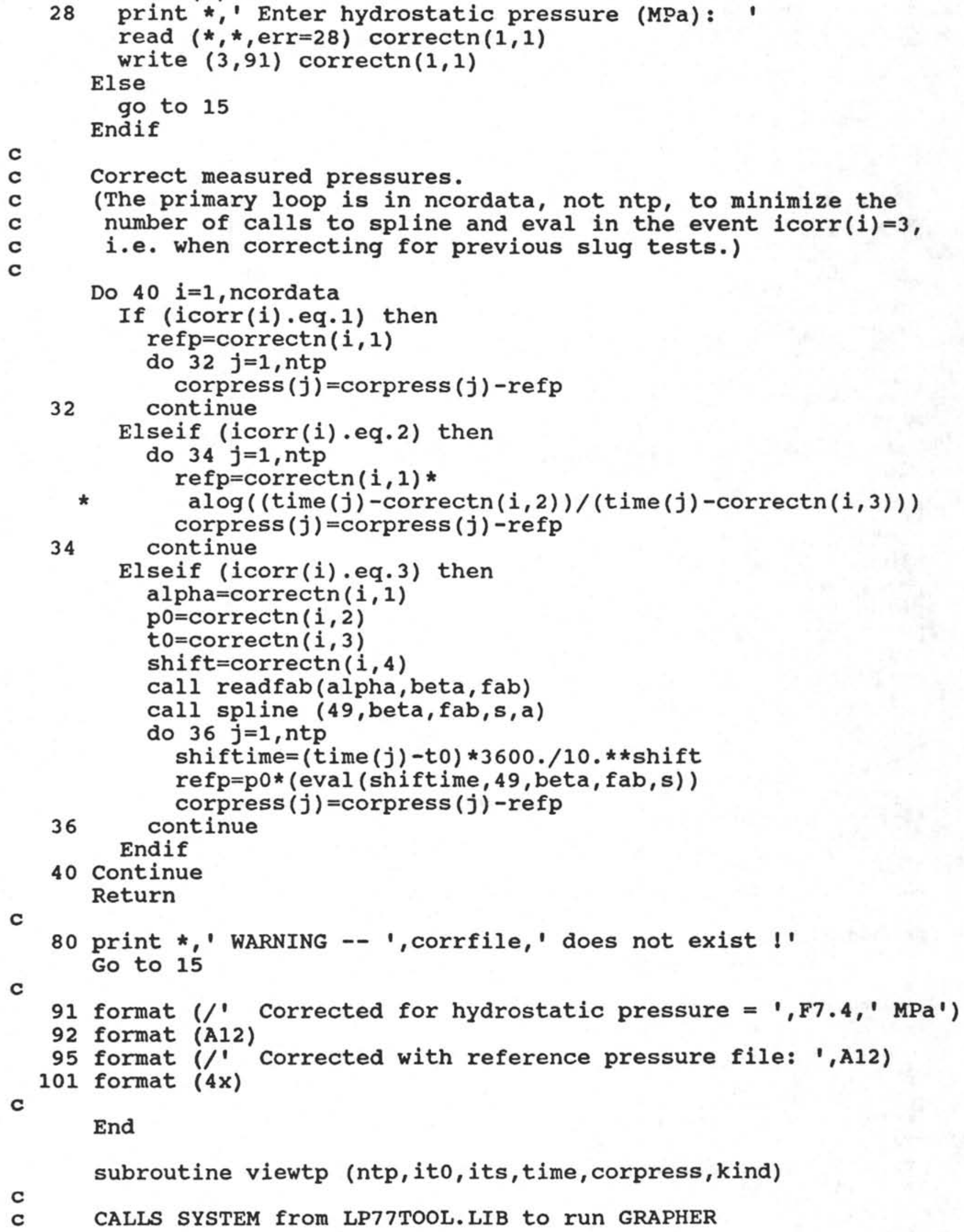


for screen plot of corrected pressures vs. time.

Allows user to adjust two endpoints of data to be processed, which are circled and labeled on screen plot.

Returns ito and its, the indices in the arrays time and corpress, which identify the two endpoints of data to be processed.

dimension time (ntp), corpress (ntp)

Writes data into file GR TP.DAT for GRAPHER.

GR_TP.DAT contains time-corrected pressure data in first 2 columns. For the two endpoints, a third column is written, and the points will be circled and labeled.

40 open (11, 'gr_tp.dat')

do 41 i=1, nt $\bar{p}$

if (i.eq.ito) then

if (kind.eq.1) write $(11,124)$ time(i), corpress(i), corpress(i)

if (kind.eq.2) write $(11,122)$ time(i), corpress (i), corpress (i)

elseif (i.eq.its) then

if (kind.eq.1) write $(11,125)$ time(i), corpress(i), corpress(i)

if (kind.eq.2) write $(11,123)$ time(i), corpress(i), corpress(i) else

write $(11,126)$ time(i),corpress(i)

endif

41 continue

close (11)

print 101

print *,' When the GRAPHER Main Menu appears,'

print *,' Import graph file GR_TP and press F2 to view.'

print 101

call system ('pause')

call system ('grapher')

42 print 101

print *,' To accept the two circled points as the'

if (kind.eq.1) then

print $*, 1$ start and end of the pressure pulse,'

elseif (kind.eq.2) then

print *,' start and end of injection,'

endif

print *,' and process the test accordingly,

print *,' To change one or both of the endpoints,

enter: $0^{\prime}$

print 101

read $(*, *$, err $=42)$ ianswer

if (ianswer.eq.0) then

return

elseif (ianswer.eq.1) then continue

else

go to 42

endif

43 print 101

print *,' To accept the first circled point as the'

if (kind.eq.1) then

print $*,+$ effective origin of the slug test, enter: 0 ' 
elseif (kind.eq.2) then

print *,' start of injection, enter: $0^{\prime}$

endif

print *,' To choose a different time origin, enter the'

print $*,{ }^{\prime}$ number of data points to move the circle $(+/-)$ ' print 101

read $(*, *, e r r=43)$ ianswer

if (ianswer.ne.0) then

itmaybe $=i$ to + ianswer

if (itmaybe.1t.1.oR.itmaybe.gt.ntp) then

print *,' This value would move the circled point' if (itmaybe.1t.1) then

print *,' earlier than the first data point !' elseif (itmaybe.gt.ntp) then

print *,' later than the last data point !' endif

else

go to 50

it $0=$ itmaybe

endif

endif

c

44 print 101

print *,' To accept the second circled point as the'

if (kind.eq.1) then

print $\star^{\prime}{ }^{\prime}$ end of the slug test, enter: $0^{\prime}$

elseif (kind.eq.2) then

print $*, 1$ end of injection or shut-in time, enter: $0^{\prime}$ endif

print *,' To chose a different end time, enter the'

print *,' number of data points to move the circle $(+/-)$ ' print 101

read $(*, *, e r r=44)$ ianswer2

if (ianswer2.ne.0) then

itmaybe $=i t s+i a n s w e r 2$

if (itmaybe.le.ito.or.itmaybe.gt.ntp) then

print $\star, '$ This value would move the circled point'

if (itmaybe.le.ito.AND.kind.eq.1) then

print $\star,{ }^{\prime}$ earlier than the origin of the slug test !'

elseif (itmaybe.le.ito.AND.kind.eq.2) then print *,' earlier than the start of injection !' elseif (itmaybe.gt.ntp) then

print *,' later than the last data point !' endif

go to 50

else

its=itmaybe

endif

endif

c

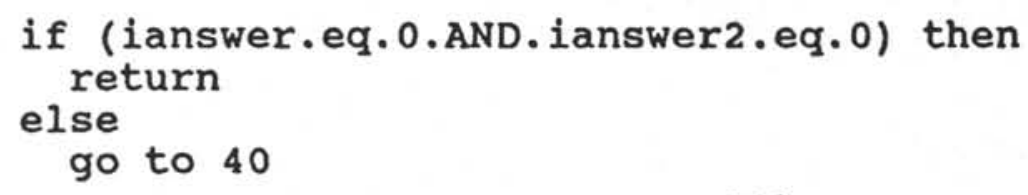

if (ianswer.eq.0.AND.ianswer2.eq.0) then return

else

go to 40 
endif

c

C

101 format $(4 \mathrm{x})$

122 format ( $3(1 \mathrm{x}, \mathrm{F} 8.5), 1 \mathrm{x}, 19 \mathrm{H}$ 'START INJECTION ?')

123 format ( $3(1 \mathrm{x}, \mathrm{F} 8.5), 1 \mathrm{x}, 17 \mathrm{H}^{\prime}$ END INJECTION ?')

124 format ( $3(1 \mathrm{x}, \mathrm{F} 8.5), 1 \mathrm{x}, 15 \mathrm{H}^{\prime}$ 'SLUG ORIGIN ?')

125 format $(3(1 \mathrm{x}, \mathrm{F} 8.5), 1 \mathrm{x}, 12 \mathrm{H}$ 'END SLUG ?')

126 format $(2(1 \mathrm{x}, \mathrm{F} 8.5))$

C

end

subroutine getfab (alpha, beta, fab)

c Prompts user for proper value of alpha to use, and

C

c

c

c

C

\section{dimension beta (49), fab (49)}

if (alpha.eq.0.) go to 15

12 print 110 , alpha

print *,' Enter 0 to use the same value,'

print *,' or enter the new value to use: '

read $(*, *, e r r=12)$ answer

if (answer.eq.0.) then

else go to 18

alpha=answer

go to 18

endif

15 print *,' Allowable values of alpha are: $3.0^{\prime}$

print *,'

print *,'

print *,'

print *,'

print $\star, '$

print *,'

print $\star, '$

print *,"

print *,'

print 101

print *,' Enter value of alpha to use: ' read $(*, *, e r r=15)$ alpha

18 if (alpha.eq.3.0.0R.alpha.eq.2.0.0R.alpha.eq.1.0.0R.

* alpha.eq.0.3.0R. alpha.eq.0.1.OR.alpha.eq.0.03.OR.

* alpha.eq.0.01.0R.alpha.eq.0.001.0R.alpha.eq.0.0001.

* OR.alpha.eq.0.00001) go to 20 go to 15

C

ENTRY READFAB (alpha, beta, fab) $2.0^{\prime}$

$1.0^{\prime}$

$0.3^{\prime}$

$0.1^{1}$

$0.03^{\prime}$

$0.01^{\prime}$

$0.001^{\prime}$

$0.0001^{\prime}$

$0.00001^{\prime}$ 
20 print 101

print *,' Reading F (alpha, beta) file...'

open $(7, f i l e=' f a b . f i l ')$

do $30 \quad i=1,10$

read $(7, *)$ alpha 2

if (alpha2.eq.alpha) then do $25 j=1,49$

25 $\operatorname{read}(7,105)$ beta $(j), f a b(j)$

else

do $26 j=1,49$

read $(7,101)$

26 continue

endif

30 continue

close (7)

C

101 format (2x)

105 format $(8 x, f 11.7,6 x, f 10.7)$

C

110 format (' The current value of alpha is: ',F7.5)

end

SUBROUTINE SPLINE(NN, X, U, S, A)

C\$\$\$ CALLS NO OTHER ROUTINES

C FINDS ARRAY S FOR SPLINE INTERPOLATOR EVAL.

C NN NUMBER OF DATA POINTS SUPPLIED (MAY BE NEGATIVE, SEE BELOW)

$C X$ ARRAY OF $X$-COORDINATES WHERE FUNCTION IS SAMPLED,

C WHICH MUST BE A STRICTLY INCREASING SEQUENCE.

C U ARRAY OF SAMPLE VALUES THAT ARE TO BE INTERPOLATED.

C S OUTPUT ARRAY OF 2ND DERIVATIVE AT SAMPLE POINTS.

C A WORKING SPACE ARRAY OF DIMENSION AT LEAST NN.

C IF THE USER WISHES DERIVATIVES AT THE ENDS OF SERIES TO ASSUME

C SPECIFIED VALUES, HE/SHE MUST PUT DU(1)/DX, DU(NN)/DX IN S1,S2

C AND CALL WITH NN=-NUMBER OF TERMS IN SERIES. NORMALLY A PARABOLA

C IS FITTED THROUGH THE 1ST AND LAST 3 POINTS TO FIND THE SLOPES.

C IF LESS THAN 4 POINTS ARE SUPPLIED, STRAIGHT LINES ARE FITTED.

C

COMMON /STARTX/ ISTART

DIMENSION $X(N N), U(N N), S(N N), A(N N)$

C

$Q(U 1, X 1, U 2, X 2)=\left(U 1 / X 1 * * 2-U 2 / X_{2} * * 2\right) /(1.0 / X 1-1.0 / X 2)$

C

C ASSIGN DERIVATIVES AT THE ENDS.

C

ISTART $=1$

$\mathrm{N}=\operatorname{IABS}(\mathrm{NN})$

IF (N.LE.3) GO TO 5000

$Q 1=Q(U(2)-U(1), X(2)-X(1), U(3)-U(1), X(3)-X(1))$

$\mathrm{QN}=\mathrm{Q}(\mathrm{U}(\mathrm{N}-1)-\mathrm{U}(\mathrm{N}), \mathrm{X}(\mathrm{N}-\mathrm{I})-\mathrm{X}(\mathrm{N}), \mathrm{U}(\mathrm{N}-2)-\mathrm{U}(\mathrm{N}), \mathrm{X}(\mathrm{N}-2)-\mathrm{X}(\mathrm{N}))$

IF (NN.GT.0) GO TO 1000

$Q 1=S(1)$

$\mathrm{QN}=\mathrm{S}(2)$

$1000 \mathrm{~S}(1)=6.0 *((\mathrm{U}(2)-\mathrm{U}(1)) /(\mathrm{X}(2)-\mathrm{X}(1))-Q 1)$ 


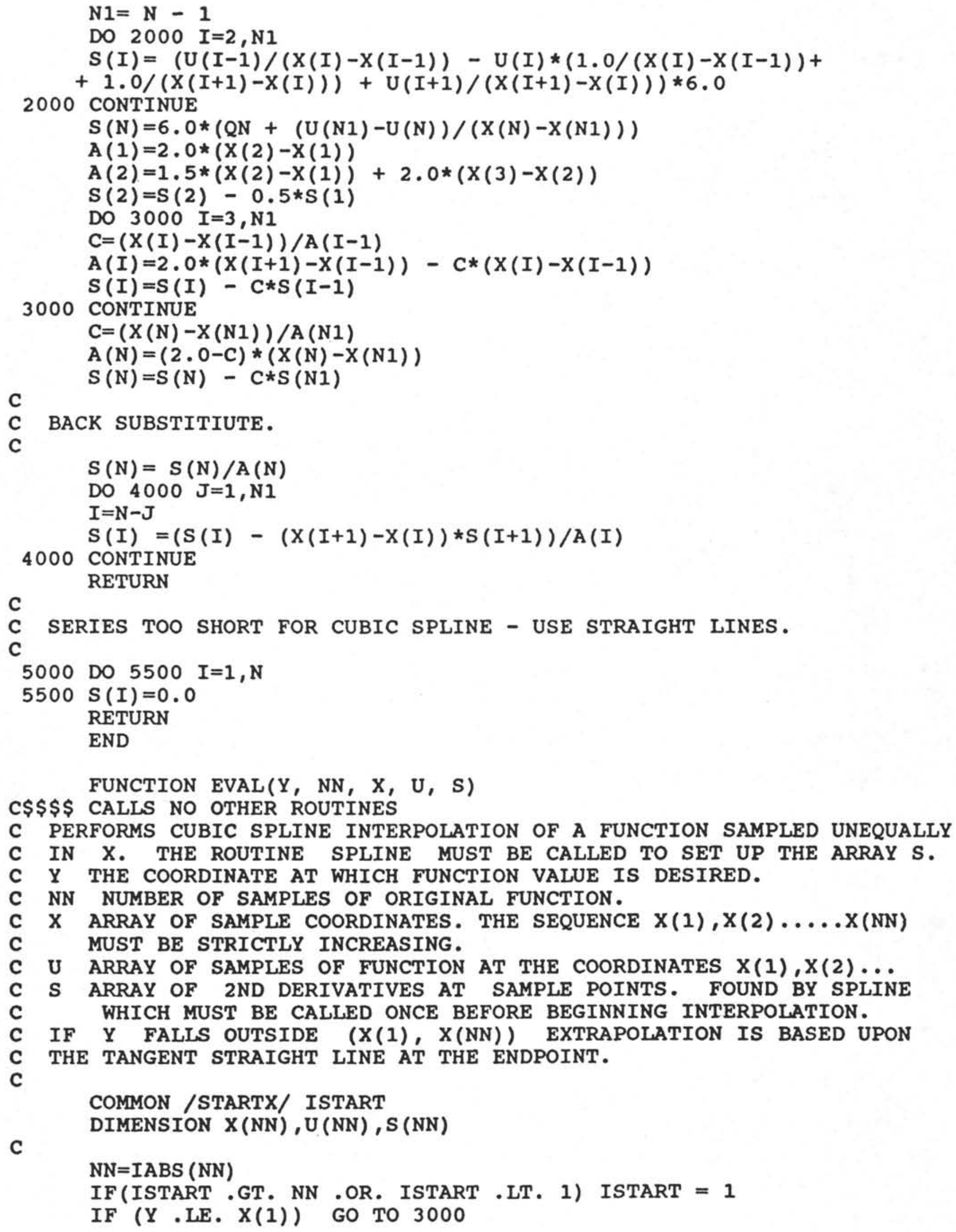

